\title{
Part-Time Work in the Nordic Region III
}

An introductory study of the Faroe Islands, Greenland and Åland Islands

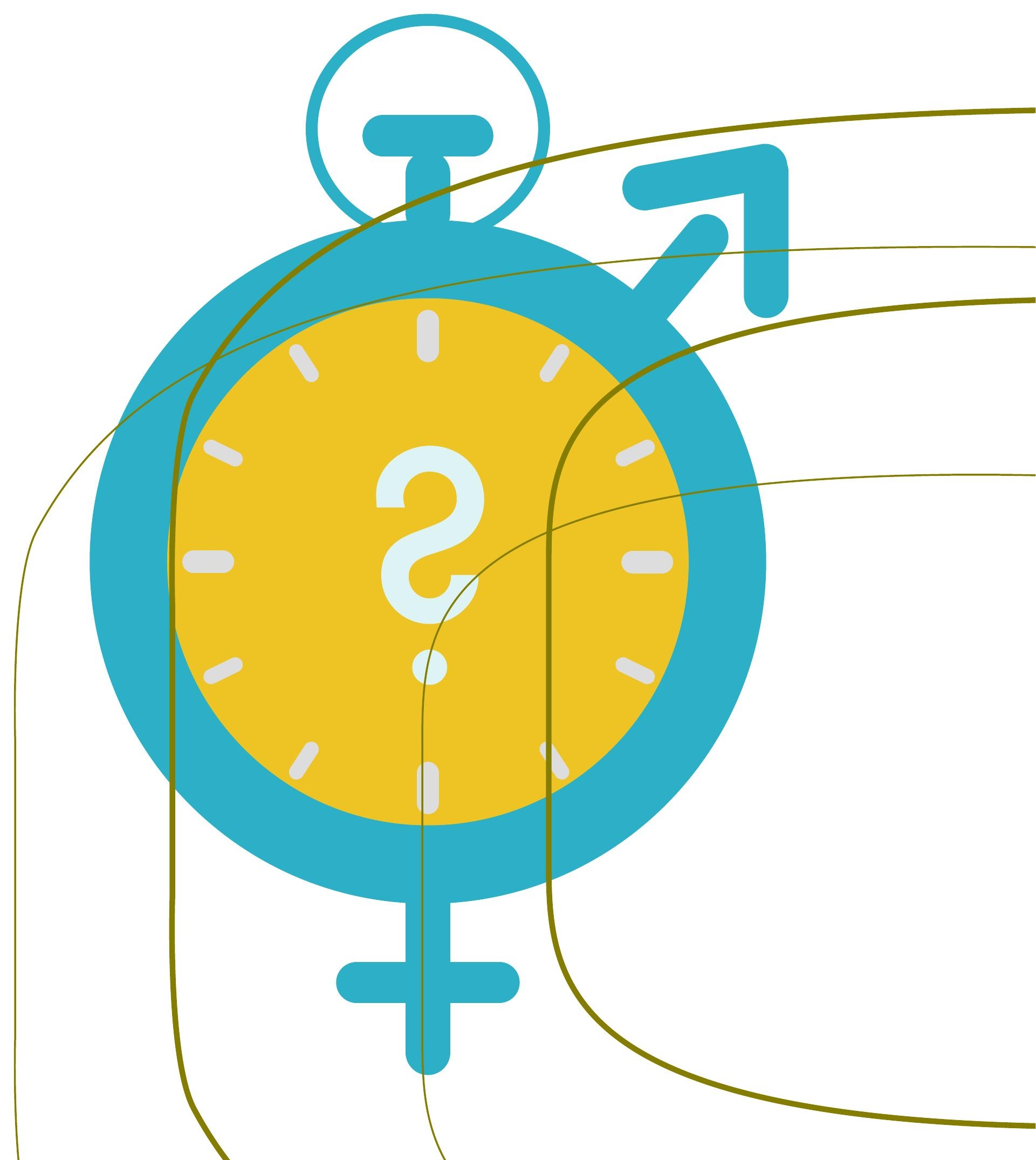







\section{Part-Time Work in the Nordic Region III}

An introductory study of the Faroe Islands, Greenland and Åland Islands

Erika Anne Hayfield, Rógvi Olavson and Lív Patursson

TemaNord 2016:518 
Part-Time Work in the Nordic Region III

An introductory study of the Faroe Islands, Greenland and Åland Islands

Erika Anne Hayfield, Rógvi Olavson and Lív Patursson

ISBN 978-92-893-4531-6 (PRINT)

ISBN 978-92-893-4529-3 (PDF)

ISBN 978-92-893-4528-6 (EPUB)

http://dx.doi.org/10.6027/TN2016-518

TemaNord 2016:518

ISSN 0908-6692

(C) Nordic Council of Ministers 2016

Layout: Hanne Lebech

Cover photo: NIKK (Swedish Secretariat for Gender Research, University of Gothenburg)

Print: Rosendahls-Schultz Grafisk

Printed in Denmark

This publication has been published with financial support by the Nordic Council of Ministers. However, the contents of this publication do not necessarily reflect the views, policies or recommendations of the Nordic Council of Ministers.

www.norden.org/nordpub

\section{Nordic co-operation}

Nordic co-operation is one of the world's most extensive forms of regional collaboration, involving Denmark, Finland, Iceland, Norway, Sweden, and the Faroe Islands, Greenland, and Åland.

Nordic co-operation has firm traditions in politics, the economy, and culture. It plays an important role in European and international collaboration, and aims at creating a strong Nordic community in a strong Europe.

Nordic co-operation seeks to safeguard Nordic and regional interests and principles in the global community. Common Nordic values help the region solidify its position as one of the world's most innovative and competitive.

\section{Nordic Council of Ministers}

Ved Stranden 18

DK-1061 Copenhagen K

Phone (+45) 33960200

www.norden.org 


\section{Contents}

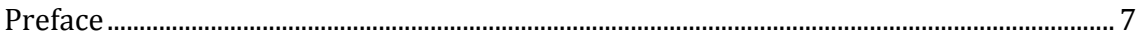

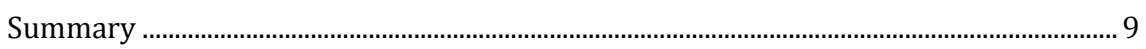

1. Introduction.................................................................................................................

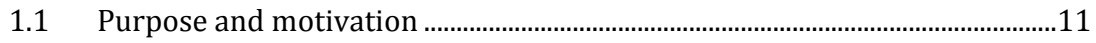

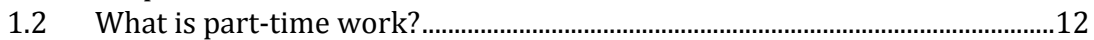

1.3 Key Issues .............................................................................................................13

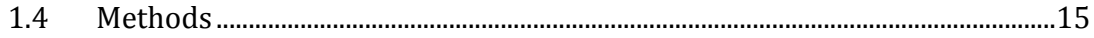

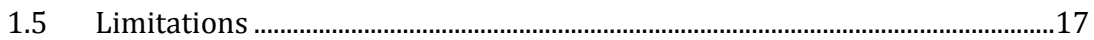

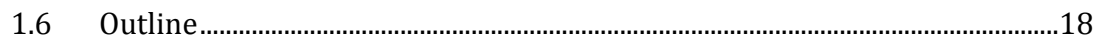

2. Overview of the Self-Governing Areas and Their Labour Markets ..........................19

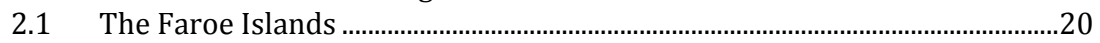

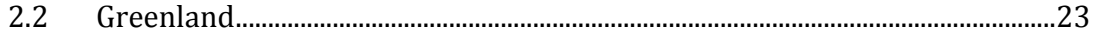

2.3 The Åland Islands ..............................................................................................27

3. Part-time work in the self-governing areas ...............................................................31

3.1 Part-time work in the Faroe Islands.......................................................................

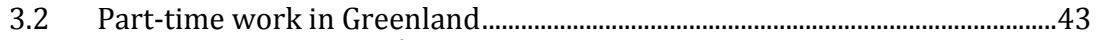

3.3 Part-time work in the Åland Islands....................................................................55

3.4 Part-time work: A comparative review..............................................................66

4. Part-time work: An exploratory study ………..............................................................75

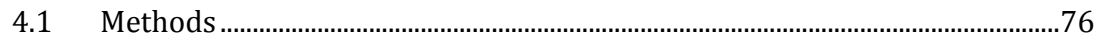

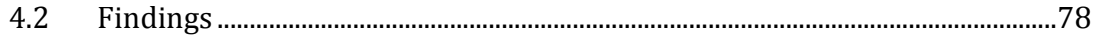

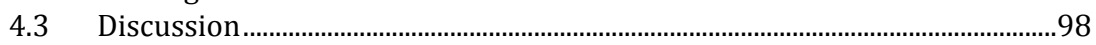

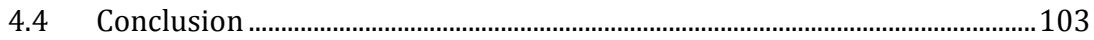

5. Conclusion and recommendations................................................................................ 107

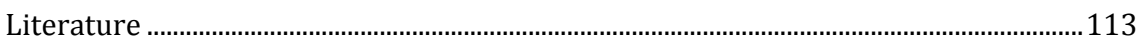

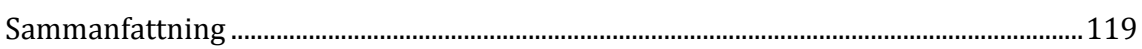





\section{Preface}

Creating equal economic opportunities for women and men in the Nordic region is an important focus area for the Nordic cooperation. Part-time work correlates with a lower level of economic independence on an individual level and is likely to impact opportunities for positions of influence in society. As part-time work is highly gendered, the question why parttime work is so much more common among women than men is one of the most pressing issues concerning gender equality in the Nordic region.

With support from the Nordic Council of Ministers, NIKK (Nordic Information on Gender) has coordinated several projects on part-time work in the Nordic region. The projects are part of NIKK's assignment to gather and distribute comparative information that can inform political discussions related to gender equality. The aim of the project is to investigate part-time work in the Nordic region and to disseminate knowledge on the topic through e.g. reports and conferences.

In the summer of 2015, NIKK requested a report on part-time work in the self-governing areas of the Nordic region as a follow-up to the two earlier reports on part-time work in the Nordic countries. Erika Anne Hayfield, PhD and Assistant Professor of Social Sciences at the University of the Faroe Islands, and Rógvi Olavson, MSc in Sociology, wrote the report in the winter months of 2015/2016. One of the chapters is based on group interviews with women working part-time in the Faroe Islands, and was carried out by Erika Anne Hayfield and Lív Patursson, MSc in Gender Studies and research assistant at the University of the Faroe Islands. All estimations, inferences and conclusions in the report are those of the authors and do not necessarily represent the viewpoints and position of NIKK. 
The authors received help from many people and would especially like to thank Rasmus Ole Rasmussen for his support and assistance in obtaining and preparing data from Greenland. Furthermore, the authors are thankful for the support and helpful comments from Elin Engström and Josefine Alvunger at NIKK as well as from the reference group members appointed by NIKK: Niels Thomas Andersen, Ministry of Family, Equality and Social Welfare, Greenland; Linus Rispling, NordRegio; Annemette Lindhardt Olsen, Statistics Denmark and Iris Åkerberg, Statistics and Research Åland. 


\section{Summary}

Women in Åland and the Faroe Islands display the highest rates of parttime work in the Nordic region. In fact, the rates are high also in a European perspective. In Greenland, there are no gender differences in parttime work, yet a significant difference is found between people in rural and urban areas, as the former are more likely to work part time.

These are some of the findings presented in this report on part-time work and gender in Greenland, Åland and the Faroe Islands. The report was produced by Nordic Information on Gender at the request of the Nordic Council of Ministers. It was written by Erika Anne Hayfield, Assistant Professor in Social Sciences at the University of the Faroe Islands, Rógvi Olavson, MA in Sociology, and Lív Patursson, Research Assistant at the University of the Faroe Islands. Nordic Information on Gender has previously published two reports on part-time work and gender in the Nordic countries, and the present report provides complementary information with a focus on Greenland, Åland and the Faroe Islands.

The report gives a general overview of the labour markets, people's level of education and demographics in the three areas, in relation to parttime work. The researchers describe what is known about part-time work in Greenland, Åland and the Faroe Islands, with a particular focus on the relationship between part-time work on the one hand and employment, salaries, education and family policy on the other.

The report includes a small study of women in the Faroe Islands who have been interviewed about why they work part time. The study shows that although most of the interviewed women have voluntarily chosen to work part time, they have decided to do so within the framework of social structures and cultural expectations, as well as individual circumstances. For example, the women identified motherhood and the expectations that come with it as important factors, and that their participation in the labour market is constrained by their family responsibilities.

In the conclusion of the report, the researchers give recommendations regarding future research on the studied areas. There is a need for more data and research on how part-time and full-time work is divided according to gender. The researchers point out that it is of utmost importance that Greenland, Åland and the Faroe Islands understand their own unique conditions in the labour market and how these conditions relate to gender and 
gender equality. This is not least important considering that many young women are moving away from the three studied areas, in particular Greenland and the Faroe Islands. From a policy-making perspective, it is important that the unique challenges in Greenland, Åland and the Faroe Islands are available to decision maker. 


\section{Introduction}

\subsection{Purpose and motivation}

The overall purpose of this report is to provide an introductory overview of part-time work in the self-governing areas of the Nordic region, i.e. the Faroe Islands, Greenland and the Åland Islands, in the context of gender. Although they are all part of the Nordic region, the labour markets in these areas differ in many respects. Thus, this report describes and to some extent explains the role of part-time work in the self-governing areas and compares them with each other. This inevitably involves taking into account several factors that may have an effect on part-time work, such as cultural gender expectations, welfare policy, education, geography and labour market segregation.

So far, NIKK has published two extensive reports on the topic of parttime work in the Nordic region: Part-Time Work in the Nordic Region Part-time work, gender and economic distribution in the Nordic Countries (Lanninger \& Sundström, 2014) and Part-time Work in the Nordic Region II - A research review on important reasons (Drange \& Egeland, 2014).

The first report mapped out the prevalence of part-time work and described various factors relating to part-time work in the Nordic countries: Denmark, Finland, Iceland, Norway and Sweden. The second report focused on the underlying causes of the varying prevalence of part-time work across the region. Together they provide a valuable analysis of gender and part-time work in the Nordic countries.

Both reports confirm that part-time work is more common among women than men in the Nordic region. However, some countries have a much higher proportion of women in part-time work than others. Some of the reasons for this disparity are presented, particularly in the second report, in which Drange \& Egeland (2014) find that the reasons for parttime work are highly complex. The authors draw attention to similarities and differences between the countries that may explain the pattern of women's part-time work across the region.

Dange \& Egeland (2014) point out that the economic situations and labour market practices seem to be of importance in explaining and shaping differing part-time working patterns in the Nordic countries and how part-time work is understood in these contexts. Furthermore, different 
labour market structures, politics and policies lead to different effects on women's part-time work. Another important point is the significant impact that family policy can have on shaping women's attachment to the labour market. In many Nordic countries there is a cultural mandate surrounding women's part-time work, while in others gender equality is more important. Importantly though, they also find that a discursive hegemony surrounding the full-time norm coexists with the cultural mandate for women's part-time work in many of the Nordic countries (Drange \& Egeland, 2014).

However, it is unclear whether the conclusions in these reports apply to the self-governing areas of the Nordic region. Moreover, the scope of this introductory report on the Faroe Islands, Greenland and the Åland Islands does not permit an extensive review of the important causes as put forward by Drange \& Egeland (2014). The present report is intended as a first step in continuing the abovementioned publications with a focus specifically on the Faroe Islands, Greenland and the Åland Islands. As a first step, this third report on part-time work will shed light on and map existing knowledge on part-time work in the self-governing areas. It will describe and compare key issues related to part-time work, thus complementing existing knowledge and to some extent enabling comparisons between the different labour markets. Finally, the report will present gaps in knowledge concerning part-time work in the self-governing areas as well as recommendations for further research into this topic.

\subsection{What is part-time work?}

For the purpose of this report, part-time work refers to a form of labour market participation that does not involve the number of working hours considered full-time work in a given country. Thus, the existence and definition of the concept of part-time work is contingent upon a corresponding full-time norm. Part-time work sometimes overlaps with seasonal work, which may constitute full-time work over a short period of time.

The full-time standard varies across countries, which also means that the definition of part-time work is relative to the labour market where the work is carried out. The inconsistency in the definition of part-time work from one country to another poses a challenge to a cross-country study such as this one. For Statistics Faroe Islands (Hagstova Føroya), the definition of part-time work corresponds to the ILO (International Labour Or- 
ganization) standard, which is anything below 35 hours per week. However, for Statistics and Research Åland (Ålands Statistik och Utredningsbyrå), part-time work is defined as anything below 33.5 hours per week.

In Greenland there is no official distinction between part-time and full-time work, rather the concern in Greenland is with underemployment and seasonal work, which are dealt with in some of the available data and literature. Consequently, a full-time worker in the Åland Islands, such as a person working 34 hours per week, would be considered a part-time worker elsewhere in the Nordic region, except possibly in Greenland, where the classification would depend on one of two different ways of calculating part-time work (see also Chapter 3.2). Therefore, the concept of part-time work is somewhat arbitrary.

Nevertheless, this report will present a picture of part-time work as defined relative to the norms of the Faroe Islands, Greenland and the Åland Islands. This means that we will adopt the definitions and categories employed by the country in question and urge the reader to keep this in mind when making cross-country comparisons. That said, although there are slight variations in the full-time standard, we still believe it to be useful to observe and compare patterns in the different areas.

\subsection{Key Issues}

Part-time work is a common feature of the Nordic labour markets and Europe in general (Statistics Faroe Islands, 2014b) and is also reflected in the other OECD countries (OECD, 2007). The flexibility associated with working less than the full-time norm, either out of necessity, e.g. due to illness or disability, or to suit individual or family needs, is for many an essential part of labour market participation.

However, although part-time work is widespread, the circumstances that cause some people to work less than what is considered "the norm" (full-time) are complex. Despite important contributions (Drange \& Egeland, 2014; Lanninger \& Sundström, 2014; Pfau-Effinger, 1998, 2004), it is still relatively unclear why some countries, regions and sectors have a large share of part-time workers while others do not. As for the selfgoverning areas, there is a gap in knowledge about part-time work in general. Most importantly, little is known about the reasons why people work part-time, including whether they do it by choice (voluntary part-time workers) or out of necessity (involuntary part-time workers).

There are two significant and well-documented tendencies related to part-time work. Firstly, women are more likely than men to work part-time, 
both in the Nordic region (Drange \& Egeland, 2014; Lanninger \& Sundström, 2014) and in a wider European context (Statistics Faroe Islands, 2014b). Secondly, there are differences in the extent of female parttime work across countries (Lanninger \& Sundström, 2014; Pfau-Effinger, 1998, 2004). These two tendencies demonstrate the relevance of investigating the relationship between gender and working patterns in most labour markets. The reasons for part-time work, then, are highly complex and should be viewed in relation to a range of intertwined factors, including the ways in which gender is constructed in different societies.

Studies on the nature of part-time work have frequently focused on the conditions surrounding women's availability for work (supply side) and on how employers make use of part-time workers (demand-side) (Fagen \& O'Reilly, 1998). While such studies are valuable in shedding light on various issues pertaining to the gendered nature of part-time work, they may fail to provide insight into the complexities of women's labour market participation. The realities of combining paid employment with family commitments entail women and men making choices in the contexts of institutions, gender cultural norms and values as well as individual circumstances and preferences (Närvi, 2012).

When speaking of choice and part-time work, economists typically differentiate between voluntary part-time workers, i.e. those who prefer to work part-time, and involuntary part-time workers, i.e. part-time workers unable to find full-time employment. While the agency (freedom to choose) of women in opting for part-time or full-time work is central to our perspective, the structural and cultural constraints framing these choices are of fundamental importance. Therefore, we will, to the extent resources and the limited availability of data allow, attempt to address some institutional issues, touch on structural features in the labour market, point to geographical features as well as shed light on women's own experiences and perspectives.

To make sense of this complexity and call the reader's attention to our standpoint, we find it useful to make reference to the theoretical framework proposed by Pfau-Effinger $(1998,2004)$. This framework provides an analytical tool through which she addresses women's labour market work patterns (including part-time work) in various countries. Rather than focusing on separate factors pertaining to women's labour market participation, Pfau-Effinger's framework provides a more complex analysis of the relationship between work and gender. It is based on the interrelationship between culture and social structures as an approach for explaining labour market and family choices. The limited availability of data on the Faroe Islands, Greenland and the Åland Islands, however, does not 
allow us to systematically apply Pfau-Effinger's framework in our analysis. Nonetheless, it has guided what questions we have asked and how we have interpreted the data.

Pfau-Effinger $(1998,2004)$ uses the concept of gender culture to refer to common assumptions about gender ideals and values concerning work, parenthood and the division of work between men and women. Yet, the cultural values surrounding gender are contested and there may be more than one gender culture present in a society. She further uses the concept of gender order to refer to the structure of relations between societal institutions, e.g. the labour market, the welfare state and the family, all of which must be understood in the context of gender structures. Finally, the concept of gender arrangement refers to the relatively binding forms of action resulting from negotiations between social actors in the context of gender culture and societal institutions within the gender order. The strength of this framework is that it allows any particular circumstance to be viewed simultaneously as an outcome of cultural influences, policy or labour market organisation, while also taking into account the effects of people's choices and actions (Drange \& Egeland, 2014).

With this framework as our mindset, we will explore what data is available and attempt to understand women's labour market participation in the self-governing areas. As a first step in addressing available data on certain structural issues impacting women's labour market participation, we include some information on family policy, educational levels and other structural labour market features for each of the areas. In order to explore women's individual and family choices in the context of culture and structure, we have conducted a qualitative study among women who work part-time. This has enabled us to better understand gendered practices, women's own experiences in the labour market, the complex realities of living in peripheral societies, cultural gender ideas of motherhood and fatherhood as well as women's individual circumstances.

\subsection{Methods}

Information on part-time work in the self-governing areas is sparse. We have relied on data and studies that give some idea of labour market working patterns in the Faroe Islands, Greenland and the Åland Islands. The information about part-time work in the Fare Islands and Greenland are based on large samples, while for the Åland Islands it is based on a small sample. We used data and studies from a variety of institutions, in particular official national statistics agencies and various government offices in the 
studied areas. For additional knowledge we have relied mostly on academic publications, reports and personal communication with agencies and experts on the Faroe Islands, Greenland and the Åland Islands.

In our mapping of gender and working patterns in the self-governing areas, we have explored a range of issues including the extent of part-time work, trends in part-time work, variations in private/public sectors, industries and professions as well as the importance of age and education. For the Faroe Islands, some of the available data was not quite up-to-date, as most of the statistics are from 2011. The statistics were rather limited for Greenland, yet we were able to obtain data that gives a picture of parttime work in Greenland based on unemployment figures. The data for the Åland Islands, drawn mainly from a survey conducted in 2014, was also limited. The conclusions in this report are based on a combination of available data on part-time work, relevant studies and reports as well as the findings of an introductory qualitative study we conducted. The collected material was supplemented with expert interviews in order to either confirm or problematise what emerged from the data.

We further directed our attention to certain welfare issues with respect to the labour market and in particular family welfare policies. The purpose is to go some way to explain the context of working patterns in the selfgoverning areas and to identify specific labour market issues that may be reflected in family policies. One such example is the case of long-distance workers in some peripheral areas, involving employment far away from home - a factor that can have implications for gender relations and the division of labour in both the labour market and the domestic sphere.

Due to the limited data, we have been unable to conclude much about the reasons why people in the self-governing areas work part-time. However, the report does include an exploratory study of female part-time workers in the Faroe Islands in Chapter 4, which investigates reasons for women's part-time work in one of the three self-governing areas. The exploratory study consists of three group interviews carried out in October and November 2015 in three Faroese towns. A further outline of the methods used for the group interview study is presented in Chapter 4 . The purpose of the study in Chapter 4 is to supplement the quantitative mapping of part-time work in the self-governing areas with a qualitative analysis of some of the reasons for part-time work, thus providing a better idea of future research needs.

As explained in the previous section, our point of departure is based on an understanding that takes culture, structure and individual choice into account. In this context, the exploratory study attempts to analyse part- 
time work taking into account the individual and cultural level in the context of structure. Our general mapping of part-time work in the self-governing areas, on the other hand, will provide us mainly with a structural perspective. The authors of this report are Faroese. Therefore, for practical reasons, taking factors such as available resources, language and access to interviewees into consideration, the exploratory study was carried out in the Faroe Islands. The study gives a good view of the Faroese context, whereas a better understanding of the reasons for part-time work in Greenland and the Åland Islands will require further research.

\subsection{Limitations}

The countries and areas in the Nordic region display many similarities in terms of cultural and political evolution (Drange \& Egeland, 2014; Kautto, Heikkillä, Hvinden, Marklund, \& Plough, 1999). However, when delving into each of these countries and areas, it is evident that they are also disparate and face different circumstances. Studying the small areas of the Faroe Islands, Greenland and the Åland Islands involves several challenges with regard to obtaining and integrating data. This is clearly a difference compared with the larger Nordic countries, for which the production of data is more standardised and extensive. Thus, a compilation and analysis of data concerning the self-governing Nordic areas requires a pragmatic approach. The reader should also keep in mind that data on small populations generates greater uncertainty, especially when divided into several variables, e.g. educational background or municipalities, which in effect separates an already small sample into even smaller chunks.

As mentioned in the previous section, the self-governing areas have different definitions of part-time work. Information on part-time work of direct relevance proved to be more extensive in the Faroe Islands than in the Åland Islands and Greenland. The concept of part-time work is not much used by Statistics Greenland, where other work-time categories are preferred, such as underemployed and seasonal workers. This is mainly due to the uniqueness of the Greenlandic labour market and its challenges, which we shall return to in Chapter 3 . The limited data means that the Faroe Islands is the only area about which we could comment on certain aspects of part-time work, such as whether part-time workers work part-time voluntarily or involuntarily.

Historical data on part-time work in these areas is almost non-existent. This means that historical developments that have led to the current situation are difficult to observe. Therefore, the report will give some idea 
of part-time work at present and include developments from the recent past where the data is available.

The intention is to produce a preliminary study of part-time work in the self-governing areas. This is reflected in the time designated for the task. In light of this, and given the limitations mentioned in this section, we stress that this report should not be viewed as a definitive source on part-time work in the self-governing areas, but rather as an important step in mapping out future research requirements.

\subsection{Outline}

This introductory chapter has thus far provided the backdrop for an analysis of part-time work in the Faroe Islands, Greenland and the Åland Islands. The remainder of the report is structured as follows:

Chapter 2: Overview of the Self-Governing Areas and Their Labour Markets presents a general overview of the Faroe Islands, Greenland and the Åland Islands in order to provide the reader with relevant background knowledge for the remainder of the report. This includes the key characteristics of labour markets, education and demography of these societies, with a focus on what is relevant to part-time work.

Chapter 3: Part-time work in the self-governing areas outlines what is known about part-time work in the Faroe Islands, Greenland and Åland Islands. A particular focus has been on the relation between part-time work on the one hand and employment, wages, education and family policies relating to children and childbirth on the other. The final section in this chapter is a discussion, where part-time work in the self-governing areas will be compared.

Chapter 4: Part-time work: An exploratory study is a study based on group interviews with women from three different towns in the Faroe Islands. The purpose is to provide a deeper insight into the reasons for parttime work in a peripheral area of the Nordic region.

Chapter 5: Conclusion brings together the key conclusions of this report, including gaps in our knowledge concerning part-time work in the self-governing areas. In this final chapter, we point to the needs for future research on part-time work in the Faroe Islands, Greenland and the Åland Islands. 


\section{Overview of the Self-Governing Areas and Their Labour Markets}

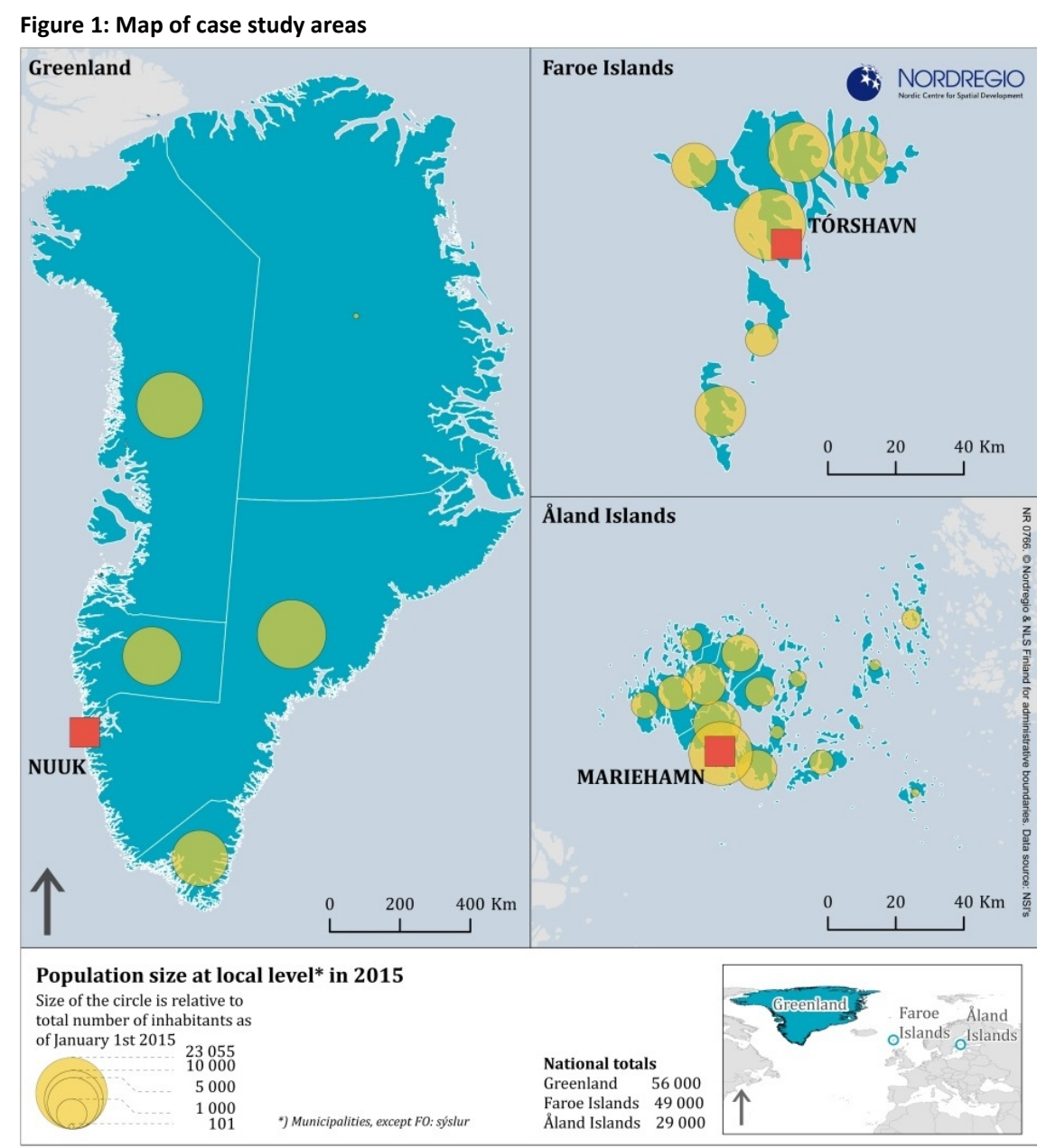

Source: Nordregio 
The purpose of this chapter is to set the scene for the analysis of part-time work in the Faroe Islands, Greenland and the Åland Islands in Chapter 3. In doing so, the reader is presented with some key characteristics of the three societies, in particular what may be relevant in relation to part-time work. This includes addressing issues related to geography, demography, education and labour markets in the studied areas.

The self-governing areas share certain characteristics, such as small populations and labour markets. Furthermore, high rates of out-migration of young people and, for Greenland and the Faroe Islands, a significant female deficit in the population imply significant demographic challenges for these areas. All three areas have strong formal and cultural links with the main Nordic countries - the Faroe Islands and Greenland with Denmark and the Åland Islands with both Sweden and Finland. However, the self-governing areas differ from their larger neighbours in several respects. They are self-governing areas within sovereign states, yet are geographically remote, especially the Faroe Islands and Greenland, and heavily reliant on primary resource industries and maritime industries. The native populations of the three areas also differ, both linguistically and ethnically, compared with the majority populations in the states they are formally part of (Ackrén \& Lindstöm, 2012). Thus, although the Faroe Islands, Greenland and the Åland Islands have similar political systems as in the Nordic countries, their location, origin and natural environment result in different challenges, which may impact on gender culture and the labour market, as we shall see.

In terms of industry, all three areas are characterised by what would be considered primary or traditionally male-oriented industries and a high proportion of women employed in the public sector or traditional femaletyped occupations. With respect to education, they also share the notable trend of having a greater number of females undertaking higher education, which is a well-known tendency throughout the Nordic region. However, the Faroe Islands, Greenland and the Åland Islands each have distinctive characteristics and challenges, several of which we will present below.

\subsection{The Faroe Islands}

The Faroe Islands is a self-governing area within the Kingdom of Denmark. The islands are in the middle of the North Atlantic, midway between Iceland and Shetland. Around $40 \%$ of the 49,000 inhabitants live in the municipality of Tórshavn (Statistics Faroe Islands, 2015b), creating a modern urbanised centre. The land area of 1,400 square kilometres is 
spread over 18 islands, which are well connected by road and sea. In terms of international infrastructure, there are several daily flights to Denmark and also regular flights to Iceland, Norway, Scotland and other destinations. Furthermore, year-round ferry services are available between the Faroe Islands, Iceland and Denmark.

\subsubsection{Demography}

The people of the Faroe Islands are highly mobile, both in terms of migration and work - features with clear implications for the demography of the islands in general and the labour market specifically. The Faroe Islands have a long history of international migration (Patursson, 1942) with almost $40 \%$ of the entire current population and two-thirds of the 30-44 year olds having lived abroad at some point - the vast majority of these former expatriates being native Faroese (Statistics Faroe Islands, 2014a). Furthermore, it is estimated that there are 22,500 Faroese expatriates (first, second and third generation) living in Denmark (The North Atlantic Group in the Danish Parliament, 2008), which is by far the most common destination for Faroese out-migrants.

The net migration pattern for the past 80 years shows clearly that more women than men have migrated from the Faroe Islands. This has resulted in a female deficit of more than 2,000 women of working age - a considerable figure considering the small size of the labour market (Statistics Faroe Islands, 2015b). Therefore, Faroese women are quite literally a minority group in the Faroe Islands. Apart from the obvious obstacles to human reproduction, it is conceivable that this situation can impact not only female representation in politics and in positions of influence in the labour market, but also gender equality in society in general.

\subsubsection{Education}

The Faroese educational system offers secondary schooling, apprenticeships and manual training opportunities as well as tertiary education in e.g. maritime subjects, social sciences, natural sciences, law, Faroese language, education and nursing. Still, many young people choose to study abroad, even if the subjects they are interested in are available in the Faroe Islands. This has become a typical feature of the Faroese culture of migration. At present, two-thirds of the approximately 2,500 Faroese fulltime students at the tertiary level are studying abroad, in particular in Denmark (Studni, 2015). 


\subsubsection{Labour market}

With its position in the middle of the North Atlantic, the Faroe Islands relies heavily on fishery and maritime industries. Consequently, these industries have a substantial impact on people's employment opportunities. Jobs in the private sector are largely centred around the fishery and fishery-related industries. Many workers are also employed in the offshore industry. As all of these industries are male-dominated, it is conceivable that women consider the economic opportunity structure of the Faroe Islands to be less attractive than the opportunities available to them in urban areas abroad. This, some have argued, is a partial explanation for the Faroese women's out-migration and hence the skewed ratio between men and women in the rural North Atlantic (Hamilton \& Otterstad, 1998).

At present, more than 3,000 men reside in the Faroe Islands but work either at sea or abroad (Statistics Faroe Islands, 2015b). The corresponding figure for women is very low. These mobile men are so-called longdistance workers, spending time away from home for weeks or months at a time (Hovgaard, 2015) It is conceivable that this labour market pattern influences the scale of part-time work for female partners, particularly when children are involved. Therefore, the presence of a highly mobile male workforce is possibly constraining women and limiting their labour market opportunities.

The Faroese gender equality law of 1994 is aimed at eliminating gender inequality and balancing gender relations in the labour market. However, the Faroese labour market remains highly gender segregated in terms of occupation, occupational hierarchy and education (Hayfield, 2016). Women are heavily concentrated in occupations such as care, cleaning, health, sales and food production (75-92\% of employees are females) while electronics, construction, transport and fisheries are areas where 9799\% of all employees are male (Statistics Faroe Islands, 2015b).

Overall, $80 \%$ of those in the labour market aged 15 and above are in occupations where they are likely to have mostly same-sex co-workers (Hayfield, 2016). Areas of employment where the sex ratio is more balanced include law, social sciences, finance and administration (Statistics Faroe Islands, 2015b). When exploring on a sector basis, women are overrepresented in public sector employment e.g. in health care, social work and teaching and areas such as trade, whereas men are more evenly spread throughout the private and public sectors (Knudsen, 2009, p. 335).

As is the case in many other countries, Faroese women are more likely than men to be in tertiary education and also tend to pursue higher academic degrees than men (Gíslason, 2011; Studni, 2015). Although this is a feature one could expect to have an impact on the labour market, it may 
be the case that the gender culture still perpetuates traditional gender roles. Consequently, we may be faced with a "delayed reaction" in terms of differences in pay between men and women (Gíslason, 2011) as well as the clear gender hierarchy that can be observed in the labour market.

In terms of vertical gender segregation in the labour market, women are underrepresented in management positions as only $27 \%$ of managers and directors in the Faroe Islands are female (Statistics Faroe Islands, 2015b). Only in management in health care, social work and teaching are females well represented.

The Faroese welfare system is similar to that of its Nordic neighbours, yet some have argued that there is a degree of familialism woven into its fabric (Jákupsstovu, 2007; Sundström, 2006). Thus, while basic welfare services provide for guaranteed full-time childcare and education, a maternity/paternity and parental leave scheme (although somewhat limited in a Nordic perspective), elderly care etc., there is an underlying expectation that families are to contribute whenever welfare services are not adequately delivered by the public services infrastructure. This expectation is especially evident in the sphere of childcare, care for elderly or ill family members and (lack of) provisions for families with children with special needs (Føroya Landsstýri, 2013).

\subsection{Greenland}

Greenland is a self-governing area within the Kingdom of Denmark. It is by far the largest Nordic country by size, but the third smallest in terms of population. With just over 56,000 inhabitants, it is according to The World Bank the least densely populated country in the world (2015). It is also the Nordic region with the biggest infrastructural challenges. Greenland differs from the Faroe Islands and Åland Islands (and the other Nordic labour markets) in several respects. Firstly, it may be argued that the Greenlandic labour market is not a single integrated labour market, but rather a series of tiny insular labour markets (Nordregio, 2016b). Although people do migrate between these labour markets, commuting workers are practically non-existent since road networks are limited to internal transport within towns and settlements. ${ }^{1}$ Commuting between towns and settlements is therefore almost impossible and much more expensive than in both the Faroe Islands and the Åland Islands.

${ }^{1}$ Settlement populations range from 20 to 500 residents. 


\subsubsection{Demography}

Only 12,000 people lived in Greenland in the early 20th century, but a late industrialisation similar to in the Faroe Islands has made the population almost quintuple in the space of a century. Greenlanders are very young in a Nordic perspective, with a third of the population being under the age of 20 (Faber, Nielsen, \& Bennike, 2015). By comparison, this proportion is on average only $15 \%$ in the other Nordic countries (Weyhe, 2011).

Since the 1960s, women have been underrepresented in the Greenlandic population, a challenge similar to that faced by the Faroe Islands. Today, males outnumber females by more than 3,000 , i.e. by $12 \%$ (Haagensen, 2014; M. Poppel, 2010). This significant female deficit can be attributed to several factors, but can be briefly explained by the combination of more males having immigrated to Greenland (often from Denmark) and the more recent tendency of Greenlandic females to out-migrate (Hamilton \& Rasmussen, 2010; M. Poppel, 2010).

According to Hamilton \& Rasmussen, the vast majority of Greenlandborn females who out-migrate move to Denmark. If the entire (male and female) population of Greenland-born immigrants to Denmark is added to the Greenlandic population, the female deficit practically disappears (Hamilton \& Rasmussen, 2010). The main reason for female out-migration is better opportunities and choices related to education, or the idea that education obtained outside of Greenland is of higher quality (M. Poppel, 2010). Correspondingly, Nordregio's (2010) report on mobility within Greenland confirms that people with higher educational levels are more likely than people with lower levels of education to move, and that especially females with higher educational levels are less likely than those with lower educational levels to move back to where they came from.

Migration within Greenland seems to be related to out-migration from Greenland to some extent. Traditionally, males have been more likely than females to move from one area to another, but today females make up an equal share of migrants within Greenland. However, the migrant patterns of females are different from those of men. According to Nordregio, male Greenlanders have a tendency to move temporarily and often move back to where they came from. This is mostly due to the large amount of seasonal work available in certain places in Greenland during the summer (Government of Greenland, 2016). Female migration, on the other hand, is characterised by "stepstone mobility", where they gradually move from settlements to larger more populous areas, and often end up leaving the country. According to a survey of the Greenland labour 
force exploring people's migration intentions, this trend is likely to continue as the desire to move is greater in less populated areas than in more urban areas (Nordregio, 2010).

\subsubsection{Education}

On average, women in Greenland have a higher level of education than men, and a majority of all students in both upper secondary and higher education are women. Women also outnumber men in all degree programmes at the University of Greenland. In 2013, 68.3\% of all new graduates from the university were women (Eistrup \& Kahlig, 2005; Haagensen, 2014; M. Poppel, 2010).

Boolsen (2010) has gone so far as to label Greenlandic women the "educational elite" in the sense that when one looks at educational levels statistically, the higher the level, the greater the proportion of women. This is the case even though there are more males than females in younger student age groups in Greenland (Faber et al., 2015). The male deficit in the Greenland educational system can, according to Boolsen (2010), be explained by the fact that both infant mortality and suicide rates are higher for men, and that women on average live five years longer than men. Women also tend to commence their studies at an older age, which can be explained by the fact that Greenlandic women often have children at a young age. According to Christensen (2013), 60\% of Greenlandic women have their first child before age 22 .

\subsubsection{Labour market}

An important aspect of Greenlandic society is that life in small settlements is very different from life in larger towns. Greenland contains 67 small settlements with 20-500 inhabitants, and these are all characterised by a reliance on nature, through fishery, hunting and sheep rearing. Women are generally underrepresented in Greenlandic political institutions and are especially missing from the local committees and authorities in the small settlements (M. Poppel \& Kleist, 2009). Furthermore, there is a clear correlation between the gender ratio in a particular area and its dominating economic activities. More activity within the service industry means a relatively larger proportion of women in the population. This means that when the service industry in a given area is highly developed, that area is likely to have a smaller female deficit than an area with a less developed service industry (Nordregio, 2010). 
The Greenlandic labour market is gender segregated. In 2014, twothirds of all women in the Greenland labour market worked in the public sector, while there is a male dominance in the private sector (Statistics Greenland, 2015a). The unemployment rate was $9.8 \%$ in 2013, the highest in the Nordic region, and it was particularly high among young people. However, there are only small differences in unemployment between men and women (Haagensen, 2014).

Relations between the sexes in Greenland have undergone significant changes in recent years, since Greenlandic women are no longer economically dependent on their husbands or partners to the same degree they used to be (M. Poppel, 2010; Rasmussen, 2009). It is rather the case today that many women are earning the main household income, and hence even successful fishermen and hunters may in practice be dependent on their wives' income. In more than half of those homes, where hunting and fishing make up a sizeable part of the income, women still earn more than their husbands. According to Rasmussen, "[s]ingle men without these income sources [...] are confronted with severe economic problems" (2009, p. 526). Despite women's increasing levels of education and economic contributions in Greenlandic households, women are not to the same extent as men represented in management jobs, and they still earn less than men on average.

According to Faber et al. (2015), it is difficult to imagine a change in the traditional gender-segregated structures in the Greenland labour market in the near future despite changing gender roles in society (see Section 3.2). In this respect, the foremost challenge in Greenland is the female deficit in the population, which may be partly related to the fact that the Greenlandic labour market is both geographically fragmented and gender segregated.

In addition to jobs and educational opportunities, Greenland's less developed health and social services (compared with Denmark in particular) is cited as an important reason for women's desire to move. A less comprehensive welfare system means that women in Greenland are often more dependent on their families than they would be in Denmark (Poppel, 2010). Overall, women seek job opportunities and social conditions that are more readily available in the larger towns of Greenland, Nuuk in particular, and to an even greater degree abroad (Nordregio, 2010). This means that Greenland is facing some serious gender-related demographic problems, which can only be solved by taking into account the different perspectives - especially related to gender - on what sort of living conditions are desired and how these desires result in particular migration patterns (Faber et al., 2015). 


\subsection{The Åland Islands}

The Åland Islands is a self-governing area of the Republic of Finland. Its total land area comprises just over 1,500 square kilometres spread over more than 6,000 islands, of which just over 60 are inhabited. Six of the Åland Island's 16 municipalities are not connected by road to the main island. The farthest location from the main island takes five hours (and three different ferries) to reach from the capital Mariehamn (Dahlström et al., 2006). The Åland Islands are well connected to the Nordic and Baltic regions. Regular flights are available to both Finland and Sweden, and there are ferry services to Estonia, Finland and Sweden (Dahlström et al., 2006). With respect to transport, the Åland Islands differ significantly from the Faroe Islands and Greenland, as the physical distance and cost of travel to its nearest neighbours Sweden and Finland is short and cheap in comparison.

\subsubsection{Demography}

The Åland Islands have a population of nearly 29,000. Due to rapid urbanisation since the 1950s, the population has become much more centralised: $40 \%$ are residents of the capital Mariehamn, $50 \%$ live on the rest of the main island, and the remaining $10 \%$ are spread out over the other 59 inhabited islands. Urbanisation has coincided with a steady population growth, fuelled in part by immigration. The population increased by more than $18 \%$ from 1990 to 2014, and the population growth is expected to continue over the coming decades (Haagensen, 2014; Statistics and Research Åland, 2015g).

The Åland Islands' demography is significantly marked by its somewhat unusual migration pattern. Those out-migrating from the Åland Islands tend to move to Finland, Sweden and other Nordic countries, while immigrants tend to come from outside the Nordic region. Immigration surpassed out-migration each year from 1987 to 2014 and is one of the main reasons for the Åland Island's consistent population growth over the past few decades. The most recent numbers, however, show a rare overall decline in the population during the first three quarters of 2015 (Statistics and Research Åland, 2015f).

Since immigrants to the islands are generally older than those who out-migrate (Dahlström et al., 2006), the average age of the Åland Island's population is relatively high and is expected to rise further. Demographic projections indicate that $50 \%$ of the adult population will be older than 65 years in 2030, making the Åland Island's future dependency ratio one of the highest in the Nordic region (Haagensen, 2014). 


\subsubsection{Education}

The Åland Islands have a polytechnic school but no university, and this educational structure has profound implications for young people's location of study. The Åland Islands' youth is characterised by a "stepstone mobility," similar to both the Faroe Islands (Hovgaard, Eythórsson, \& Fellman, 2004) and especially Greenland (Nordregio, 2010), where young people tend to look towards the greater population centres in their pursuit of education. This means that it is common to move to the capital Mariehamn to obtain upper secondary education, and from there to Finland or Sweden for tertiary education (Hovgaard et al., 2004).

Although the Åland Islands is a self-governing area of Finland, more people go to Sweden than to Finland to study since the main language in the Åland Islands is Swedish. In the scholastic year of 2012/2013, there were 288 Ålandic students in Finland and 726 in Sweden (Haagensen, 2014). ${ }^{2}$ Thus, compared with the Nordic region as a whole, the Åland Islands have a small population of tertiary-level students as most are abroad studying - as is the case of the Faroe Islands and to some extent Greenland. Of those aged 15-39 years, 5.8\% of Åland Islanders were registered as tertiary-level students during 2013/2014. In comparison, the corresponding student share of the population aged 15-39 years was 5.6\% in the Faroe Islands (Statistics Faroe Islands, 2015b; Studni, 2015), 9.3\% in Greenland, ${ }^{3}$ and roughly $13-16 \%$ in the larger Nordic countries (Haagensen, 2014).

The overall educational level of the population has increased since the 1980s, especially among women, and this development is expected to continue (Statistics and Research Åland, 2013, 2015d). Today, six out of ten people have at least secondary education (Statistics and Research Åland, 2013). Women have increased their representation among students studying abroad and have also surpassed men in terms of educational level (Statistics and Research Åland, 2014).

Educational choice is linked to traditional gender patterns in education, as men are better represented in natural sciences and technical education while there are more women in the fields of health, social work and teaching (Statistics and Research Åland, 2013, 2015d). However, certain types of education that have traditionally been dominated by either men or women seem to be very slowly evening out in terms of gender distribution.

\footnotetext{
2 The information on exams taken by Ålanders outside of the Åland Islands is incomplete. Therefore, the number of overseas students is likely to be higher than represented here.

${ }^{3}$ A smaller proportion of the Greenlandic tertiary-student population study abroad than is the case for the Åland Islands and Faroe Islands, which explains why the total number of students in Greenland itself is greater than in the Åland Islands and Faroe Islands.
} 


\subsubsection{Labour market}

The Åland Islands had a population of just over 15,000 working persons in 2013, of which $50.4 \%$ were female (Statistics and Research Åland, 2015b). The business sector with the most employees is transport and storage with almost 2,900 people employed, followed by care and welfare services with around 2,700 employees. The Åland Islands are highly dependent on the shipping industry, which employs one-fourth of the labour force. Manufacturing accounts for $10 \%$ of total employment and the public sector employs more than one-third of the labour force. The development of the Ålandic shipping industry represents a shrewd exploitation of its geographical position in the Baltic: midway between significant population centres in Finland in the east and Sweden in the west. The shipping industry is the main reason for the Åland Islands' relatively high GDP per capita, which has consistently been among the highest of the Finnish regions, surpassing both the Finnish average and neighbouring Sweden (Dahlström et al., 2006; Statistics and Research Åland, 2015c).

Unemployment is generally low in the Åland Islands and the female unemployment of $3.1 \%$ was the lowest in the Nordic countries in 2013 (Haagensen, 2014). According to Dahlström (2006), the Åland Islands' small labour force lacks the dynamism characterising its larger Nordic neighbours, with many employees remaining in the same job for long periods. Notably, low unemployment coincides with the lowest employment rate in the Nordic region, which is mainly due to a high number of pensioners on the islands.

Also, unemployment is, according to Dahlström (2006), stigmatised in the Åland Islands, which means that there is an inclination towards creating one's own job if a suitable occupation is not available. In many cases this means starting one's own business, since the unemployment stigma overlaps with a very strong entrepreneurial spirit in the islands (Dahlström et al., 2006). According to a report by Statistics and Research Åland, $88 \%$ of all of the Åland Islands businesses had fewer than five employees and only three had more than 250 employees in 2008 (Statistics and Research Åland, 2008). Thus, apart from the two largest employment sectors, shipping and the public sector, which are dominated by men and women, respectively, the Ålandic labour economy is characterised by a large number of small enterprises and start-ups (Dahlström et al., 2006). Although many businesses end up closing down, each year around 200 new businesses are launched in the Åland Islands.

In $2008,32 \%$ of all small business owners were women, compared with $25 \%$ in Sweden and 33\% in Finland. While male business owners often ply their trade within construction and other technical occupations, female business owners are more likely to operate in retail and service 
industries (Miiros, 2008). As explained below, the Ålandic labour market is gender segregated, and since men and women tend to start up businesses in different industries, the high degree of entrepreneurship in the Åland Islands does not help mitigate the persistent gender segregation (Statistics and Research Åland, 2008).

The female participation rate surpassed the male participation rate in the early 2000s and has been consistently higher since then. In the other Nordic countries male participation rate tends to be higher than female participation rate, which means that the Åland Islands stand out in this regard (Haagensen, 2014; Statistics and Research Åland, 2012b, 2013, 2014, 2015d). However, when applied at a regional level, others have found that regions in eastern and northern Finland (e.g. the area of Lappi) have female participation rates that are either equal to or more than $1 \%$ higher than the male participation rates. Thus today, in a Nordic context, the Åland Islands might not be so unique in this respect (Nordregio, 2016a).

According to Statistics and Research Åland (2014), a plausible explanation for this development is the general growth of public care services. The number of public sector employees increased by $20 \%$ from 2000 to 2010, accounting for the growth of so-called "female" jobs in the public sector. At the same time, male employment is more common in the parts of the private sector - particularly the shipping industry - that have been subject to significant rationalisation measures, especially following the beginning of the financial crisis in 2008. From 2000 to 2010, a period when the public sector grew significantly, the transport and shipping industries experienced a decline in employment of $8 \%$, thus diminishing the amount of traditional "male" jobs. Further contributing to the difference between female and male participation rate is the fact that men tend to retire earlier than women (Statistics and Research Åland, 2013).

A lower average female wage means that women can expect a lower retirement income. Today, female pensioners outnumber male pensioners but still receive a smaller proportion of the total pensions paid in the Åland Islands. In 2013, the average pension paid was EUR 1,220 per month for women and EUR 1,744 per month for men. There are, however, recent indications that the wage difference is levelling out (Statistics and Research Åland, 2015d), although this is unlikely to be observable in paid pensions for some time. 


\section{Part-time work in the self-governing areas}

Whereas the previous chapter presented an overview of the self-governing areas, this chapter will focus more specifically on part-time work in the Faroe Islands, Greenland and the Åland Islands. Although the emphasis is on part-time work in the context of key areas such as the labour market, education and welfare services, the content of each section is diverse, given the different kinds of data available in each area.

The available data on part-time work in the Faroe Islands was relatively extensive, although some of the material dates back to 2011. The data from the Åland Islands was based on a sample survey of the labour force in late 2014, and part-time work was calculated using wage statistics. Finally, the data for Greenland was based on a large sample and calculations were based on the average number of months worked. What follows, then, should be read as an overview of what we presently know about part-time work in the self-governing areas. The final section (3.4) discusses how the self-governing areas compare with each other and which tendencies and challenges they have in common.

\subsection{Part-time work in the Faroe Islands}

Seen from a gender perspective, one of the most prominent features of the Faroese labour market is the high rate of females working part-time. ${ }^{4}$ While part-time work is more common in the Nordic countries than the EU average (Drange \& Egeland, 2014), the Faroe Islands has one of the highest levels of female part-time work in Europe, surpassed only by Switzerland and the Netherlands (Statistics Faroe Islands, 2014b). Yet at the same time, Faroese women are highly active in the labour market and the Faroe Islands has one of the highest labour market participation rates in Europe for both sexes. Indeed, in 2005 the participation rate for Faroese females was $84.4 \%$ (Statistics Faroe Islands, 2015a). Therefore, while Faroese women are active in the labour market, their contribution rate is 
more likely to be in the form of part-time work than observed in many other countries - a feature we shall explore in more detail below.

Overall, 49\% of Faroese women and 10\% of Faroese men aged 20-64 work part-time (Statistics Faroe Islands, 2014a). ${ }^{5}$ These are substantially higher figures than in the other Nordic countries. Norway tops the list with $40 \%$ of women working part-time and the Nordic women least likely to work part-time are the Finnish, with $18 \%$ of women work part-time. (Lanninger \& Sundström, 2014).

In the past decade, the distribution of part-time work in the Faroe Islands has varied by gender and age. See Table 1 for the period 2005-2013 (Statistics Faroe Islands, 2015b). ${ }^{6}$

Table 1: \% of labour force working part-time, 2005-2013, by gender and age group

\begin{tabular}{|c|c|c|c|c|c|c|}
\hline \multirow[b]{2}{*}{ Year } & \multicolumn{2}{|c|}{$15-24$ years } & \multicolumn{2}{|c|}{$25-44$ years } & \multicolumn{2}{|c|}{$45-64$ years } \\
\hline & Males & Females & Males & Females & Males & Females \\
\hline 2005 & $40.4 \%$ & $61.2 \%$ & $10.9 \%$ & $45.9 \%$ & $13.6 \%$ & $56.7 \%$ \\
\hline 2009 & $50.9 \%$ & $68.2 \%$ & $8.2 \%$ & $55.6 \%$ & $13.5 \%$ & $46.7 \%$ \\
\hline 2013 & $42.6 \%$ & $73.3 \%$ & $11.7 \%$ & $54.1 \%$ & $10.6 \%$ & $50.4 \%$ \\
\hline
\end{tabular}

Source: Statistics Faroe Islands (2015b).

Upon examining the figures in Table 1, the most striking feature of parttime work in the Faroe Islands is the difference between male and female working hours. The contrast is particularly evident in the age groups 2544 and 45-64, where women are much more likely than men to work part-time. Among the 15-24 year olds, however, the incidence of male part-time work is considerably greater than in the older male age groups. In this age group (15-24), young people are entering the labour force and are typically in education, which in part explains the higher levels of parttime work among younger men.

Fagen \& O'Reilly (1998, p. 9) have pointed out that “...the common gender pattern is that part-time work is generally triggered by motherhood, whereas for men it is more likely to occur at the point of labour market entry or exit." When looking at the figures for the Faroese men, the findings by Fagen and O'Reilly appear to be substantiated for the 1524 age group.

\footnotetext{
5 These figures are from the Faroese census conducted in 2011.

${ }^{6}$ The figures in Table 1 are based on the Faroe Islands labour force survey conducted biannually by Faroe Islands Statistics. The survey is based on around 1,000 respondents. Fluctuations in the figures may be partly attributed to the limited sample size.
} 
However, it is evident that Faroese women in all three age groups are much more likely than their male counterparts to work part-time. Furthermore, part-time work among women does not necessarily appear to be triggered by motherhood (25-44 year age group). Rather, women's part-time work in the Faroe Islands is a general phenomenon across the age groups. Therefore, and in conclusion, not only do a significant amount of Faroese women work part-time, they do so in all age groups.

\subsubsection{Distribution of labour market participation}

We have identified to what extent Faroese men and women work parttime. However, in exploring gender and working patterns, an equally valid issue is the number of hours people work on a weekly basis. Figure 2 provides an overview of working hours in per cent of males and females (aged 15-64) in the labour force.

Figure 2: Distribution of hours worked by gender as \% of labour force

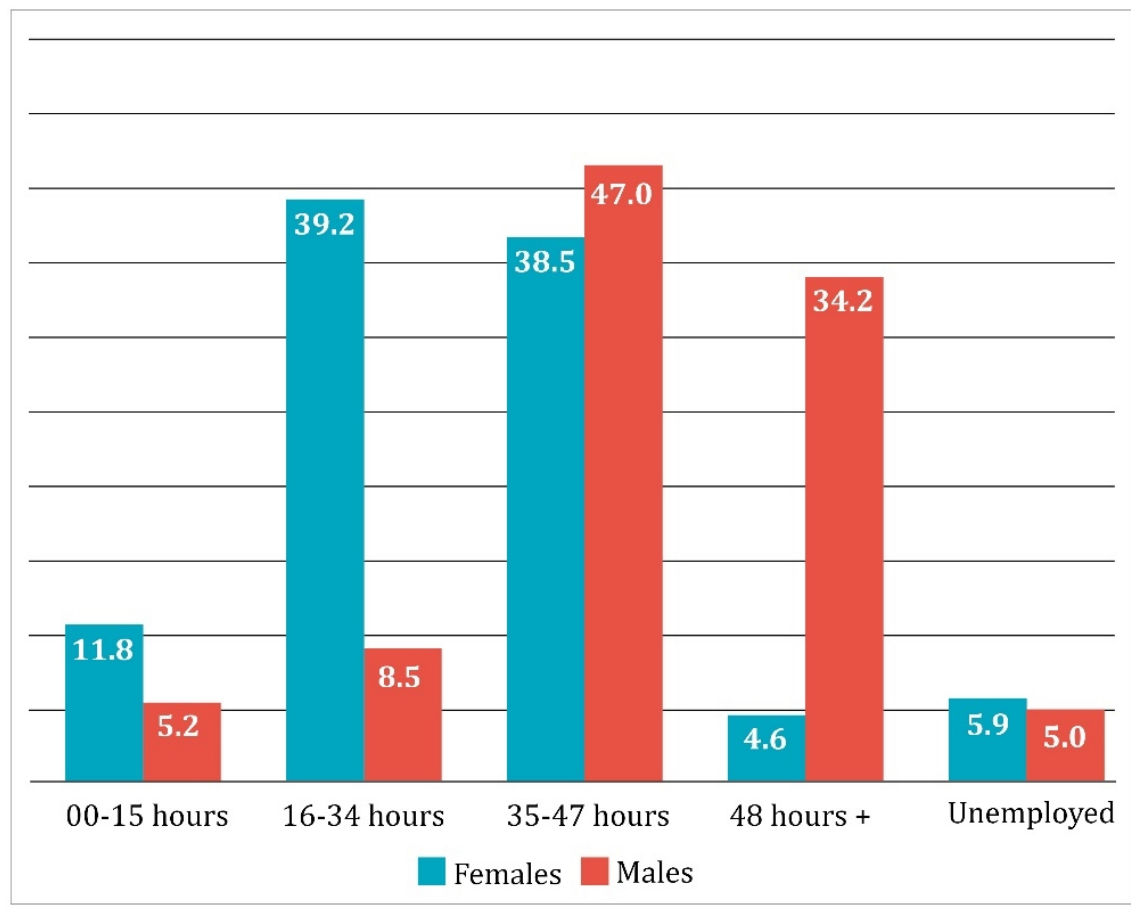

Source: Statistics Faroe Islands (2015b). ${ }^{7}$

${ }^{7}$ Based on the official statistics from the 2011 census. The figures are for the $15-64$ age group. 
We can see from Figure 2 that a large proportion, (i.e. 39.2\%, of females in the labour force) work 16-34 hours per week. Only $11.8 \%$ of females have a more marginal role in the labour market and work less than 15 hours. Furthermore, as almost half of these females (working 0-15 hours) are 15-24 years old, 8 there is a strong correlation between female age and working 15 hours or less per week. As pointed out earlier, this is no doubt connected to a relatively high proportion of females in the 15-24 age group being in education.

In a study by Mandel \& Semyonov (2006) of gender and working patterns in 22 countries, it is noteworthy that in countries with a progressive welfare system, ${ }^{9}$ Mandel \& Semyonov found that there were relatively few women who had a marginal participation in the labour market (working 0-15 hours per week). They further report that a relatively high proportion of women in countries with progressive welfare systems work parttime, yet their working hours generally correspond to half time $50 \%$ of full-time) or more. ${ }^{10}$

The working patterns of Faroese women are similar to Mandel \& Semyonov's findings for countries with progressive welfare systems. That is, Faroese women work part-time, but tend to have an important role in the labour market with around 3 out of every 4 female part-time workers working 16-34 hours per week. This means that relatively few Faroese women have a marginal position in the labour market (0-15 hours). Therefore, we can conclude that the Faroese women's work patterns are comparable to those of women in the other Nordic countries. However, it is clear that the extent of part-time work among Faroese women is not only higher but also more pronounced throughout the entire working life, regardless of age.

One further point worth addressing in Figure 2 is that Faroese men appear to work long hours, with more than one-third working in excess of 48 hours per week. This high figure may be partly explained by the registration of working hours among long-distance workers. These are people who work at sea or off-shore or who otherwise have employment involving extended periods of time away from the Faroe Islands. In the census questionnaire guide, employment involving being at home and at sea

\footnotetext{
8 These calculations are not presented here but are based on the same statistics.

9 Mandel and Seymyonov (2006) measured state welfare intervention in 22 countries in Europe as well as in Canada and the US. They found that Sweden, Denmark, Norway and Finland scored highest (Iceland was not included in the study). Others (Sundström, 2006) have found that the Faroese welfare system is similar to the other Nordic countries (i.e. high state welfare intervention), yet the Faroe Islands has a greater degree of familialism.

10 The distribution of working hours that Mandel and Seymyonov applied in their study consists of four intervals: full, reduced, half and marginal. For further details, see Mandel and Seymyonov (2006).
} 
at a ratio of approximately 50/50 was, for the purpose of the census, defined as working 48 hours or more per week. This means that working away from home is frequently recorded as 48 hours or more per week regardless of shift length. We have previously noted that in the Faroe Islands, more than 3,000 men and few females are long-distance workers (Statistics Faroe Islands, 2015b). The prominence of Faroese long-distance workers and the impact on women's labour market participation will be addressed further in Chapter 4 .

\subsubsection{Involuntary part-time work}

Statistical overviews of part-time work frequently distinguish between voluntary and involuntary part-time workers. According to Eurostat (2015), involuntary part-time work means working part-time because one is unable to find full-time work. However, to speak of voluntary or involuntary part-time work in the context of gender may seem inappropriate since choices should be seen in the context of structural constraints (Webber \& Williams, 2008). Notwithstanding the shortcomings of such categories, we will attempt to map the level of satisfaction with working hours from a gender perspective. The Faroese census questionnaire asked participants to report whether they felt their working hours were just right or if they wanted to work more or less. While this is not entirely consistent with the Eurostat definition of involuntary part-time work, we will for the sake of our analysis treat them as comparable. Table 2 indicates satisfaction with weekly working hours for Faroese men and women. 
Table 2: Satisfaction with weekly number of working hours

\begin{tabular}{|c|c|c|c|c|}
\hline & \multicolumn{4}{|c|}{ Weekly hours } \\
\hline & $0-15$ & $16-34$ & $35-47$ & $48+$ \\
\hline \multicolumn{5}{|c|}{ Women: Satisfaction with weekly working $(\mathrm{N})^{11}$} \\
\hline \multirow[t]{2}{*}{ I work about right } & $71 \%$ & $77 \%$ & $72 \%$ & $52 \%$ \\
\hline & $(1,099)$ & $(3,813)$ & $(3,392)$ & (299) \\
\hline \multirow[t]{2}{*}{ I would like to work more } & $27 \%$ & $19 \%$ & $3 \%$ & $2 \%$ \\
\hline & $(420)$ & $(913)$ & $(143)$ & (10) \\
\hline \multirow[t]{2}{*}{ I would like to work less } & $2 \%$ & $4 \%$ & $25 \%$ & $46 \%$ \\
\hline & $(32)$ & (199) & $(1,149)$ & (265) \\
\hline Total (\%) & 100 & 100 & 100 & 100 \\
\hline \multicolumn{5}{|c|}{ Men: Satisfaction with weekly hours (N) } \\
\hline \multirow[t]{2}{*}{ I work about right } & $69 \%$ & $68 \%$ & $85 \%$ & $70 \%$ \\
\hline & $(611)$ & (978) & $(5,744)$ & $(3,393)$ \\
\hline \multirow[t]{2}{*}{ I would like to work more } & $30 \%$ & $28 \%$ & $7 \%$ & $3 \%$ \\
\hline & (263) & $(408)$ & $(466)$ & (153) \\
\hline \multirow[t]{2}{*}{ I would like to work less } & $1 \%$ & $4 \%$ & $8 \%$ & $27 \%$ \\
\hline & (12) & (53) & $(576)$ & $(1,309)$ \\
\hline Total (\%) & $100 \%$ & $100 \%$ & $100 \%$ & $100 \%$ \\
\hline
\end{tabular}

Source: Statistics Faroe Islands (2015b).

The majority of people, both men and women, feel they work about the right amount of hours, including those who work part-time. Of all women who work part-time ( $0-15$ hours and 16-34 hours), 76\%12 feel they work about the right amount of hours. Some of the reasons for this will be further explored in Chapter 4. Furthermore, men who work 48+ hours are more inclined than their female counterparts to feel that they work about the right amount of hours.

Another significant tendency found in the data is that women working 35-47 hours per week are three times as likely as their male counterparts to want to work less, i.e. $25 \%$ vs. $8 \%$. Furthermore, of those working $48+$ hours per week, women are $70 \%$ more likely to want to reduce their

${ }^{11}$ In this table we have included the numbers of women and men for each category (N), as well as the percentages. When working with such small samples as for the Faroe Islands, Greenland and Åland Islands, percentages can easily become misleading.

12 This figure is for all women who work part-time ( $0-34$ hours) and who state they work about the right amount, in proportion to all women who work part-time. 
hours. Thus, women working full-time or more are much more inclined than their male counterparts to feel that they work too much.

On the other hand, the figures also reveal a degree of involuntary parttime work. From the combined figures by gender, for respondents who would like to work more, in proportion to total amount of each gender working part-time (0-15 and 16-34), it emerges that as many as $21 \%$ of females and $29 \%$ of males would like to work more than they do. While the reasons for male underemployment are no doubt of relevance, we will here focus mainly on potential reasons for female underemployment.

In some sectors in the Faroe Islands, there are structural barriers to female full-time employment. For instance, in public job announcements from January 2013 to May 2014, around 75\% of advertised part-time jobs were found to be in female-dominated professions, e.g. elderly care, teaching, secretarial work, nursing and canteen work. (Faroe Islands Unemployment Agency, 2014). In another survey, the Practical Nurse Association (2014) found that $12 \%$ of their members had unsuccessfully requested more working hours in the preceding year. Yet another factor worth mentioning is that the working week in the Faroe Islands is 40 hours per week, which is somewhat higher than in some other Nordic countries (e.g. in Denmark, a full-time working week is 37 hours) - something that may affect women's choice to opt for part-time employment, especially in professions where the predominant mode of work in shift work.

Furthermore, in the female-dominated care professions, trade union representatives have reported that from an employer's perspective, the reasons for promoting a part-time rota structure include 1) that employers prefer to have the flexibility of having many "reserves", i.e. more employees (rather than fewer full-time employees) and 2) that the nature of the job is too challenging (physically and mentally) to permit full-time work (Practical Nurse Association, 2014). In other words, employers too, at least in some business sectors, consider it beneficial to have part-time staff. Some of these structural barriers to females working full-time will be further explored in Chapter 4.

\subsubsection{Part-time work and educational level}

In this section we explore part-time work in the Faroe Islands in the context of educational attainment. To this end, Table 3 provides an overview of the educational level of men and women aged 15-69 working parttime. Furthermore, the table outlines the overall male and female educa- 
tional attainment as a proportion of the male/female population. This enables a comparison between the educational level of those working parttime and the educational make-up of the entire population (aged 15-69).

Table 3: Part-time work and educational level

\begin{tabular}{|c|c|c|c|c|}
\hline & \multicolumn{2}{|c|}{$\begin{array}{l}\text { Educational level for those working part- } \\
\text { time ( } 34 \text { hours or less) in \% }\end{array}$} & \multicolumn{2}{|c|}{$\begin{array}{l}\text { Proportion of males/females by educa- } \\
\text { tional level }\end{array}$} \\
\hline & Males Aged 15-69 & Females Aged 15-69 & Males Aged 15-69 & Females Aged 15-69 \\
\hline Secondary or below & $55.8 \%$ & $49.5 \%$ & $37.3 \%$ & $49.2 \%$ \\
\hline Vocational & $27.9 \%$ & $27.6 \%$ & $32 \%$ & $25.2 \%$ \\
\hline Tertiary or above* & $16.3 \%$ & $22.9 \%$ & $30.4 \%$ & $25.1 \%$ \\
\hline Total & $100 \%$ & $100 \%$ & $100 \%$ & $100 \%$ \\
\hline
\end{tabular}

Note: *Tertiary education, including certificates, diplomas, bachelor, master and above.

Source: Statistics Faroe Islands, 2015b.

Upon examination of Table 3, a gendered picture emerges. Firstly, it becomes clear that men with the lowest educational attainment (secondary education or below) are more likely than other men to work part-time. In other words, $55.8 \%$ of men who work part-time have secondary education or below, despite the fact that this educational category represents only $37.3 \%$ of the entire male population. On the other hand, males with a vocational education and especially those holding a certificate or above are less likely to work part-time, especially those with the highest qualifications.

Secondly, educational level appears to have less of an impact on whether Faroese women work part-time. Turning firstly to females with the lowest educational level (secondary education or below), it is evident that $49.5 \%$ of women who work part-time have secondary education or lower and at the same time, $49.2 \%$ of the entire female $15-69$ year old age group hold secondary education or below. Therefore, the figures for women with the lowest education working part-time correspond well with their representation in Faroese society. In other words, holding a low level education does not make Faroese women more likely to work parttime compared with more educated females.

When compared to how well they are represented in the total population females in the vocational education category are slightly more likely to be working part-time, while females in the highest educational category are slightly less likely to be working part-time. Overall though, it appears that educational level has less of an impact on whether females work part-time or not compared to for men. This means that Faroese women in general work part-time across all educational levels as parttime work is not concentrated at particular educational levels. 
Interestingly, this appears to differ somewhat from the findings in other Nordic countries, where part-time female workers were found to have significantly lower levels of education than those working full-time (Lanninger \& Sundström, 2014). ${ }^{13}$

\subsubsection{Part-time work and welfare}

In piecing together knowledge on gender and part-time employment patterns, welfare provisions aimed at families will be addressed. In doing so, the key focus is on maternity/paternity leave, parental leave and childcare provision.

Presently, Faroe Islanders enjoy in total 44 weeks of paid leave when becoming parents. The total paid leave was increased by 6 weeks (from 38 weeks) in legislation passed in the Parliament in December 2015. The first 14 weeks are reserved for the mother and a total of 4 weeks are reserved for the father, which means that none of these weeks can be transferred to the other parent. The remaining 26 weeks are left for the parents to divide between them. Furthermore, the maximum pay parents can receive from the state-funded system during their leave is DKK 25,000 per month. ${ }^{14,15}$ This, coupled with the reality that men earn more in the Faroe Islands (in some cases even for doing the same work in the public sector) (J. Joensen, 2009; Statistics Faroe Islands, 2015b), signals that the financial structure cannot be overlooked as part of the overall complex picture.

Being able to combine paternity leave with work in a society, where many men are long-distance workers, working patterns are often used as an explanation for not taking paternity leave. For these men, the nature of working rotas means being away for, say, 2 months and then being home for 2 months although some long-distance workers have longer periods away than at home. Also, many of these men have paid leave at home regardless and may not consider it necessary to "skip" a fishing trip to take paternity leave (Fiskimannafelagið, 2014).

Yet, such resistance may be more connected with the financial disincentive many men face when considering taking paternity leave, along

\footnotetext{
13 Overall, Faroese women with lower levels of education are more likely to work part-time. However, we have chosen to relate these figures to the educational level of males and females relative to the population as a whole. Therefore, it is unclear whether our figures are directly comparable to those of Lanninger and Sundström (2014).

${ }^{14}$ Some employees whose salary is over DKK 25,000 have job contracts providing them with their full salary during parental leave, i.e. their employer pays the difference over DKK 25,000.

15 It should be noted that holiday allowances and pension as well as tax are deducted from the pay that parents receive during their leave. The net figure is therefore lower.
} 
with the traditional Faroese gender culture, which will be further explored in Chapter 4. In a system where the state regulates paid leave for parents, the underlying societal message is that females are considered more natural caregivers. Thus, the state and labour market are implicated in setting the scene for the division of caring responsibilities between men and women.

Figure 3 below reveals that Faroese men on average utilise a very low share of their allotted parental leave when becoming parents. In 2003, they took only $5.7 \%$ of the total parental leave. This figure increased slightly over the period up to 2011 , only to fall again to $5.8 \%$ in 2011 . The trend in Denmark, Finland, Iceland and Sweden showed a higher increase over the same period.

Figure 3: Percentage of total parental leave taken by fathers

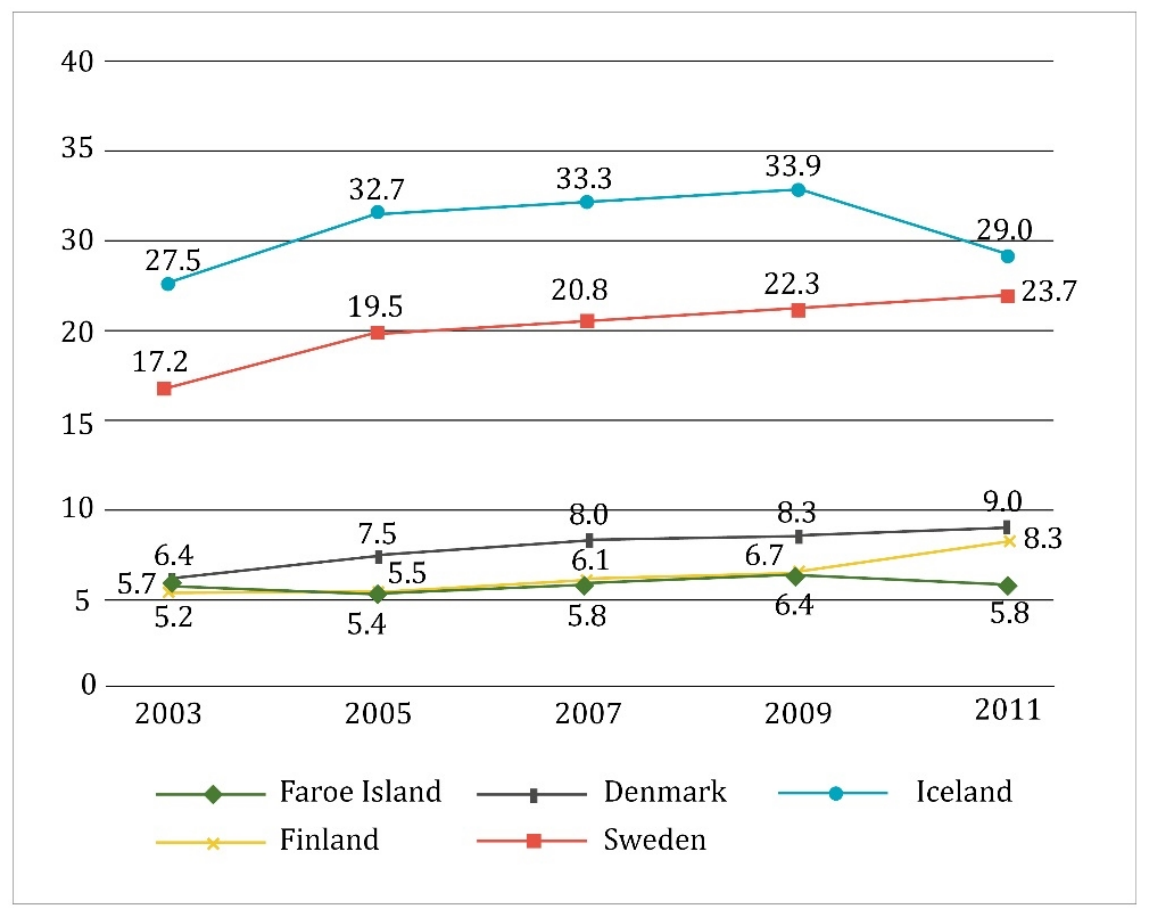

Source: Ministry of Trade \& Industry (2014).

As can be seen, not only are Faroese men less likely to go on parental leave than their Nordic counterparts, the pattern is proving resistant to change. ${ }^{16}$

16 The recent legislation voted through parliament increased earmarked paternity leave by 2 weeks. Previously, there have been efforts to increase the amount of paternity leave (earmarked for fathers) by law. However, this has generated much public debate and one attempt in 2013 to increase paternity leave failed. 
Faroese municipalities are obligated to provide full-time childcare following the parental leave. As a result, parents are able to obtain childcare for children of a young age. This means that parents (although in practice mostly mothers) are able to return to work after 38 weeks. However, parents 0ften keep their children at home until they are one year old.

In conclusion, it appears that the incentive structure may partly be framing parental choices on how parental leave is distributed among parents - and indeed whether fathers take their earmarked paternity leave. However, the resistance to fathers taking leave may well be indicative of a traditional gender culture in which caring is associated with females.

\subsubsection{Case: Teachers and part-time work}

The Faroese labour market is highly gender segregated (Hayfield, 2016). Consequently, when analysing part-time work, it can be challenging to compare different occupation sectors or job types. Yet as an example, one profession with a women-to-men ratio of 2 to 1 is that of teachers in the public school system, representing a relatively large occupational group in the public sector. Therefore, for the purpose of comparing male and female working patterns within one sector, we will here as a case in point examine teachers and part-time work from a gender perspective. ${ }^{17}$

In this sector we find there is a gender difference in the likelihood of a teacher having a part-time contract. ${ }^{18}$ Overall, the figures indicate that $13 \%$ of male teachers work part-time, whereas the corresponding figure for female teachers is 28\% (Faroe Islands Agency of Accounting \& Financial \& IT Administration, 2015). Teachers can broadly be divided into the following four categories. As can be seen, the vast majority fall into the first three:

1. Teachers with permanent contracts: $65 \%$ of teachers.

2. Teachers who are head teachers, deputy heads and sole teachers (in small schools): $10 \%$ of teachers.

3. Teachers with temporary contracts: $22 \%$ of teachers.

4. Others (e.g. teachers without a teaching qualification): $3 \%$ of teachers.

Upon closer inspection of part-time work in the various categories, it is worth noting that teachers with a temporary contract are much more

\footnotetext{
${ }^{17}$ The calculations in this section are based on employment figures from the Agency of Accounting, Financial \& IT Administration and do not indicate whether these people have other forms of employment.

${ }^{18}$ For the purpose of this analysis, part-time is defined as any contract less than full time.
} 
likely to be working part-time ( $36 \%$ of men and $45 \%$ of women), as is evident from Figure 4 below.

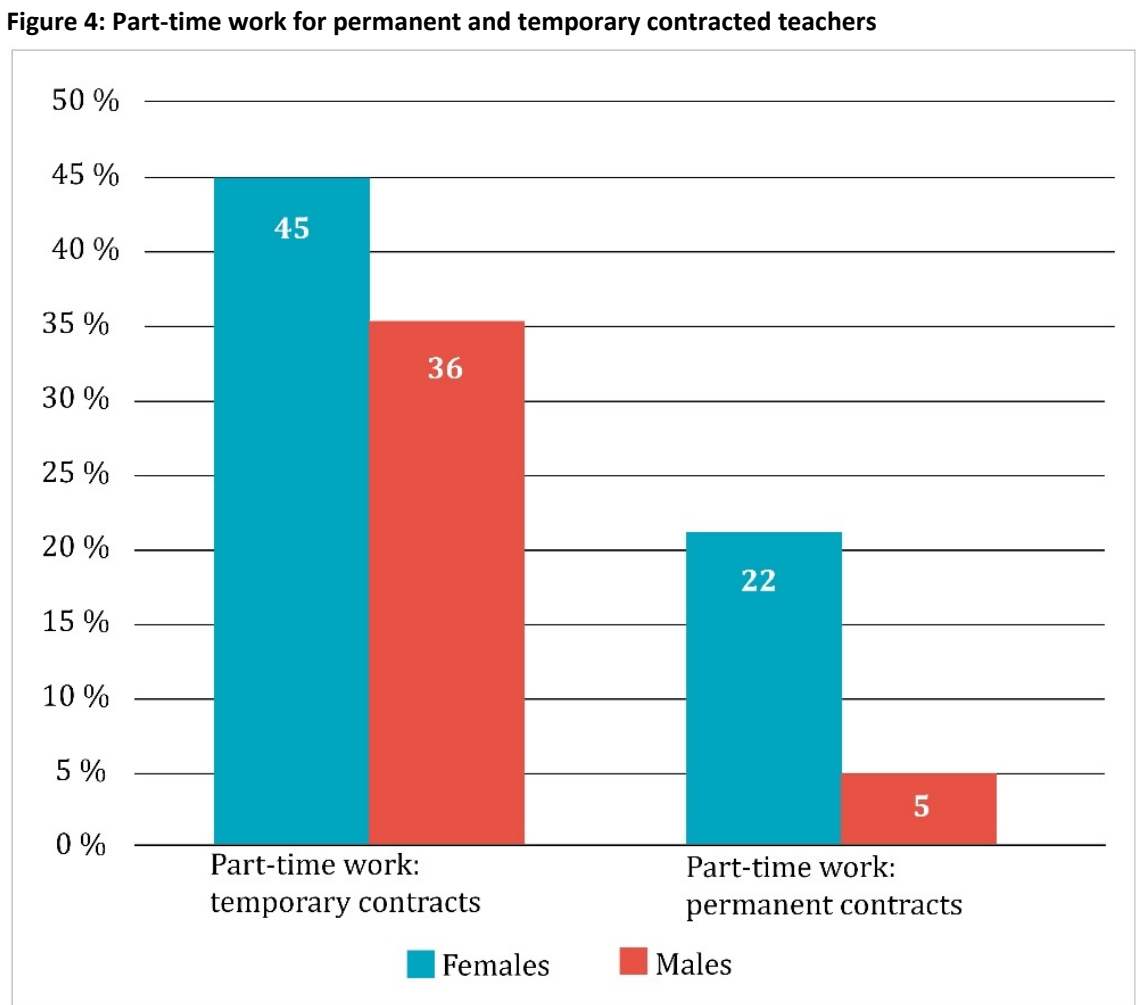

Source: Faroe Islands Agency of Accounting, Financial \& IT Administration (2015).

Most interesting, though, is the significant gender difference in part-time work among those with permanent contracts. Here females are more than four times as likely as men to be working part-time, i.e. $22 \%$ of females and $5 \%$ of males. Furthermore, almost half of permanently employed female teachers who work part-time are on a contract with working hours over 0.8 up to 0.9 of full-time. ${ }^{19}$ Therefore, relatively few female teachers with part-time contracts have a marginal role in the labour market. Rather, they tend to work a relatively high fraction of full-time.

In conclusion therefore, we can see that within a relatively genderneutral profession in the public sector, females are still, under the same employment conditions, more likely to be on part-time contracts. How-

19 These figures are not presented in the table but are based on the same statistics. Teachers' contracts are categorised as a fraction, with full time being classified as 1.0 and anything less being classified as part-time. 
ever, this does not tell us how much males and females actually work, rather it states what contracts these teachers are on. We shall return to the complexity of part-time contracts and actual hours worked in Chapter 4 .

\subsubsection{Conclusion}

Throughout the analysis in this section on part-time work in the Faroe Islands, it is evident that part-time work is a common employment form among Faroese women. Compared with women in the rest of Europe, the rate of female part-time employment is high in the Faroe Islands. More importantly, from a gender perspective, women in the Faroe Islands are much more likely than men to work part-time. However, a large majority of Faroese women who work part-time tend to work 16-34 hours per week and therefore are not confined to a marginal role in the labour market.

Overall, a majority of men and women who work part-time are satisfied with their working hours. Yet, $21 \%$ of women and $29 \%$ of men who work part-time would like to work more than they do. In figures, $21 \%$ corresponds to over 1,300 women, a rather high number considering the small size of the Faroese labour market.

When considering educational level and part-time work, the most significant finding was that for men there appeared to be a correlation between lower education and being more likely to work part-time. Faroese women on the other hand appear to work part-time regardless of educational level. Even when considering the teaching profession, which is well represented by both genders, we found that women are more likely than men to work part-time.

In addressing the welfare incentive structure of the Faroese labour market, we have focused especially on parental leave opportunities for men and women. We concluded that the underlying gender culture, along with the incentive structure, are important in explaining why the father's share of the entire parental leave entitlement is so low.

Overall, we are presented with a picture of a highly gendered labour market in the Faroe Islands, where the working patterns of a large proportion of women is significantly different than that of men.

\subsection{Part-time work in Greenland}

As previously pointed out, Greenland has considerable infrastructural challenges compared with the Åland Islands and the Faroe Islands. Road networks are extremely limited, which means that most settlements and 
towns are connected by sea or air. This means that the Greenlandic labour market is much less integrated than the other two self-governing areas, and life in the smallest settlements differs significantly from that in the larger towns, such as Nuuk and Sisimiut. Furthermore, and as noted earlier, it has been suggested that the Greenlandic labour market should not be viewed as a single labour market but as a series of relatively isolated labour markets (Nordregio, 2016b). Nevertheless, in this section we will mostly look at tendencies that apply to Greenland as a whole. We will assess part-time work in Greenland in the context of employment and wages, as well as education and parental leave.

In 2014, Greenland's workforce comprised 33,000 people, when including only those employed for at least one month in that year. Of these, just over $45 \%$ were women (Statistics Greenland, 2015a). In addition to the categories of employed and unemployed persons, the Government of Greenland (2015) uses the term "underemployed" to refer to those who are unable to find full-time permanent employment and therefore must settle for part-time or temporary work. Statistics Greenland has recently taken steps to establish the extent of underemployment in order to clarify the difference between the working population and the potential working population. This includes finding out to what degree the workforce is working part-time, which includes seasonal and temporary work. Most of the data in this section is from Statistics Greenland, with data analyses carried out by NordRegio.

\subsubsection{Employment}

Statistics Greenland uses two separate methods to calculate the share of part-time workers in the workforce, both of which utilise ILO (International Labour Organization) methods. The first method involves calculating how many months on average the total workforce ${ }^{20}$ has worked, and based on that the share of part-time and full-time workers can be determined. The second method categorises all those who earn less than the average wage in their occupation as part-time workers. The purpose is to combine both methods in order to assess the number of part-time workers more reliably than merely adopting one method. However, calculations using the second method have not yet been made available. Therefore, our figures are based on calculations of the average total employ-

\footnotetext{
${ }^{20}$ A person is statistically part of the workforce, if he/she has worked more than eight hours in a given month.
} 
ment and unemployment. While this method may not be directly comparable to the Faroe Islands and Åland Islands data, it does provide some idea of working patterns in Greenland's labour market.

According to the method based on average number of months worked, there is very little difference between males and females in relation to part-time work in Greenland (see Figure 5). The proportion of male part-time workers is relatively large in a Nordic perspective and comparable to that of the Åland Islands. On the other hand, the proportion of women who work part-time in Greenland is relatively small in a Nordic context at $25 \%$, and significantly smaller than in Norway $(37 \%)^{21}$ (Lanninger \& Sundström, 2014) and the Faroe Islands (49\%) ${ }^{22}$ (Statistics Faroe Islands, 2015b). Thus, compared with the rest of the Nordic region, the difference in part-time work between females and males is very small.

Figure 5: Proportion males and females in full-time and part-time work (\%)

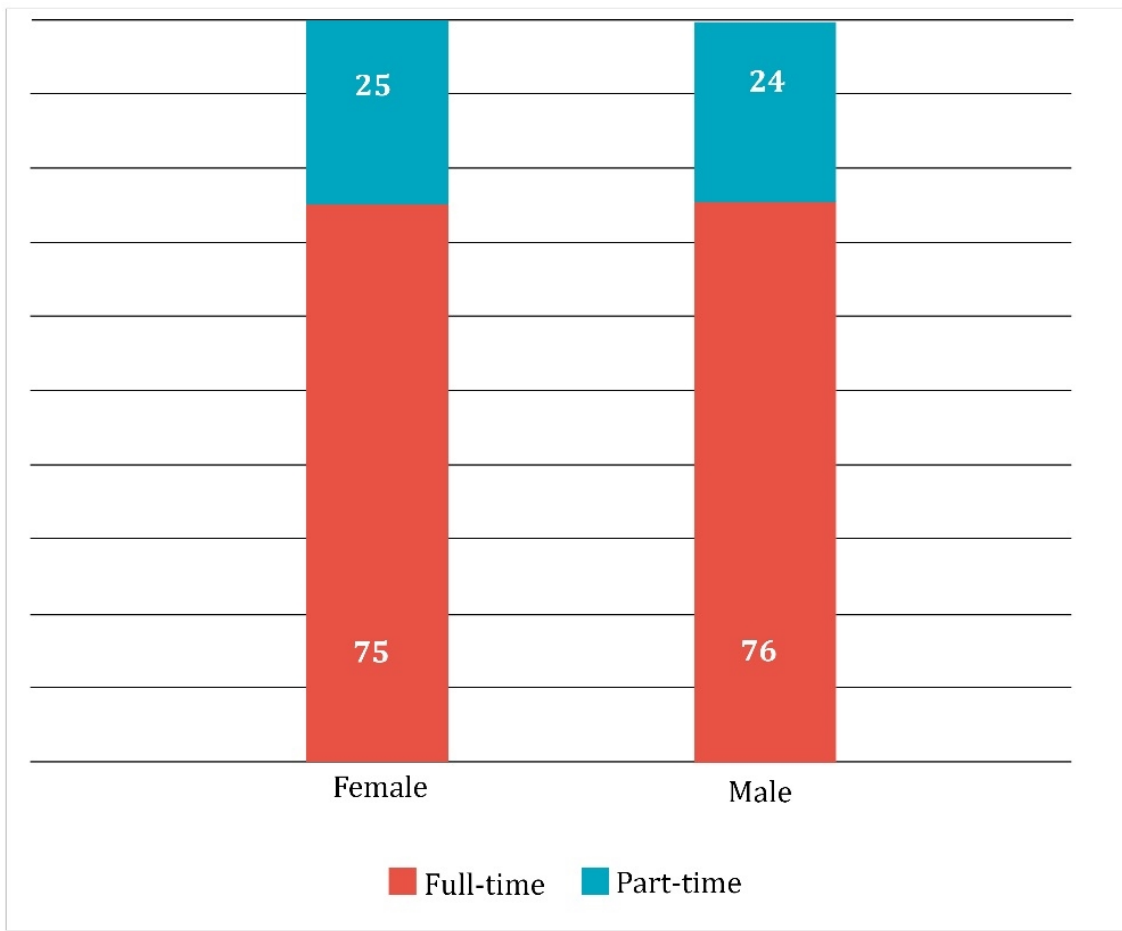

Source: Greenland Statistics \& Nordregio (2015).

21 Figures for Norway are based on women aged 25-64 years.

${ }^{22}$ Figures for the Faroe Islands are based on women aged 20-64 years. 
Figure 6: Full-time/part-time workers by towns/settlements and gender (\%)

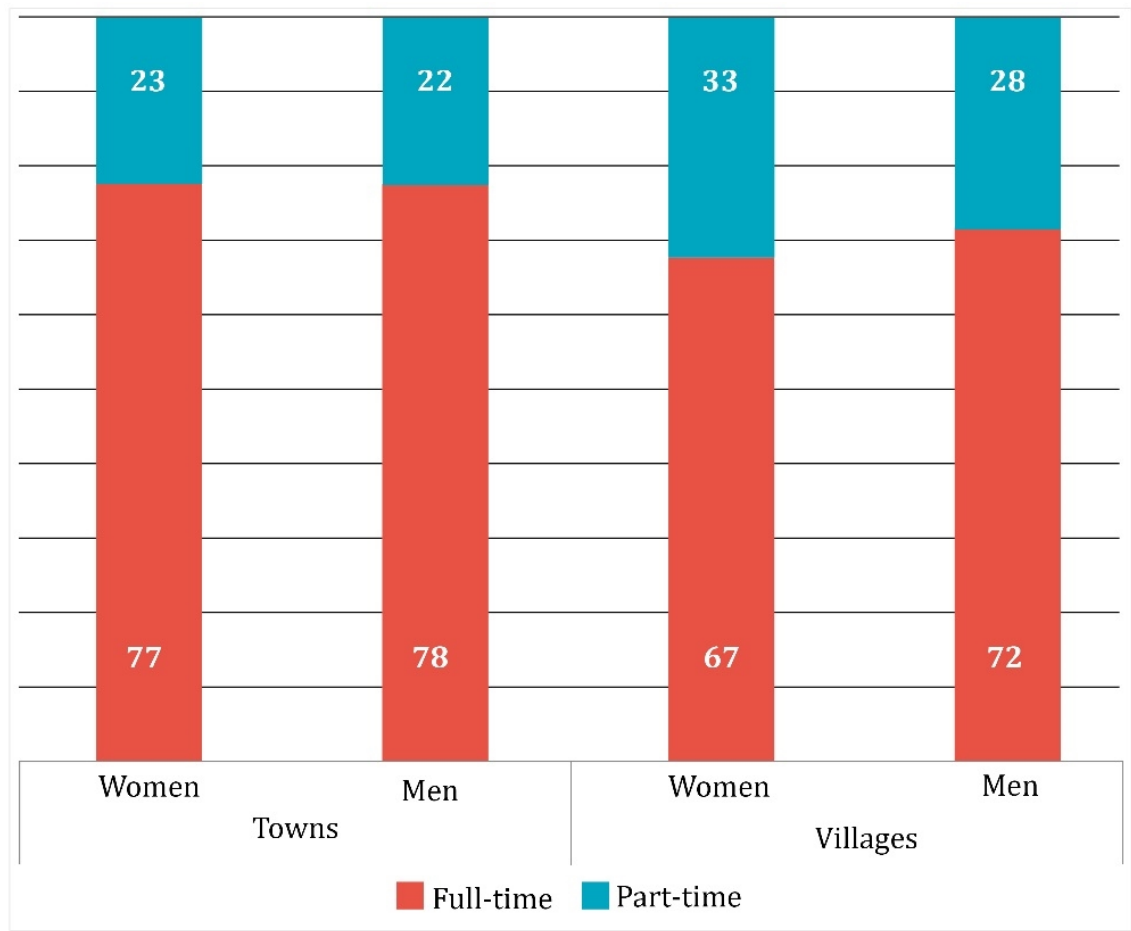

Source: Greenland Statistics \& Nordregio (2015).

A factor that in Greenland seems to correlate stronger with part-time work than gender is whether people live in urban or rural areas. According to the data, people in settlements are more likely to work part-time, as we can see in Figure 6. It is notable that women in urban areas are more likely than men in rural areas to hold full-time jobs.

Public administration and service is by far the largest business sector in Greenland and accounts for almost $40 \%$ of all employment. ${ }^{23}$ As we can see in Figure 7, close to two-thirds of all working women in Greenland and more than twice as many women than men work in this sector. Fishery is the second largest sector, and involves mostly male workers.

${ }^{23}$ Employment refers to individuals who are 1) over the age of 15,2) who have worked for an employer or who have earned a "wage" from their own business, and 3) whose earnings exceed what would correspond to eight hours worked at the minimum wage. 


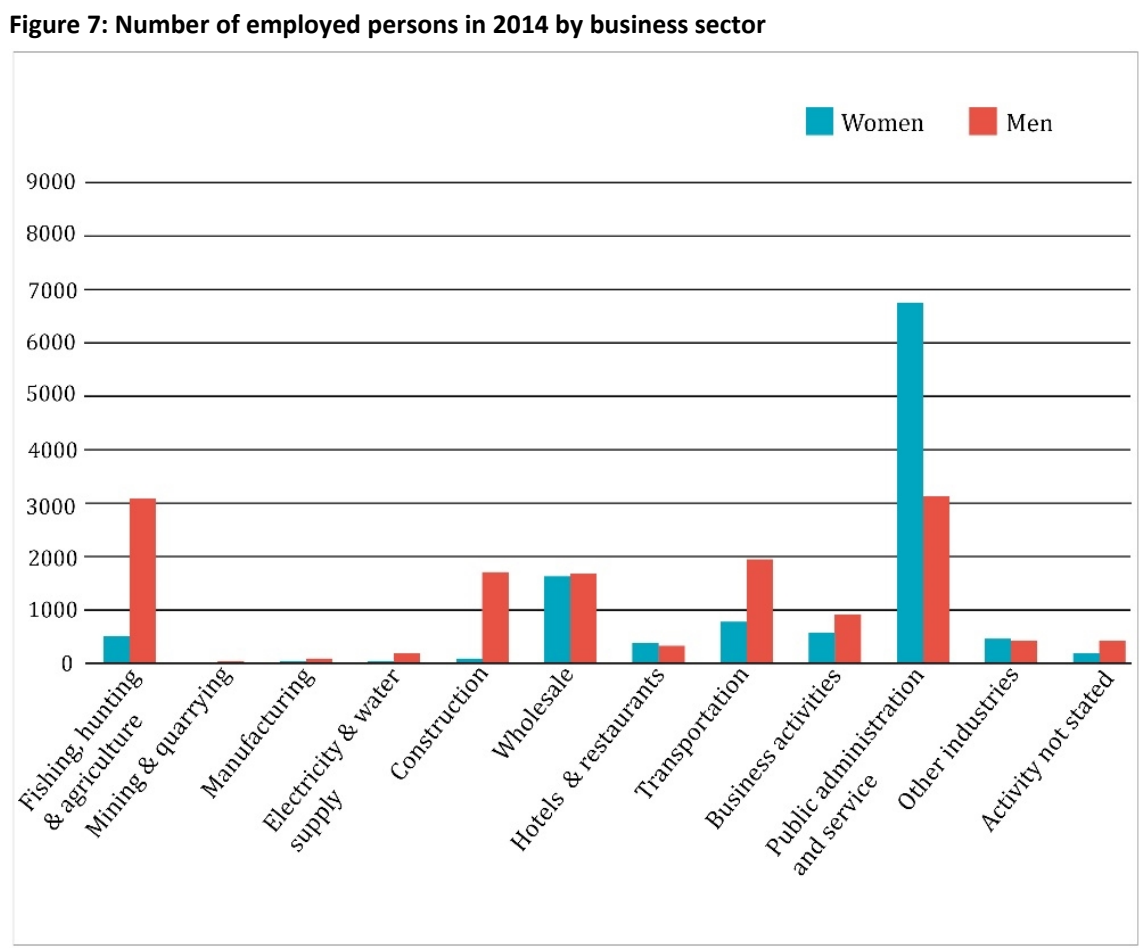

Source: Statistics Greenland (2015a)

The rate of employment in Greenland is cyclical. Figure 8 (below) shows considerable fluctuations in employment, with around 2,000 more persons employed in the 3rd quarter than in the 1st quarter each year. These fluctuations demonstrate the significance of seasonal work in Greenland. Although the size of fluctuations varies from one year to the next, employment is consistently lowest in the winter and highest in late summer and autumn.

The fluctuations coincide with seasonal mobility, as males tend to move to take up work in the fishing industry during the summer. The fishing town of Ilulissat, for example, has more inhabitants in the summer than in the winter. The peak in Greenland's tourism in the summer is the main reason for the slight female fluctuation seen in Figure 8. It is also worth mentioning that many Greenlandic students living abroad come back to Greenland to work during the summer. 


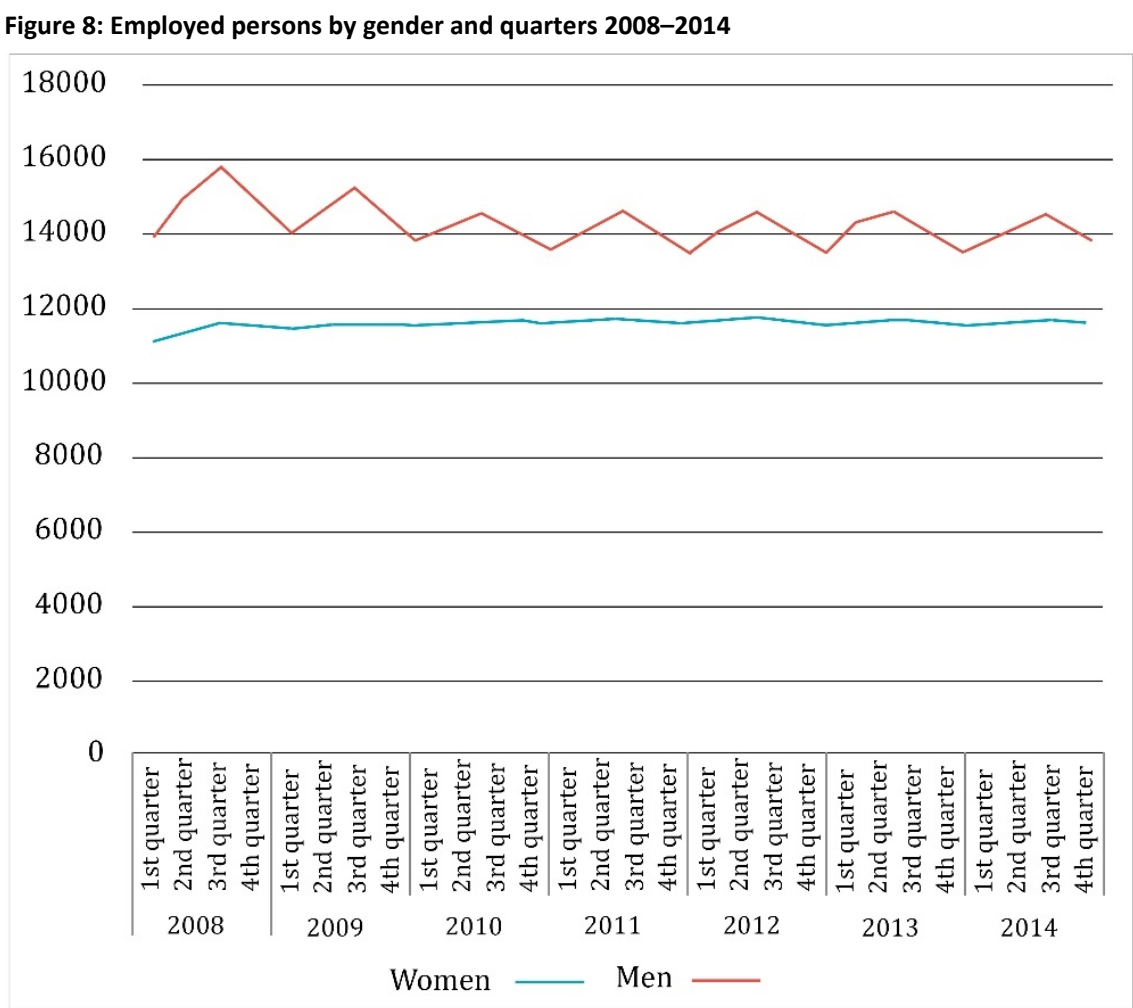

Source: Statistics Greenland (2015a).

Based on the aggregated data presented earlier in Figure 5, it is difficult to identify to what extent part-time work is seasonally based. However, the trend in Figure 8 clearly indicates that male part-time work fluctuates seasonally. Such fluctuations are clearly discernible in the unemployment rate with unemployment peaking in the 1st quarter and reaching its lowest point in the 3rd quarter. Furthermore, female part-time work is more stable, i.e. the number of hours worked and wages earned do not change as much from one quarter to next. This is not surprising, given that women overwhelmingly are employed in the public sector, in which employment is associated with greater stability in working hours. 


\subsubsection{Wages}

Despite the similar levels of part-time work for men and women, especially in urban areas, women earn less than men. According to Statistics Greenland (2015b), men earn on average around DKK 7,250 more than women per month. This figure is not adjusted for employment function, educational background and working hours. However, working hours is probably not a significant driver of this difference, since women work almost as much as men. In Greenland, educational background is strongly correlated with higher wages (Statistics Greenland, 2015b). Since women on average have higher levels of education than men (see Section 2.2), educational difference is unlikely to be a reason for the lower average female wages. Consequently, the more likely explanation for the differences in male and female wages may be related to business sector or occupational type.

Furthermore, a majority of single parents in Greenland are women who became mothers at a young age. It is common for single mothers to complete lower secondary school in their mid to late twenties, which is likely to weaken career opportunities and by implication earnings in the longer term (Government of Greenland, 2016).

\subsubsection{Education}

In Greenland there is a connection between educational level and the likelihood of working part-time, mostly due to seasonal variations in employment. Figure 9 shows the average unemployment rate per month, which is used as an indication of part-time work for people at different educational levels. For instance, people with primary school education were on average unemployed more than $15 \%$ of the months in 2013 and employed just short of $85 \%$ of the months. People with tertiary education were unemployed on average less than $1 \%$ of the months in question. Given this measurement of work activity, it is safe to assume that people with a higher level of education are more likely to work full-time than people with only a primary school background. 


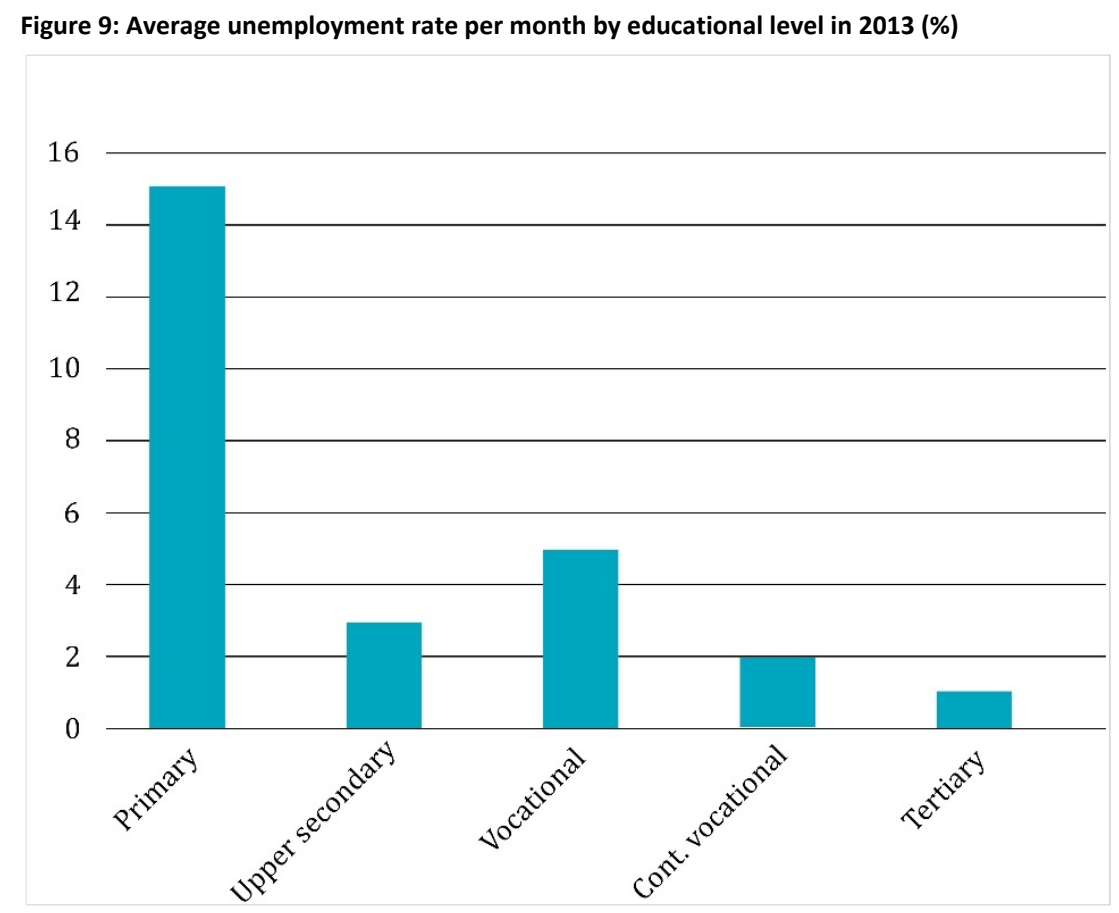

Source: Statistics Greenland \& Nordregio (2015)

Figure 10: Completed upper secondary level education in 2003-2013

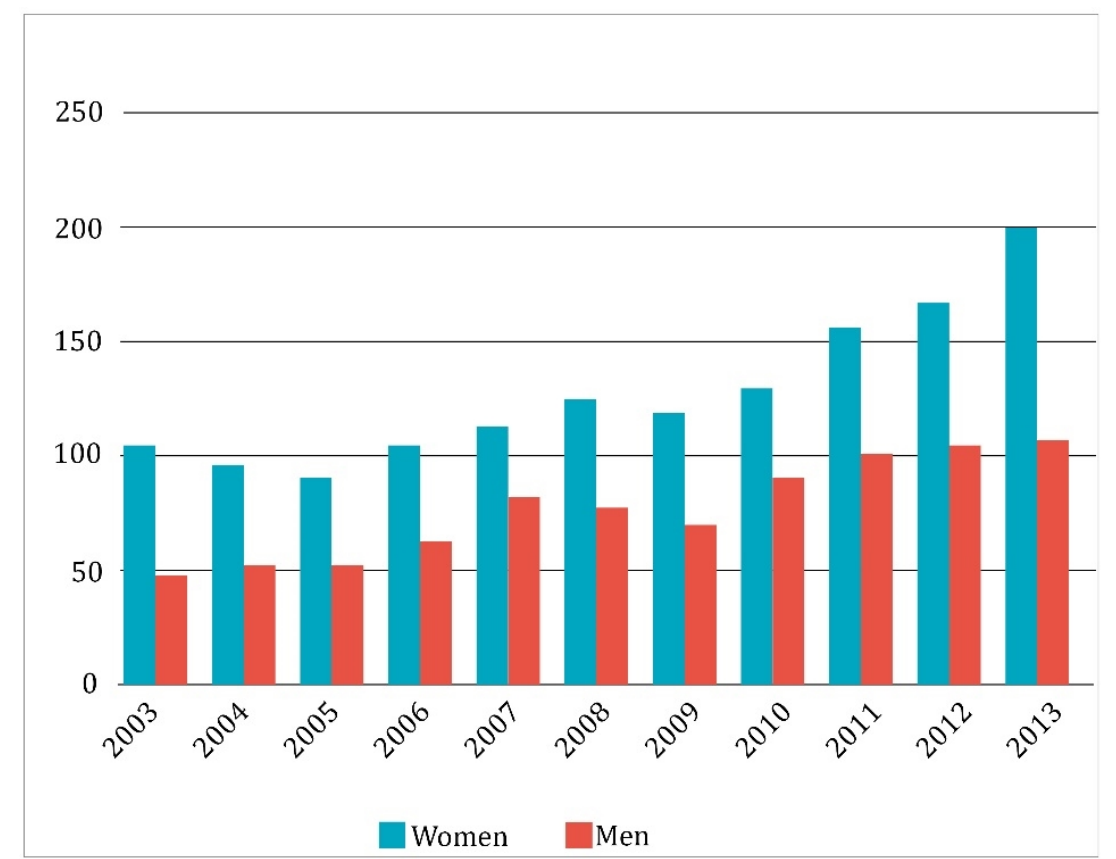

Source: Statistics Greenland \& Nordregio (2015). 
Overall therefore, we can see from Figure 9 that people who have at least upper secondary education have a much lower average unemployment rate than those with only primary education. Yet, it also noteworthy that people with upper secondary education have on average higher work rates than people with vocational education. ${ }^{24}$ This is due to certain vocational occupations having very high unemployment rates, thus skewing the data for this group. Notwithstanding the higher unemployment rate of those with vocational education, there is a clear trend for the Greenlandic labour market: the higher the educational level, the more likely one is to be in full-time employment.

The most striking feature of Figure 10 is the difference in women's and men's educational attainment, at least with respect to upper secondary level education exams. Yet we have pointed out previously (in Section 2.2) that when taking secondary and tertiary educational levels into account, women in Greenland on average have a higher level of education than men. Also, when looking at educational levels statistically, the higher the level, the greater the proportion of women represented in that group. In other words, women may be referred to as the "educational elite" in Greenland, as Boolsen (2010) has previously pointed out. 


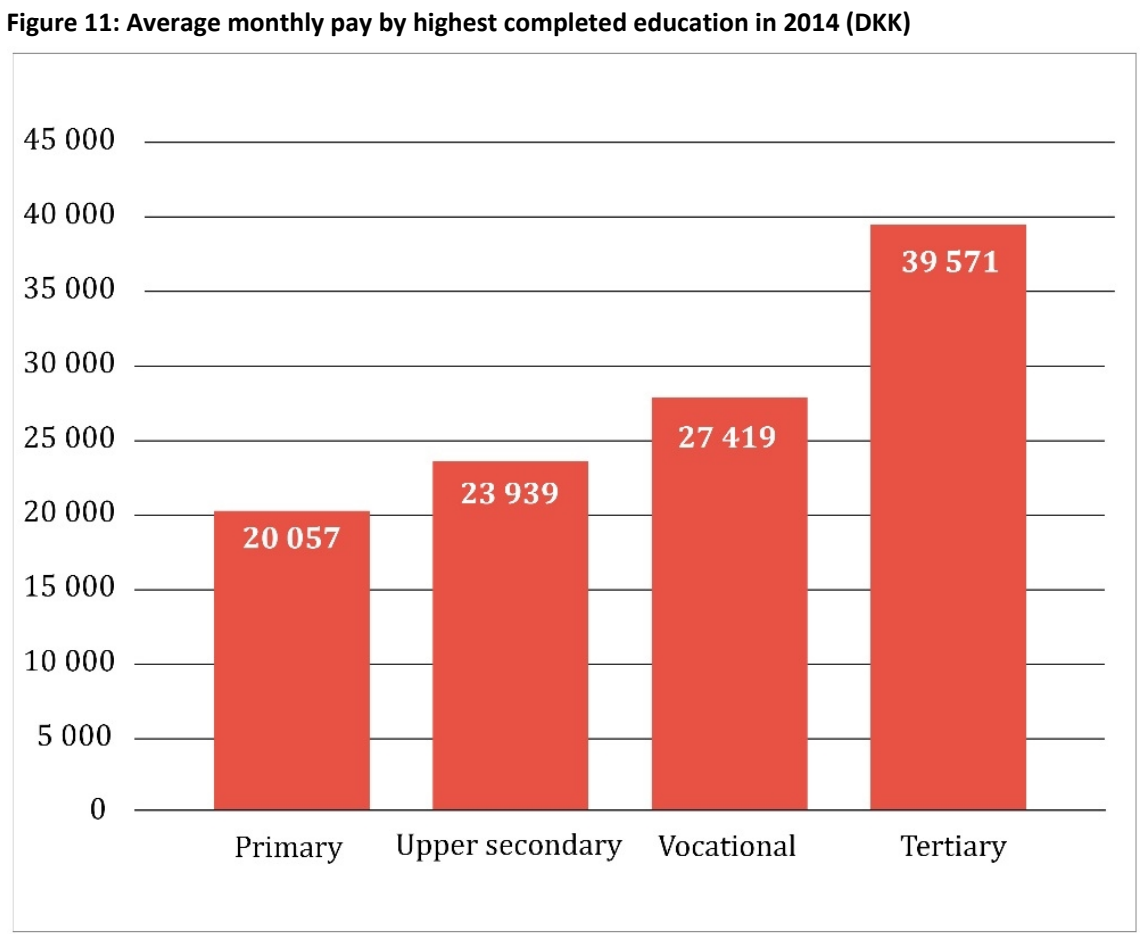

Source: Statistics Greenland (2015a).

When comparing income and education, we can clearly see in Figure 11 that a higher educational level is correlated with higher monthly pay. But when taking into account that women in Greenland are better educated than men, we are presented with something of a paradox, i.e. that women are better educated and lower paid, despite the fact that a higher educational level (on average) leads to better pay. Thus, despite the positive development in women's educational levels, women are still at a disadvantage when it comes to wages.

Since reliable data combining wages with education and gender is not currently available, it is unclear why female wages are lower than male wages despite their educational levels being higher. Several explanations are possible, such as occupational or sector-based segregation. It is further possible that the educational levels of women have not yet had time to impact their pay, but this development is certainly worthy of further examination. 


\subsubsection{Parental leave}

Mothers are entitled to maternity leave for 15 weeks and fathers to three weeks of paternity leave after childbirth. In addition to these ear-marked maternity/paternity leave periods, the parents may share 17 weeks of parental leave as they wish between them. The potential leave for mothers, then, is 34 weeks in total, providing they take the full 17 weeks of the shared parental leave, while for fathers the maximum potential leave is 20 weeks.

The amount of parental allowance ${ }^{25}$ payments to females and males is unbalanced, as women have consistently received more than $93 \%$ of all parental allowance payments in the period 2009-2014 (Figure 12). The difference in parental allowance indicates that women take on more responsibility at home in families with children, which is a tendency also found in the Faroe Islands and the Åland Islands. It is further evident from Figure 13 that a large proportion of women's total maternity pay are paid out to recipients aged 18-29 years. This corresponds with figures on age and childbirth as Greenlandic women are more likely than their Nordic counterparts to have children early (Haagensen, 2014).

Figure 12: Parental payments by gender (\%)

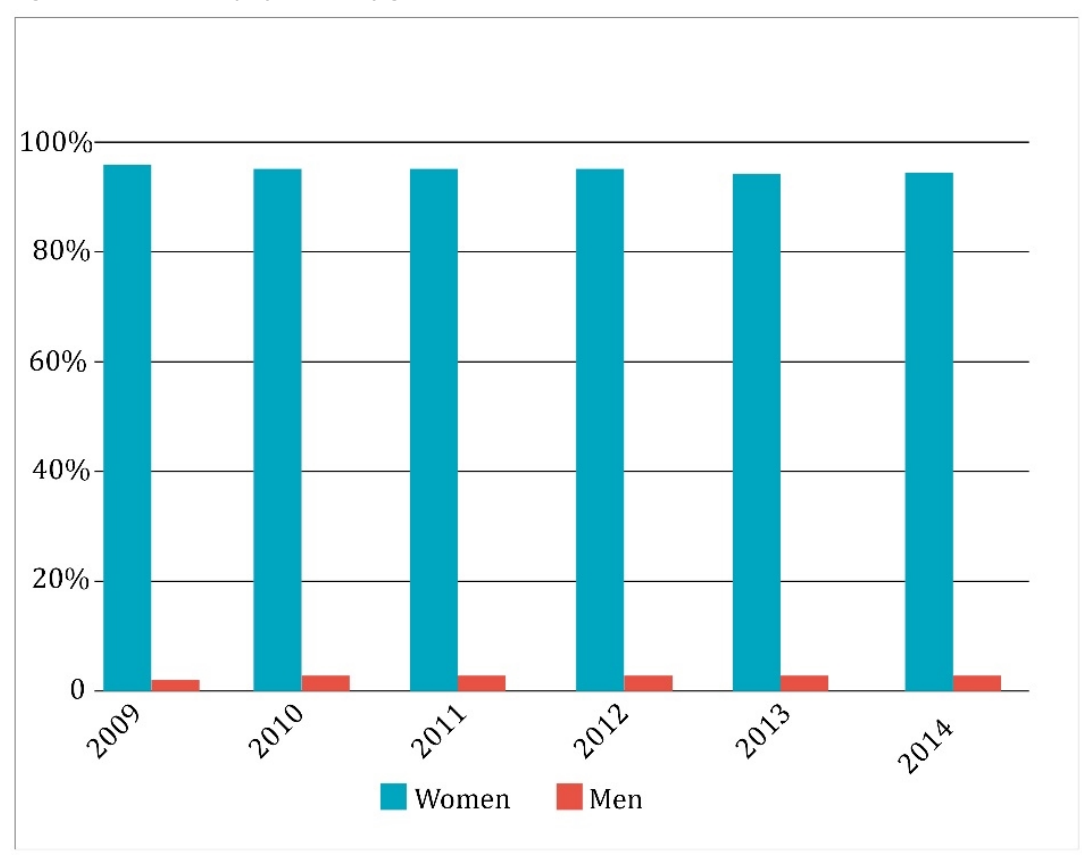

Source: Statistics Greenland (2015a).

25 Parental allowance refers to the money paid out by the state to parents, while parental leave refers to the time away from the labour market. 


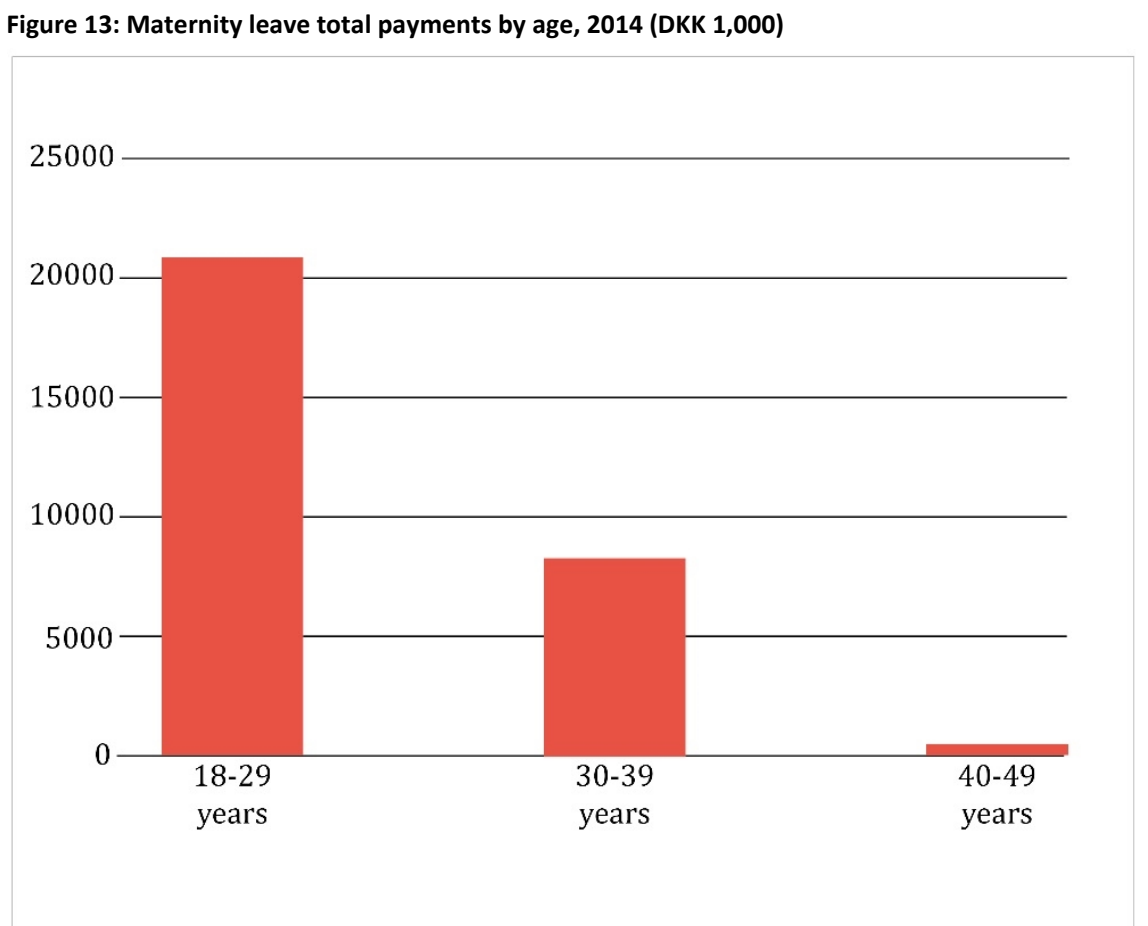

Source: Statistics Greenland (2015a).

In contrast to the vast difference in parental allowances for men and women, Poppel (2015) argues that gender roles in Greenland may indeed be changing. In her study of the perceptions of household contribution in Greenland, a majority of women 25-64 years of age stated that their most important contribution to the household was of an economic kind, which means having a job and paying bills. Notably, showing love and affection ranked as the second most important contribution to the household for both men and women (M. Poppel, 2015).

Importantly, due to the cyclical nature of (male) employment and restrictions on hunting, many Greenlandic women, especially in some less urbanised areas, find themselves being the primary bread winners. Coupled with an intense modernisation process, Van Voorst argues that this has led to "a male's loss of identity and self-worth in a fast changing society, where males lose their hunter-roles" (2009, p. 239). She further argues that the consequence of the male crisis of identity is one of the contributing factors to domestic violence as men attempt to hold on to their earlier positions of power in the household (Van Voorst, 2009). Therefore, it would appear that behind the increased female economic independence in Greenland, gender identity is being actively contested. 


\subsubsection{Conclusion}

Overall, the difference between female and male part-time work in Greenland is very small compared with the rest of the Nordic region. Geographical location is more important than gender with regard to part-time work, as people in rural areas are more likely than those in larger towns to work part-time. Considerable fluctuations in the male employment rate from the 1 st to the 3rd quarter each year indicates that male employment is characterised by seasonal work to a greater degree than female employment.

Female part-time work may be more stable, since so many women are employed in the public sector, where working hours are likely to be more evenly spread throughout the year. Despite the small difference in parttime work between men and women, men earn significantly more on average per month than women. This is something of a paradox, since higher educational background correlates with higher wages and since women are better educated than men. It is evident, then, that other factors are also in play. The difference in earnings is likely to be more related to different employment types and typical "female" jobs being lower paid.

Finally, the fact that women receive almost the entire parental leave payment strongly indicates that they take on more of the total care responsibility in households with children. However, research on male and female perceptions of their contributions to the family suggests that gender roles in Greenland are changing and that more and more females now have the main income in Greenlandic households.

\subsection{Part-time work in the Åland Islands}

The government of the Åland Islands has recently taken considerable steps to map out gender differences and inequalities in the Åland Islands. In 2012 it adopted the "Government of Åland framework programme for gender equality 2012-2015," which was based on the "EU Strategy for equality between women and men 2010-2015." The purpose of the programme was to "ensure that women and men have similar freedoms and powers to shape society and their own life" and special focus was to be given to gender equality pertaining to four areas: education, labour market, men's violence against women and power norms and identity (Government of Åland, 2012).

This framework programme has been accompanied and followed by a number of reports from Statistics and Research Åland (2012a, 2012b, $2013,2014,2015 d$ ) in the last four years with a specific focus on gender differences. One such focus is on the gender pay gap and although parttime work is rarely mentioned, the gap is mainly attributed to the gender- 
segregated labour market and gendered educational choices. These tendencies also seem linked to the fact that women take a greater responsibility for their families, i.e. children, elderly etc., than men do. Part-time work, which is only mentioned a couple of times in these reports, seems to be indicated as a symptom of the above-mentioned challenges more than as an issue in itself.

This section addresses part-time work in the Åland Islands, mainly based on statistics from Statistics and Research Åland. ${ }^{26}$ First, we address employment and part-time work, followed by a gender perspective on the educational attainment level and how it may relate to part-time work. Finally, we look at welfare services and how it may be relevant to part-time work in the Åland Islands.

\subsubsection{Employment and part-time work}

Out of the three self-governing areas, the Åland Islands have the smallest labour force with just over 15,000 working persons in 2013, of whom $50.4 \%$ are females (Statistics and Research Åland, 2015b). As mentioned previously, the sector with the most employees is transport and storage with almost 2,900 people employed, followed by care and welfare services with around 2,700 employees. However, most of the part-time work data included in this report is based on a survey with a sample of 11,044 employees, in which companies with fewer than three employees and the sea transport industry are excluded. This may well impact some of the figures, e.g. the gender difference in employed persons and the relative size of the public sector in the Åland Islands.

The Åland Islands have not had an outright female deficit in its overall population, as has been the principal demographic challenge for both Greenland and the Faroe Islands in recent decades. In fact, the population has constantly consisted of more females than males, although this difference seems to have levelled out over the past few years, as we can see in Figure 14. Unlike both Greenland and the Faroe Islands, the Åland Islands is in the European Union, which is likely to affect the migration patterns, and which may create a more diverse labour market environment than in the other two areas.

${ }^{26}$ Unless otherwise specified, all data in this section is from 2014. 
Figure 14: Åland Islands' population by gender

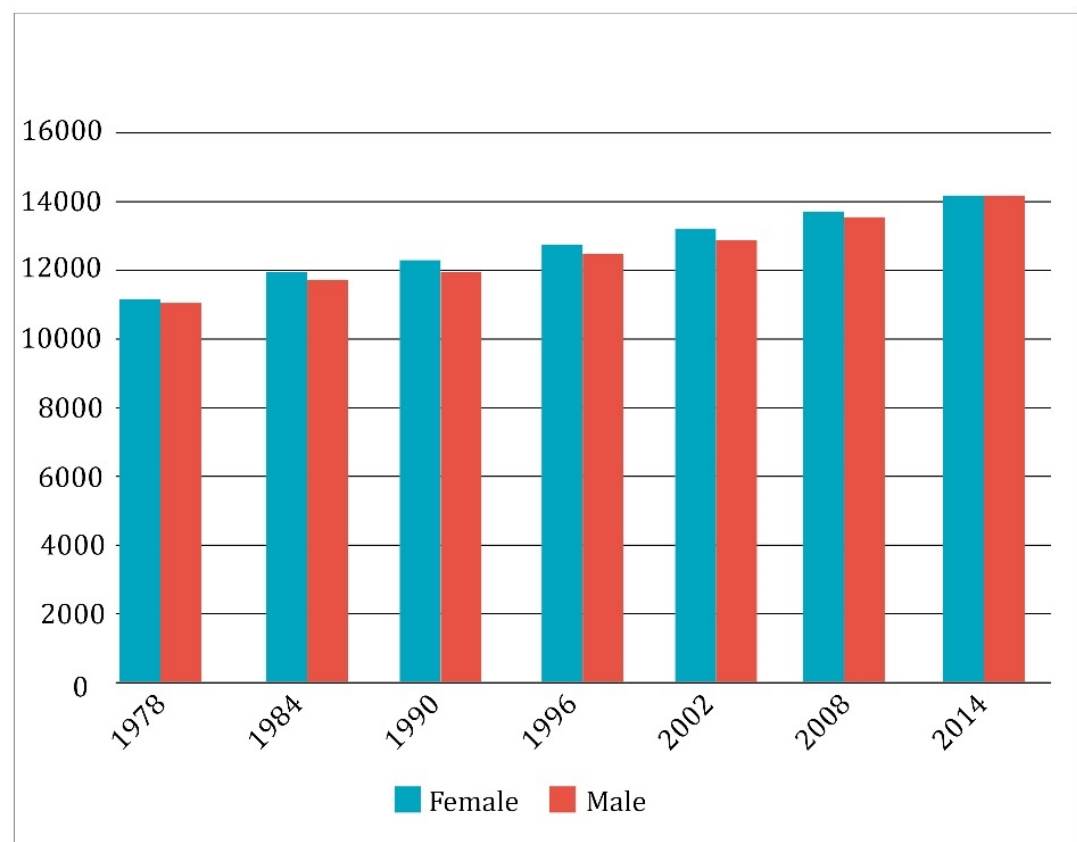

Source: Statistics and Research Åland (2015f).

Figure 15: Employment rate by gender (\%)

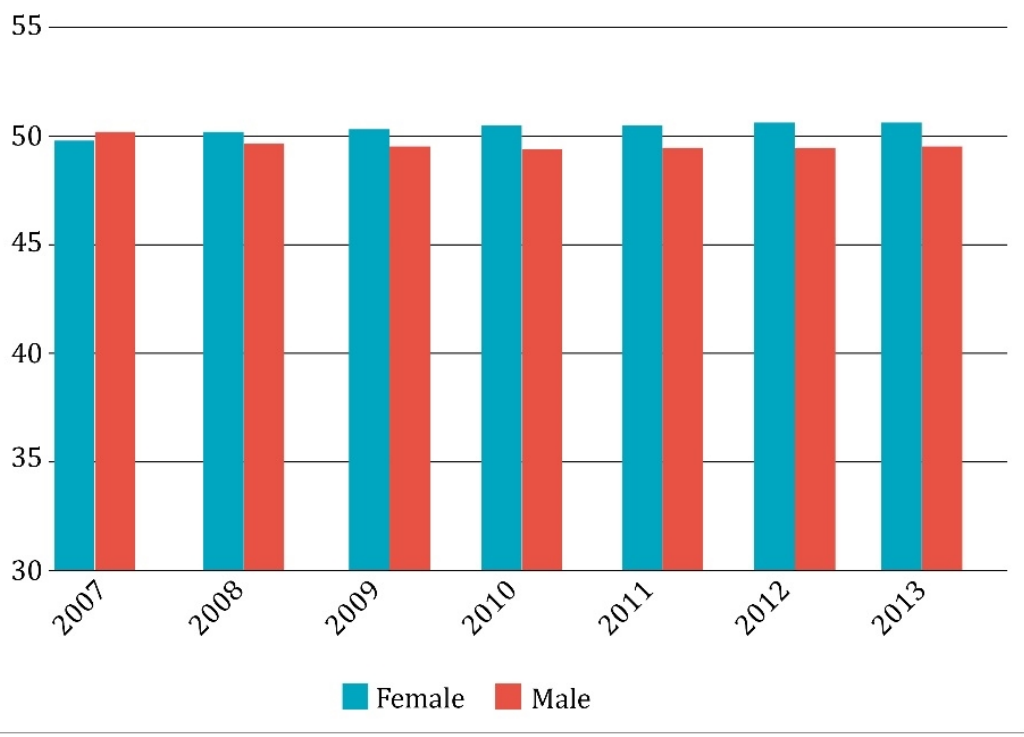

Source: Statistics and Research Åland (2015f). 
Figure 15 highlights an interesting characteristic of the Ålandic labour market, namely that women have a higher employment rate than men. The decrease in male employment rate since 2008 may have come about or at least been exacerbated by the financial crisis, since men in the Åland Islands are predominantly employed in the private sector (Statistics and Research Åland, 2014). Although Iceland and the Faroe Islands proportionately have more women employed, the Åland Islands stand out in the Nordic region in terms of the current difference in employment rate between females and males (Haagensen, 2014; Statistics and Research Åland, 2015d).

According to Dahlström, "the production structure of Åland's economy is dominated by shipping, which accounts for approximately one fourth of those employed in the labour market, while manufacturing accounts for only about $10 \%$ of total employment" (Dahlström et al., 2006, p. 91). The public sector accounts for a third of Ålands' labour market. The labour market is characterised by the fact that career choices are strongly correlated with gender. Women are overrepresented in the public sector, while men are overrepresented in the private sector (Statistics and Research Åland, 2014, 2015d).

According to Statistics and Research Åland, this gender segregation of the labour market is unlikely to change in the near future (Statistics and Research Åland, 2013), since the educational and career choices of young Åland Islanders seem to be very similar to those of previous generations (Statistics and Research Åland, 2015d). The tendency is most clearly demonstrated by taking into account the size of the Ålandic health and care sector, which employs one-fifth of the workforce and where $90 \%$ of employees are women. In fact, most occupations in the Åland Islands have a significant majority of either women or men.

Despite full-time work being defined as 33.5 hours or more working hours per week in the Åland Islands, which is lower than the other Nordic countries, the overall share of part-time workers in the Åland Islands is relatively high at $37 \%$. As we can see in Figure 16, 45.9\% of females and $25.5 \%$ of males work part-time. According to statistician Jonas Karlsson (2015e) at Statistics and Research Åland, part-time work is relatively uncommon in the shipping industry, which employs a significant proportion of males in the private sector. There is a higher degree of part-time work in other sectors, and especially in the public sector, where women are more numerous than men. 


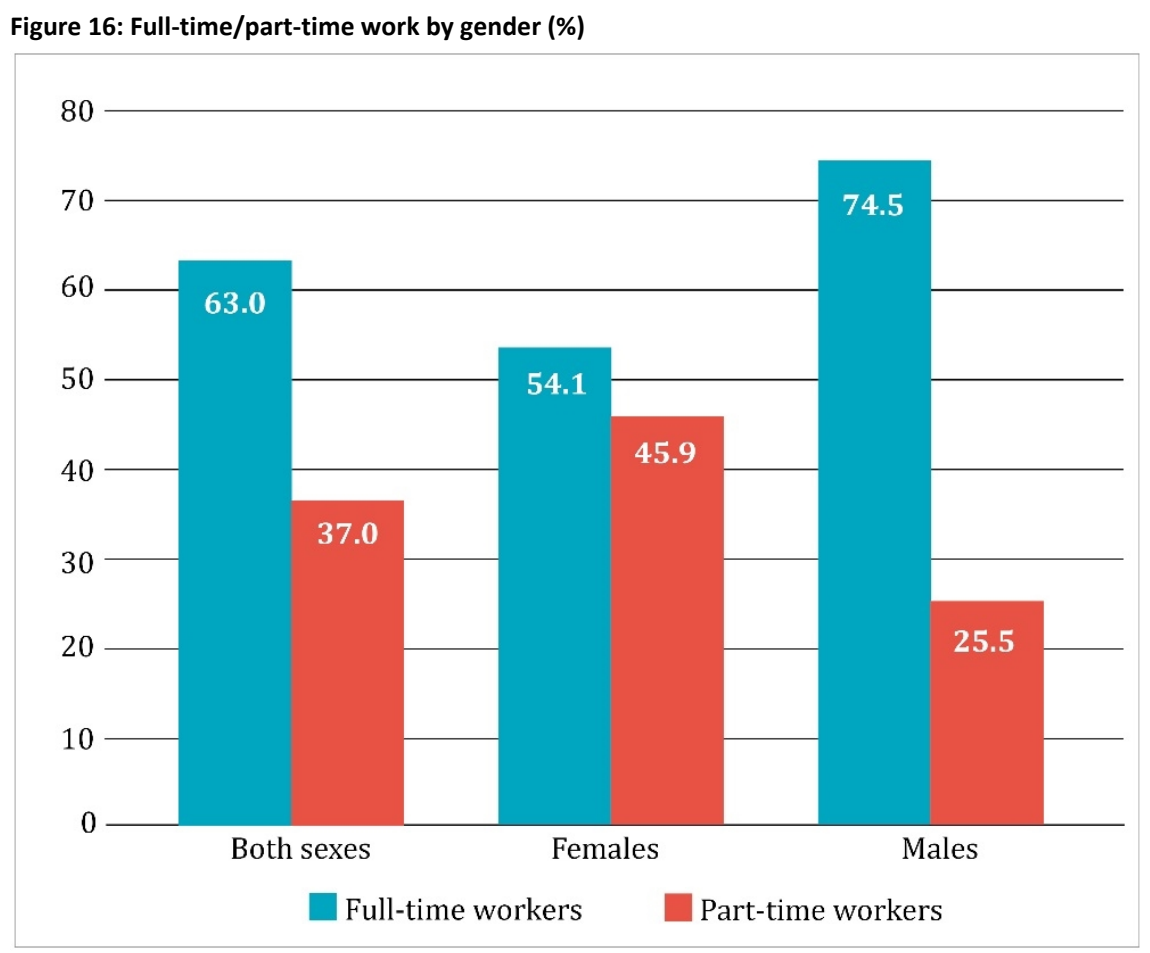

Source: Statistics and Research Åland (2015f)

Despite the higher employment rate for women than for men, the predominance of female part-time work is still evident in the Åland Islands, corresponding to the pattern for the Nordic countries and many European countries alike. Yet, there is also a relatively high number of male parttime workers. Therefore, the gender difference in part-time work in the Åland Islands is smaller than in some other Nordic countries, such as the Faroe Islands (see Section 3.1 for the Faroe Islands figures) and Norway, but still considerably greater than in e.g. Finland (Lanninger \& Sundström, 2014) and Greenland (see Section 3.2 for Greenland figures).

As mentioned, an important issue with respect to the Åland Islands is that the part-time statistics do not include smaller companies (with less than three employees). In Section 2.3 we pointed out that the Ålandic economy is characterised by a large number amount of small businesses (Dahlström et al., 2006). In 2014 there were 2,525 businesses in the Åland Islands, $88 \%$ of which had fewer than five employees (Statistics and Research Åland, 2015a). Therefore, the overall figure for part-time work in the Åland Islands might have been slightly different had the employees of small companies (with less than three employees) been included. 


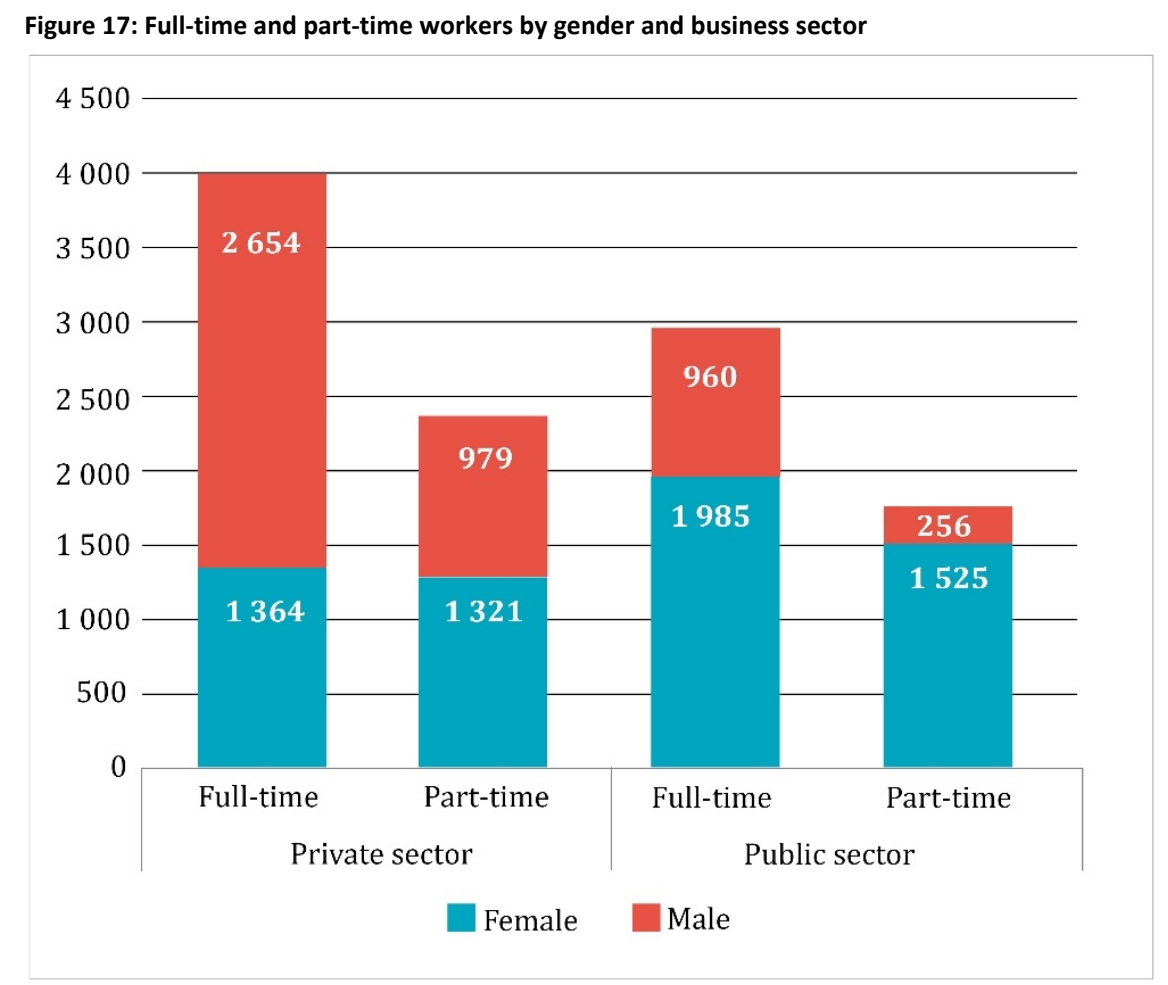

Source: Statistics and Research Åland (2015f).

As can be seen in Figure 17, the labour market in the Åland Islands is relatively gender segregated when grouped by the private/public sector. Males form a large majority in the private sector while females outnumber males by almost three to one in the public sector. Females tend to have a higher share of part-time workers in both sectors, yet more so in the public sector. Overall though, the private sector has a higher number of part-time workers than the public sector. 


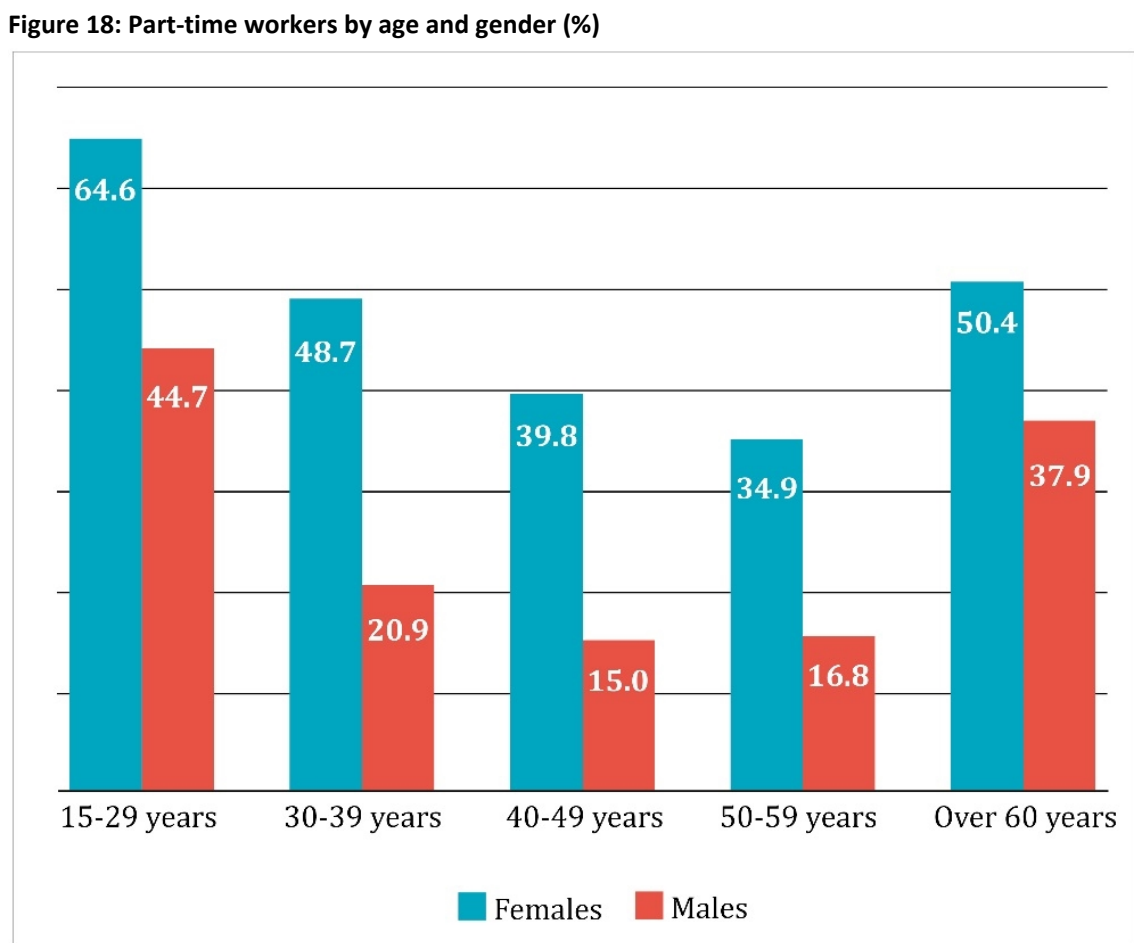

Source: Statistics and Research Åland (2015f).

Figure 18 indicates that the share of part-time workers follows a similar pattern for both women and men from the younger to the older age groups. Yet, compared with women, men's likelihood to work part-time increases much more when they enter the 60+ group, as men in this age group are more than twice as likely as men in the 50-59 age group to work part-time. The high concentration of part-time workers in the youngest age group is not surprising given their propensity to be in education. Women are consistently more likely than men to be working part-time regardless of age. Considering that around $60 \%$ of Ålandic children are born to mothers who have turned 30 (Statistics and Research Åland, 2015d), it appears that the high concentration of part-time workers in the 30-39 age group may be associated with motherhood.

\subsubsection{Wages}

The most common occupations for women in the Åland Islands are within the public sector either in care services or education. For men, the "typical" occupation is within the private sector. Women have lower average wages than men in both the private and public sectors. In 2012, women 
earned $74 \%$ of what men earned in the Åland Islands (Statistics and Research Åland, 2015d). The reasons for the wage gap is that the typical "male" jobs, such as in construction and transport, are generally higher paid than typical "female" jobs in the care and education sectors. This is exacerbated further by the fact that men often hold managerial positions, even in the business sectors dominated by female employees. Finally, the wage gap is also due to more women working part-time (Statistics and Research Åland, 2013, 2014). Furthermore, lower average wages for women, which are correlated with more part-time work, also mean that the average pension paid out is lower for women than for men (Statistics and Research Åland, 2014).

\subsubsection{Education}

Over the past decades, women's educational level has increased significantly, and today women in the Åland Islands have on average a higher level of education than men (Statistics and Research Åland, 2014). However, educational choices are, as is the case of labour participation, gender segregated. Figures for students studying in and outside the Åland Islands confirm that many males and females still undertake education in genderstereotypical fields (Statistics and Research Åland, 2014). In particular the domains of technical education and natural sciences are dominated by men, while teaching and health and social care are dominated by women. In terms of location of study, women are more likely than men to study abroad, a factor that may be linked to the lack of educational opportunities within the female-dominated professions. 


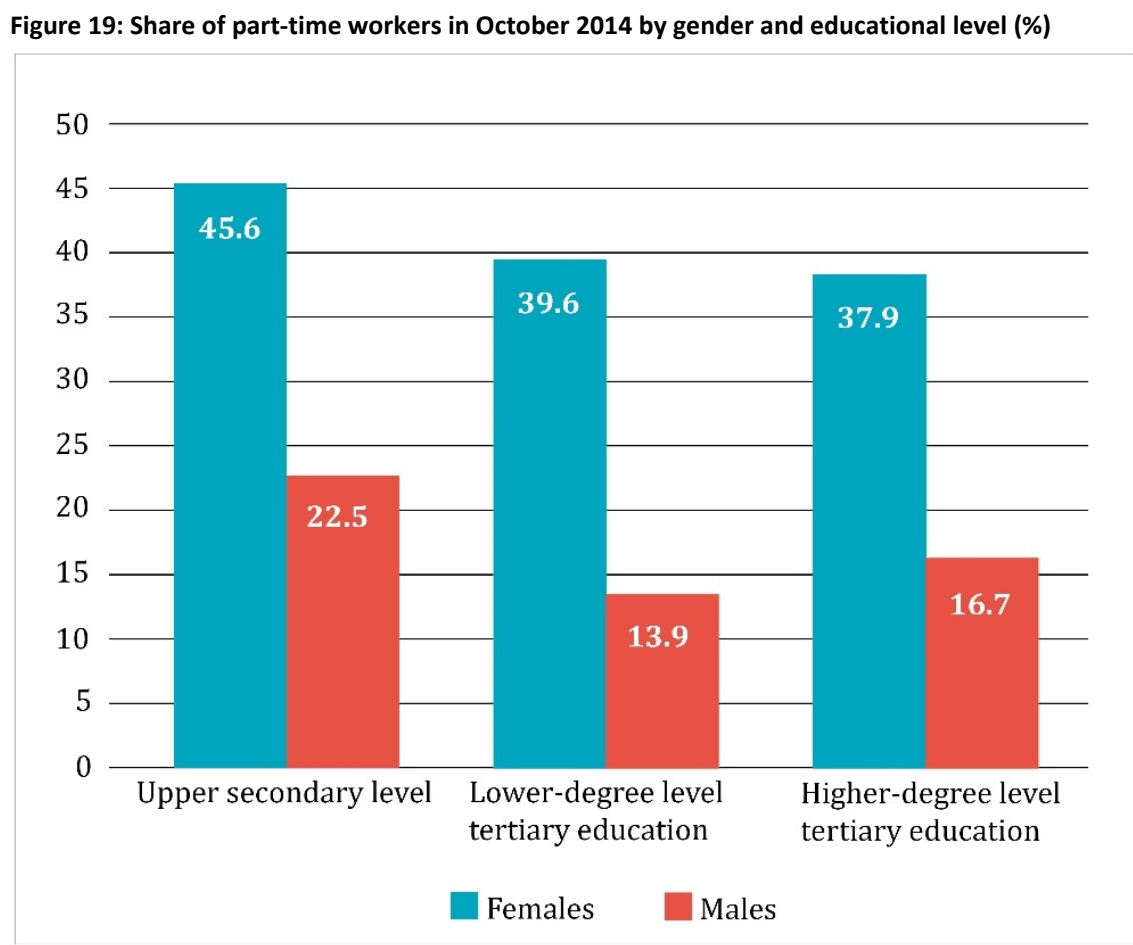

Source: Statistics and Research Åland (2015f).

Interestingly, males with a higher tertiary degree are more likely to work part-time than those with a lower tertiary degree. Why this might be is unclear. It appears from Figure 19 that the propensity for females to work part-time is more strongly connected to gender than level of education.

\subsubsection{Welfare services}

Maternity leave provides mothers with maternity allowance from up to 50 working days prior to estimated delivery and 105 working days following childbirth. Fathers receive paternity leave pay for up to 54 working days after childbirth. This maternity and paternity leave is not transferable to the other parent. Following the periods of earmarked maternity and paternity leave, parents may go on parental leave for a total of 158 days at any time until the child is nine years old. These days can be shared between the parents as they wish.

Figure 20 outlines the non-earmarked parental allowance paid to mothers and fathers in 2014. As is evident, mothers received an overwhelming majority of the total amount paid out. This pronounced difference, which has remained stable for many years, indicates that women 
take on a majority of the caring responsibility in families with children (Ålands Landsskapsregering, 2016).

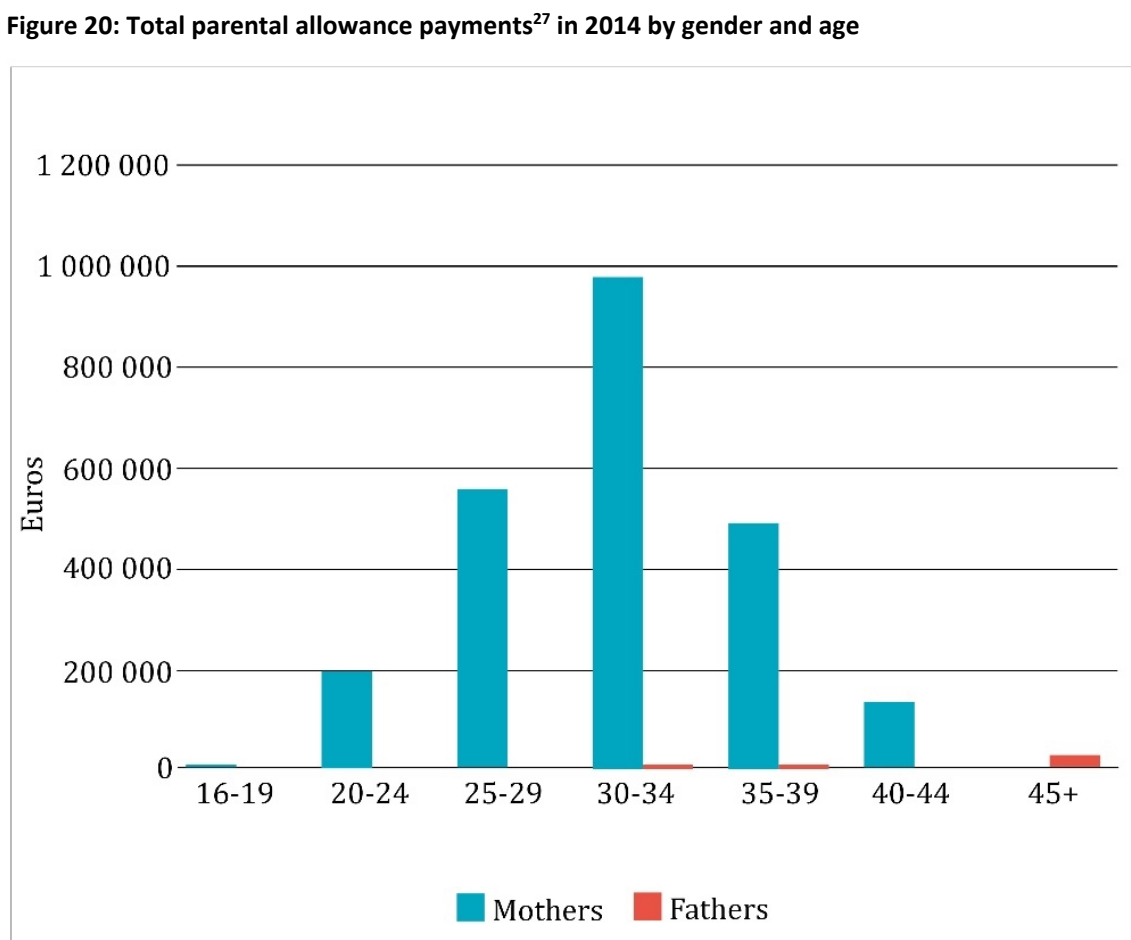

Source: The Social Insurance Institution of Finland (2015).

Home care support ("hemvårdsstöd") is a type of subsidy that Ålandic municipalities offer to parents of children under the age of three if they work part-time and care for the child at home for more than 30 hours per week. This benefit is aimed at parents who do not take advantage of institutional day care. The allocation of home care support between mothers and fathers is very similar to that of parental allowance, as fewer than $10 \%$ of those who receive home care support are males. It is also possible to receive financial support for the care of a closely related person (närståendevård) in the Åland Islands. Of the 116 people who received this type of support in 2011, 84 (72\%) were women. Overall, this indicates that females in the Åland Islands receive an overwhelming majority of the financial welfare support, which is indicative of women being primary caregivers not only for children but also for the ill, disabled and elderly (Statistics and Research Åland, 2012a).

${ }^{27}$ The earmarked maternal and paternal allowances are excluded from this figure. 


\subsubsection{Conclusion}

The overall share of part-time workers in the Åland Islands is high at 37\%. $45.9 \%$ of females and $25.5 \%$ of males work part-time. The Åland Islands have a relatively high share of male part-time workers compared with some other Nordic countries. However, these percentages may be slightly skewed, since they are not based on the entire labour force but on a sample of the labour force that does not include sea transport and small companies of three employees or less.

Women are more likely to work in the public sector than in the private sector and women in the public sector are more likely than women in the private sector to work part-time. Also, women are more likely than men to work part-time, regardless of age. The difference between the numbers of part-time working men and women is largest in the age group where they are most likely to be parents with young children, as is the case in the rest of the Nordic region.

Women earn $74 \%$ of what men earn. The reason is that women are concentrated in lower paid jobs in care and education, while typical "male" jobs in construction and transport are better paid. Furthermore, women hold fewer management positions, even in those occupations where women outnumber men. Finally, women are more likely to work part-time, which impacts the average female wage.

On average, women have a higher educational level than men, but similar to the labour market, educational choices are highly gendered. Technical programmes and the natural sciences are heavily male-dominated, while the opposite is true for teacher training and health and social care. Women are also more likely than men to study abroad.

Women take almost all of the parental leave that the mothers and fathers are free to share. The same is the case for other types of financial welfare support. According to Statistics and Research Åland (2015d), the gender roles in the Åland Islands remain stable, as the notable gender divide between the public and private sectors as well as the gender segregation in certain industries (e.g. the predominance of men in shipping and women in public care services) can be equally observed in the younger and older generations. There do not seem to be any broad trends towards fundamental changes in occupational gender segregation. In other words, it would appear that young people choose their career path as their parents did, creating the same gender patterns. 


\subsection{Part-time work: A comparative review}

This section brings together our reviews of part-time in the Faroe Islands, Greenland and Åland Islands. We will compare and contrast the three areas and identify key issues. We will look at how these societies are different and what characteristics they share in the context of part-time work and in the wider context of gender.

Throughout Chapters 2 and 3, we have explored what data is available on the labour markets and part-time work in the Faroe Islands, Greenland and the Åland Islands seen from a gender perspective. What we find is three labour markets that at first glance may seem similar, for instance in population size, in their reliance on the sea and primary resources, in their close ties with other Nordic countries and with relatively comparable standards of living and welfare systems. Yet, upon closer inspection of part-time work in the three labour markets, it becomes clear that the Faroe Islands, Greenland and the Åland Islands face different circumstances and different challenges.

In our comparison of part-time work in the Faroe Islands, Greenland and the Åland Islands, we will contextualise the discussion around important features of these labour markets, most notably infrastructure, demography, gender segregation and education. Such features are significant in shaping and structuring the labour markets and therefore cannot be overlooked. We begin our comparative discussion by summarising our overall findings, and subsequently address key findings in more detail.

\subsubsection{Key part-time work issues}

Overall, we can conclude from our examination thus far that part-time work in the Faroe Islands and the Åland Islands is gendered. Women are more likely to work part-time there than elsewhere in the Nordic region. Furthermore, women's high rates of part-time work in the Faroe Islands and the Åland Islands continue throughout working life. Yet, the gender difference in part-time work is more significant in the Faroe Islands (women being much more likely than men to work part-time) than in the Åland Islands, where men too are much more likely than their Nordic counterparts to work part-time.

Another important conclusion is that the nature of the Greenlandic labour market differs from the Faroe Islands and the Åland Islands, and for that matter also the other Nordic labour markets. The vastness of Greenland means that it is difficult to speak of one labour market. Instead, experts tend to speak of many labour markets in Greenland (Nordregio, 
2016b). Furthermore, the Greenlandic context is characterised by seasonal work, and there is considerable variability throughout the year in employment patterns, especially for males. Therefore, part-time work is a difficult category to apply in Greenland, perhaps more so than for the Faroe Islands and the Åland Islands.

Lastly, in our overall conclusion, we have identified a lack of data and studies on gender issues in general and the labour markets in particular for the Faroe Islands, Greenland and the Åland Islands. There is a need for more statistical registration, surveys and research to contribute to knowledge from a gender perspective and what it means to live and work in the three areas.

\subsubsection{Infrastructure and demography}

In terms of the domestic infrastructures of the three studied areas, there are significant differences that are likely to influence labour market structures. The Faroe Islands and the Åland Islands are well connected internally, and the longest journeys within each of these areas take no more than up to four and five hours, respectively. As a result of the sheer size and geographical environment of Greenland, however, road networks are very limited and regular commuting practically impossible. Therefore, commuting for work or educational purposes is a common practice for many in the Faroe Islands and the Åland Islands, but not in Greenland (Nordregio, 2016a). Consequently, people in Greenland must either find employment in their communities or migrate for work, either internally in Greenland or abroad. The potential for mobility, which the people of the Faroe Islands and the Åland Islands are presented with, in all likelihood provides for a broader spectrum of labour market opportunities.

The Åland Islands are much better positioned than the Faroe Islands and Greenland for international transport. Åland Islanders enjoy the opportunity of frequent, low-cost, short ferry journeys to Nordic and Baltic cities, and flights to the nearby Nordic cities take as little as 30 minutes. In contrast, Greenland is relatively isolated from the Nordic countries and the rest of Europe, both geographically and in terms of infrastructure. Travelling distances are vast and the price of travel extremely high. Therefore, Åland Islanders are better connected, providing flexibility and mobility opportunities, which Faroe Islanders enjoy to a more limited degree, and which is not even an option for Greenlanders. It is conceivable that the good connections to and from the Åland Islands along with fewer barriers to the Åland labour market (as they are part of the EU, while the Faroe Islands and Greenland are not) provide for a more diverse labour market. 
Men outnumber women by 2,000 in the Faroe Islands and by 3,000 in Greenland. Thus, women are quite literally minority groups. This deficit is mainly attributed to out-migration, especially of younger people moving abroad, mostly for educational purposes. Apart from the implications for human reproduction, this may also impact female representation in positions of influence both in politics and in the labour market.

In the Åland Islands on the other hand, women have outnumbered men for several decades, although the gender balance has levelled in over the past five years. The most notable result of out-migration of young people from the Åland Islands is an ageing population, especially since immigrants to the Åland Islands tend to be older than those who out-migrate. The Faroese population is also ageing (Føroya Landsstýri, 2013). In contrast, the Greenlandic population is young in a Nordic perspective, despite the fact that a large proportion of young Greenlanders live abroad (Faber et al., 2015).

\subsubsection{Part-time work patterns}

Compared with the rest of the Nordic region, the labour market participation rate is high for the Faroe Islands - indeed the highest in Europe. The comparable figures are somewhat lower for the Åland Islands and considerably lower for Greenland. Also, the Åland Islands have a distinctive feature in a Nordic context in that women have a higher labour market participation rate than men. However, these numbers only tell us whether people are active in the labour market or not, and not how active they are.

Despite a high participation rate for women in the Faroe Islands, a larger proportion of women than men work part-time. In the Faroe Islands, $49 \%$ of women and $10 \%$ of men (aged 20-64) work part-time, which means that the Faroe Islands has one of the highest rates of female part-time work in Europe. ${ }^{28}$ In the Åland Islands, the difference between the male and female part-time work rates is smaller, as $46 \%$ of women and $26 \%$ of men work part-time. ${ }^{29}$ However, in Greenland there does not seem to be a noteworthy difference between the proportions of men and women in part-time work, as figures from Statistics Greenland \& Nordregio (2015) indicate that $24 \%$ of men and $25 \%$ of women should be considered part-time workers. ${ }^{30}$

\footnotetext{
${ }^{28}$ Part-time employment in the Faroe Islands is defined as working less than 35 hours per week. Most part time workers in the Faroe Islands work 16-34 hours a week.

${ }^{29}$ In the Åland Islands, part-time employment is defined as working less than 33.5 hours per week.

${ }^{30}$ Part-time employment in Greenland is determined by a calculation of average months worked in a year.
} 
Part-time work in Greenland is correlated less with gender and more with whether people live in rural/urban environments. In other words, both male and female Greenlanders in rural settlements are more likely to work part-time. This may in part be linked to challenges of physical mobility in Greenland, i.e. if people wish to increase working hours they have very limited opportunities to commute elsewhere. The Greenlandic labour market is multifaceted and characterised by seasonal work, and hunting is affected by climate changes and hunting restrictions (Van Voorst, 2009), which means that the reasons for the rural/urban differences are in all likelihood more complex.

In the Faroe Islands there is a difference in part-time work patterns across different age groups. Part-time work is most common among those aged 15-24, which can be expected, since many in this age group are likely to be in education. While the likelihood of men working part-time declines considerably after the age of 25 , women are much more likely to work part-time throughout their working lives. The pattern for women in the Åland Islands is similar, peaking at 49\% for 30-39 year olds. This is likely related to child-rearing. We can conclude that the Åland Islands and the Faroe Islands not only have a high level of female part-time workers, they also display a similar pattern with many women working part-time throughout their working lives. ${ }^{31}$

The Faroe Islands was the only place where we had access to data on voluntary and involuntary part-time work. We have previously pointed out the complex nature of categorising part-time work into voluntary and involuntary. Notwithstanding such complexities, we chose to discuss the available data from the Faroe Islands. The majority of Faroese workers (part-time and full-time) feel they work about the right amount of hours. Notably, women who work part-time are somewhat more likely than their male counterparts to feel they work about the right amount. Furthermore, comparing men and women who work 35 hours a week or more, women are more likely to want to work less. Whether equivalent figures for the Åland Islands and Greenland, would indicate similar experiences to the Faroe Islands is unclear.

${ }^{31}$ Comparable age-based data for Greenland was not available. 


\subsubsection{Gender-segregated labour markets}

The labour markets in the self-governing areas are highly gender segregated. The private sectors are characterised by so-called male-dominated industries: fishery and off-shore industries in the Faroe Islands, shipping in the Åland Islands and hunting and fishing in Greenland. For all three areas, this is at least part of a plausible explanation why fewer females return following their studies abroad, since women may find the economic opportunity structure to be less attractive than in urban environments (Hamilton \& Otterstad, 1998). All three areas have relatively large public sectors, and since the private sectors are male-dominated, women are overrepresented among public employees, especially in public health and care services.

In their 2010 study on mobility in Greenland, Nordregio found a connection between the type of economic activity and the gender ratio in a local area. For example, a larger service industry in a local area was correlated with a smaller female deficit than in areas with more male-dominated industries (Nordregio, 2010). This indicates that female migration patterns in Greenland may be partly linked to private sector job opportunities outside these male-dominated industries. Whether such a correlation is applicable for the Faroe Islands and Åland Islands is unclear, yet women in these two areas are generally more likely to be employed in the service industries than in fishery and shipping.

For all three self-governing areas, there are several occupational groups with an overwhelming majority of either men or women. The most notable examples are the previously mentioned male-dominated industries as well as health and care services, which employ primarily women. Gender segregation in the labour market is also closely tied to education, as the reproduction of occupational gender segregation is inextricably linked to men's and women's educational choices, which have proven resistant to change. Given that many jobs in female-dominated professions are typically advertised as part-time work, such gender segregation may be reinforcing the gendered nature of part-time work.

\subsubsection{Education and part-time work}

In Greenland, women are generally better educated than men and also make up a significantly larger proportion of students. In the Åland Islands and the Faroe Islands, women's average educational level has been increasing over the past couple of decades, and in the Åland Islands women have recently surpassed men in terms of educational level (Statistics and Research Åland, 2015d). In 2013/2014, the student share of those aged 
15-39 years was 5.8\% in the Åland Islands (Haagensen, 2014), 5.6\% in the Faroe Islands (Statistics Faroe Islands, 2015b; Studni, 2015) and 9.3\% in Greenland (Haagensen, 2014). The lower figures for the Faroe Islands and the Åland Islands can be explained by the large numbers of young people studying abroad. At present, more than 1,500 of 2,500 Faroese tertiary-level students are pursuing their studies abroad, particularly in Denmark, and more than 1,000 Åland Islanders were registered as students in either Finland or Sweden in 2012/2013.32 Greenland had 1,300 tertiary-level students by the end of 2014, of whom fewer than 500 were studying abroad. Thus, based on these figures, Greenlanders are to a lesser degree in tertiary education and are also less likely to study abroad.

Despite these differences in educational opportunities across the selfgoverning areas, the chief demographic challenge for all three areas is that a significant majority of university students are studying abroad. The reasons why young people move to pursue education include the wider range of study programmes typically available in more urban environments. Furthermore, studying and moving away seem to be two sides of the same coin for many young people in the three areas (Absalonsen, 2009; Hayfield, n.d.; Hovgaard et al., 2004; Nordregio, 2010).

Overall, educational level is negatively correlated with part-time work in the self-governing areas. However, for the Faroe Islands and to a lesser degree the Åland Islands, this is much more pronounced for men, i.e. men with a lower level of education are more likely to be working part-time than men with tertiary level education. For women in the Faroe Islands and the Åland Islands, however, educational level does not appear to have a large impact on part-time work as a relatively large proportion of welleducated women work part-time. Therefore, part-time work is integrated across job hierarchies providing more opportunities for working parttime in occupations at higher levels, a feature evident also in other Nordic labour markets (Smith, Fagan, \& Rubery, 1998). For Greenland, educational level has a clear impact on part-time work (average unemployment rate per month). However, we are unable to determine whether there is a gender effect, as these statistics are not grouped by gender.

Therefore, at least for the Faroe Islands and Åland Islands, we can conclude from the above that part-time work is a working pattern for women across educational levels and the span of their working life. This means that women consistently have different labour market behavioural pat-

32 The information on education taken by Åland Islanders outside of the Åland Islands is incomplete, which means that this number is likely to be higher than 1,000 . 
terns compared with men. In all likelihood, this both reflects and reproduces the gender division of labour in the labour market and in the domestic sphere.

Although women from all three self-governing areas are more likely than men to be in tertiary education, and in the case of Greenland and the Åland Islands are better educated than men, this has not yet had a significant impact on differences in pay between men and women, or on the gender hierarchy in the labour market. Despite this, in rural Greenland, changes in the gender division of labour in recent years have seen more females, often wives of fishermen and hunters, earning the main household income. This is a somewhat different picture than for the Faroe Islands and the Åland Islands. If we base our conclusion on what we know about the gender division of full-time/part-time work and the female role as primary caregivers, we find that in the Faroe Islands and the Åland Islands, the (female) part-time caregiver model of the (male) breadwinner family (Pfau-Effinger, 2004) may still apply.

The most prominent indication of the role of females as primary caregivers is the difference between the amount of parental leave taken by males and females. In all three self-governing areas, the vast majority of non-earmarked parental leave is taken by the mother. The reasons for this are no doubt complex, but the perceived loss in income if fathers are on leave coupled with labour market pressures creating a disincentive for men to take parental leave may be at play. However, more realistically, the division of labour in care responsibilities is in all likelihood linked to the cultural values associated with gender, parenthood and caring. The case of the Åland Islands is especially interesting, as women are also the primary receivers of other types of state or municipal support given to carers of ill, disabled and elderly persons. This means that females are not only expected to be primary caregivers in relation to motherhood, but also in the context of caring for any closely related family member.

\subsubsection{Conclusion}

Overall we find that the labour markets of the Faroe Islands, Greenland and the Åland Islands have some commonalities and differences. They are all small labour markets, yet as self-governing areas geographically removed from the other Nordic countries, they have the societal structures typical of large societies. Therefore, it is important to understand gender in the context of each of these labour markets and their key challenges. Part-time work is a significant gendered working pattern for women in 
the Faroe Islands and the Åland Islands, and indeed very much a part of working life for many women. We may speak of a part-time culture.

However, our conclusion is clear: these are areas with their own unique challenges that need to be addressed through more statistical registration and more research in general. At the same time, due consideration must be given to principles of international comparison, while taking account of the realities of these labour markets. For instance, Greenland may require a different approach in mapping gender and labour market work patterns due to the sheer complexities of the labour markets in Greenland.

All things considered, part-time work as a vehicle to a better work-life balance should not be viewed as a problem in itself. Rather, the gendered nature of part-time work in the labour market may well be indicative of the division of labour in the domestic sphere. Therefore, part-time work is one aspect of exploring gender issues as a part-time worker is likely to have less economic independence than a permanent full-time worker. At the same time, it may have implications for a gender-equal society where men and women as equal members have the opportunity to share responsibilities in the labour market and at home.

As an important weakness in relation to the data on part-time work, it is clear that our data provides little information on actual hours worked. Furthermore, we have no insight into any potential differences in working patterns that may arise when families have more than one child or as children grow older. Therefore, a more detailed mapping of work patterns and the impact of contextual factors such as having children, available welfare services and other structural constraints is essential to further the understanding of gender and the labour market.

Nevertheless, the limited data available is an introduction to the larger picture which requires a better understanding of why women are more likely to work part-time. As a modest start to exploring these reasons and women's experiences in the labour market, we have conducted an introductory qualitative study, which we shall turn to next. 



\section{Part-time work: An exploratory study}

So far we have mapped the labour markets of the Faroe Islands, Greenland and the Åland Islands from a gender perspective. We have analysed labour market statistics and discussed structural issues framing labour market opportunities such as parental leave policies and the prevalence of long-distance work in the self-governing areas. This has provided us with an overview of labour market participation and the working patterns of women using quantitative data. Yet, it does not provide us with much knowledge as to why women, especially in the Faroe Islands and the Åland Islands, are much more likely than men to work part-time.

In this chapter we are concerned with the experiences of women working part-time and how they experience labour market participation. As mothers, women may experience conflicting demands when faced with cultural expectations of gender and parenting and at the same time being committed to the labour market. Yet relatively few studies delve into women's experiences of working part-time in conjunction with practising motherhood (Webber \& Williams, 2008). In this study we are particularly concerned with how women in the studied areas experience structural constraints and cultural demands and how they, in the context of their own unique circumstances, make decisions concerning family and work. Therefore, the objective of this study is to explore the employment and family experiences and practices of women who work part-time.

As a preliminary investigation into the gendered nature of part-time work, our qualitative study is confined to the Faroese labour market. Although our sample consists of women in the Faroe Islands, this study should also help shed light on what it means to be female in a Northern peripheral labour market. Therefore, we envisage that the study can be a small step in building knowledge on the reasons for gender and part-time work in the self-governing areas. In doing so we hope to uncover and challenge some of the underlying discourses that produce and reproduce the gender power system, and that restrict both men and women.

In this chapter we begin with an overview of the methods used in this study, followed by our findings. This leads us to our discussion and conclusion, in which we also indicate some appropriate areas of future research. 


\subsection{Methods}

Exploring the reasons for working part-time involves delving into the complexities of women's lives and providing a space for them to convey the meanings they attribute to their work and family life. In doing so, we have adopted qualitative methods by which we explore the words, meanings and actions of individuals so that they represent life as experienced by working women (Maykut \& Morehouse, 1994). Considering that the existing knowledge on gender and part-time work is limited in the selfgoverning areas, we chose to conduct group interviews. Group interviews are well-suited for exploratory studies and as a method aims to facilitate a range of perspectives rather than to reach a consensus among participants (Kvale, 2007).

Therefore, as a first step in understanding the nature of part-time work among women in the Faroe Islands, three group interviews were conducted with women in three different locations on the islands. While the Faroe Islands in itself is peripheral, there are likely to be internal differences in the various Faroese localities in terms of both the labour market and infrastructural factors.

The women were recruited through a mixture of snow-ball sampling and calling employers and asking for referrals to women who work parttime. The group interviews had between six and ten participants and all except two participants worked part-time. One participant had just increased her working hours quite substantially, from part-time to fulltime. We deemed it interesting to hear her reasons for this. There was also another participant who worked full-time, whose views on the labour market and reconciling work and family life we nevertheless were interested in hearing. Some of the participants had seasonal work, working long hours for parts of the year and not working during other periods, thus averaging part-time.

In the Faroe Islands the average age of mothers giving birth to their first child is 25 years (H. D. Joensen, 2014). Therefore, we chose to restrict our sample to women over the age of 25 as these are more likely to have completed education and have children, a factor impacting how women experience working life. Nine women were aged $25-34,10$ were aged 3544, two 45-55 and one 55+ years. All but one had children. Of these women, 18 had children living at home and three had grown-up children who had moved out. All women were in a relationship (a partner/husband) except one, who was divorced and a single parent. In terms of education, the groups were relatively mixed. Almost $60 \%$ had tertiary education, slightly more than a quarter held a vocational education and the rest 
had secondary education. All of the women were ethnic Faroese and none lived in a same-sex marriages or other family constellations. While we acknowledge that issues such as ethnicity, sexuality and religious beliefs are important, the scope and size of this introductory study did not enable us to conduct an intersectional analysis.

The interviews were conducted during November 2015 in three different towns (one large and two mid-sized) ${ }^{33}$ in settings we deemed to be relatively neutral, e.g. a primary school. One of the key features of the large town is the sheer size compared with the other towns. There are a variety of job opportunities and many retail outlets and cultural offerings. The mid-sized towns are much more dependent on industry, which has implications for the nature of the local labour market. In terms of infrastructure, one of the mid-sized towns is relatively peripheral in the Faroe Islands, profoundly affecting the opportunities for inhabitants to commute to the labour market of the large town.

Each interview lasted around two hours and every attempt was made to create an atmosphere that enabled the women to feel relaxed, reassured and able to voice their views and experiences. The interviews were recorded, transcribed and analysed using the Nvivo software. The two researchers involved in the study both coded the data and by means of coding comparison were able to verify a mutual interpretation of the data. The Faroe Islands is a small society, which means that even greater care must be taken to disguise the identities of the participants compared with larger settings. Therefore, the names of participants, towns and places have been replaced with pseudonyms as well as some personal details that could reveal their identity. In some cases, it was also necessary to change the occupations of some women to maintain their anonymity.

The group interviews were semi-structured with open-ended questions we wished to cover. These questions covered topics such as why the women work part-time, criteria for choosing one's job, gender relations in the labour market and at home including the division of labour, what it means to be a good parent, whether they would/could work full-time and how they perceive women's opportunities in the Faroese labour market and also compared with elsewhere. However, in line with qualitative methodology, the participants' answers shaped the direction of the interview, thus enabling us to gain some insight into the complexities of these women's relationship with the labour market.

${ }^{33}$ At the end of the quotes in this chapter, we have differentiated between the mid-sized towns by calling them mid-sized town 1 and mid-sized town 2. 


\subsection{Findings}

The women in our study were generally satisfied with their working hours and indicated that they themselves had chosen to work part-time. Their position as mothers with children had an immense influence on their choice and it was clear that their labour market participation was framed around their responsibilities towards the family. The women were clear on wanting to have meaningful jobs, however, with a sensible balance between employment and family.

It is evident from our data that the women's experiences with paid employment and reasons for working part-time were complex. Therefore, these women's labour market experiences cannot be separated from household labour and private life commitments, which were found to be central to women's employment choices. This is reflected in four overarching themes that emerged and stood out as shaping the women's experiences: 1) families and mothering, 2) flexible labour market participation, 3) occupational demands and labour market constraints and 4) women, gender culture and careers.

\subsubsection{Families and mothering ${ }^{34}$}

Most of the women in our study, especially those with children living at home, have busy lives. When prompted about everyday activities and how they spend their time, the women did speak of their employment; however, for most of them, children and the family were at the centre of their discourse. This means that when speaking of employment (the public sphere), it was predominantly in relation to the family and/or children (the private sphere). In describing how a typical day is structured for them time-wise, many women expressed a focus on various activities associated with being a parent, such as getting children ready in the mornings, taking them to school and their various hobbies and activities. Indeed, being committed to their children's extracurricular activities is something these women prioritise despite the challenges of fitting them into their busy schedules.

${ }^{34}$ We use the term "mothering" as it refers to the practice or process of being a mother, whereas motherhood refers to a condition or state. 
Throughout the data, in all three locations it was clear that for the majority of the women, working part-time was related to family commitments. (However, one of the women in our study had reduced her working hours due to health problems.) In discussing part-time work, their first and overriding response was related to the well-being of the family; i.e. they have partners/spouses who work full-time and therefore expressed that part-time work is very much a necessity for a balanced family life. For many of these women everyday life would simply be too stressful, not least for the children, had they worked full-time. This is illustrated in the following quote:

\begin{abstract}
Durita:..."very often I collect them [the children] straight away when I finish work. And I prioritise very highly being with them, and that they are not to just be in an institution when I have finished work... Ehm, yes my husband never gets home until, I don't know, 4:30-5, something like that, from work. He is an operations manager at HLP and works quite a lot. So me working less is maybe conscious prioritising so our everyday life is more manageable. Also for the children, yes".
\end{abstract}

25-34 years, large town

As is demonstrated in this example, these women's partners/spouses work full-time, and thus, managing to be working women with children entails working less than the full-time norm. For some women working part-time involves having full working days and regular days off. One woman recalled how her, now grown-up, children used to love Tuesdays, which was her day off. They would return home after school bringing their friends and enjoy that there was "someone home", leading her to express that she is pleased having made that choice. In reflecting on her working life, she is constructing her priorities based on being a mother and mothering.

Yet being a mother and prioritising the family has a broader meaning to these women than being around the children. The division of household labour is for many of the women manifested in their responsibility for the flow of everyday life, i.e. being the backbone of the family in terms of housework and "supervising" everyday life. This does not mean that men do not contribute to the household, but only that women ensure that everyday life flows smoothly and is organised and managed. The women spoke of feeling that they maintain the smooth running of daily life and some feel that they are responsible for family members attending daily activities, as the following quote illustrates: 
Sissal: Well, when I was doing my education, I had to go abroad for a few weeks at a time. He [husband] thought it was terrible that I was way... because automatically I think it is the woman who keeps everything in order, what everybody should be doing and things like that...Well at ours, he rings kind of like, once a day: Do I have anything scheduled for today? ... Do I also need to manage his schedule...? (laughter)

Durita: I so recognise that.

Several others: Yeah, me too (laughter)...

Sissal: But I think that after [him] having experienced it, he really appreciates it, what you do, I mean - it is just everyday life... and it is not until you have tried it, to have the responsibility, that you see how much work it is after all.

Durita: Good that they try it

25-34 years, 35-44 years, large town

We can see that the women in this extract feel that they maintain the structure of everyday life in their households. More importantly though, they seem to feel that their household labour is not necessarily understood or sufficiently appreciated by their partners/spouses. Even Sissal herself uses the expression only everyday life to signal the perceived triviality of managing daily family life. So, the women appear to agree on the daily challenges and construct men as being inexperienced in the everyday running of a household and at the same time position themselves as being the head of the private sphere and of the family. Thus, in some respects they construct a position of power in the domestic domain. The feeling of having the overall responsibility for the household and everyday chores is evident in the following extract:

Una: Sometimes I think that my husband was much better than me at relaxing and would lie on the floor playing with the kids. Food leftovers on the table, clothes and everything a mess... and he lies there and they are having a good time and stuff. I can't do that.

Durita: I often think that men are much better at that.

Una: They are much better at that and he is really present...

Inga: They don't see it [what needs to be tidied].

Durita: It does not bother them.

Una: If he is on his own with them [the children] ...it is untidy in a totally different way, you know, I could not handle it at all in the same way. My boundaries are totally different.

Inga: (laughs) I can picture myself in that situation...

Una: Haven't you tidied? (and copies spouse's response): "No but I have been with the kids." 
Durita: Yes, and we don't even ask "what have you been doing today?" The only thing I can see is how untidy it is.

Anna: We somehow maintain the structure, don't we?...

Inga: If you break it [the routine] all the time...then it's kind of like, really difficult to get them [the kids] on track again and as it is really untidy, then $O K$, if I spend the time here, then I know it is mine AND the extra tidying in the evening.

25-34 years, 35-44 years, large town

It is evident that the women in the extract actually seem to want to put housework aside and focus more on being around the children, playing with them and being present. Yet, the demands of everyday life and the division of labour at home, prevent them from ignoring tasks as they are conscious of the duties that await them later on in the evening. Nevertheless, these women indicate that their partners/spouses are good with the children and are able to be focused. This behaviour is perceived as a quality that the women appreciate and would like to be able to practise more themselves, by ignoring chores for a while. Thus, the women value their partners'/spouses' qualities as fathers. However, the construction of fatherhood in this sense entails a lesser responsibility for the daily running of the household because for these women, it is difficult to reconcile the time-consuming nature of daily chores with feeling more present.

One of the significant features of the Faroese labour market is the relatively high proportion of men who are long-distance workers. One-third of our sample of women had partners/spouses who are long-distance workers - away for weeks or even months at a time. Frequently nowadays, long-distance work involves being at home and away for equal periods of time. This means that for all but one of the women in the sample, the partner/spouse is at home for about as long as he is away. In terms of labour market participation, this poses a significant challenge for the women as they spend long periods of time essentially having the sole responsibility at home. Granted men are able to be involved in household decision making and communication with the family over Skype, Facetime and other electronic media. However, the reality for these women is that they are under a lot of pressure during the periods when their partner/spouse is away.

One key feature of these women's lives is the great difference in their everyday life between the periods when they are on their own and the periods when their partners/spouses are at home. It was clear that the stark contrast significantly shaped these women's home lives and working patterns. Women in occupations with shift work spoke of being flexible in their work schedules during periods when their partners/spouses 
are home. At the same time, everyday life is highly demanding when alone; some even go as far as to speak of two different lives, one when their partner/husband is home and one when he is away. One woman spoke of temporarily withdrawing from the labour market when her children were young, due to the nature of her husband's long-distance work:

Nina: He was away for three and five months at a time, so I was at home with our sons. Because I did not think - as we could afford it - that... when they saw their father so little, then I did not want to be away as well. That's the way it was [when they were younger].

35-44 years, mid-sized town

Therefore, the woman in the quote above stopped working for a while and later took up part-time employment. The other women though worked hard at juggling work and family life while their partners/husbands are away. The women feel though that there is a price to be paid by the family for this type of life. During times when partners/spouses are away, the women explained being extremely structured in their running of daily life in order to manage being alone. This involves more rigid structures for the children, e.g. having to be at home earlier in the evenings than when their father is home. Consequently, this family arrangement, with one long-distance worker, entails these women being less able to commit to any opportunities for added responsibility at work or to do overtime. Such restrictions on flexibility can have implications for the gender division of labour in the labour market. However, having a partner/husband who is a long-distance worker can at the same time have implications for the division of labour at home, as we can see below:

Alma: Mine is eight and eight, eight weeks away and eight weeks at home, but I also feel, well when there is one week left or something like that, till he comes home, then I am, I have no energy left...and then when he comes home then it's like, "here you are, take it [responsibility for household] ... When he is home, then ehh, then I have no idea what food is in the fridge (laughs) or what the girls get to eat in their packed lunch. Not at all. Maybe I let go of my responsibility too much.

Female, 25-34 years, mid-sized town

As in the extract above, several women spoke of their husbands as taking a highly active role in the household when at home. Therefore, while longdistance work is a challenge for the women, we are presented with a picture of a gender division of labour, where some men are highly active in the running of the home. Thus, the very labour market structure, which in some respects is a barrier to women's labour market participation, is 
manifested for some of our participants as a more equal gender division of labour at home, at least part of the time.

In this section about families and mothering, our final focus area is on those mothers who actively distanced themselves from modern career values as they spoke of themselves as having made a non-mainstream employment choice. In our sample there were in particular two women, one from a large town and one from a medium-sized town, who had previously prioritised work and their careers highly but had come to refocus their values during motherhood. These women, who are well educated, explained that they had deliberately chosen to prioritise being mothers and saw work as much less important for the time being. This is illustrated in the following quotes:

Anna: Well, I left my job in the telecommunications company to be at home having children. There were very many who just did not understand. It was like, "WHAT! You are just at home now". And they did not understand. But I feel, I don't know, I feel that in time, those that know me, they understand. And I actually feel that I am now more respected for it...

35-44 years, large town

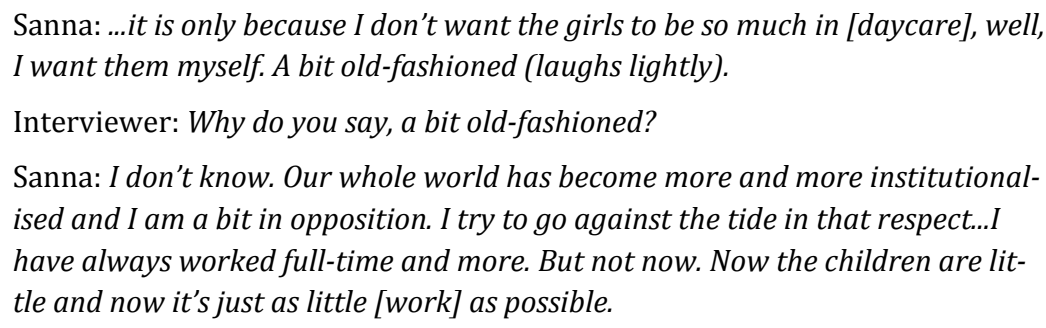

35-44 years, mid-sized town

Throughout the group interviews, these two women stood out as actively distancing themselves from the mainstream career values and positioned themselves in opposition to society, essentially feeling empowered as women and mothers. Nevertheless, these two women are implicitly complying with the idea that it is not possible for women to "have it all". In this sense they may be participating in the reproduction of structural barriers to a balanced work/family life for women. Instead of questioning the barriers and focusing on what structural measures could or should be taken, they are complying with the discourse. However, it is clear that these women represent an opposition towards material values and have actively refocused on their core values: relations, their children and the family. 
In this subsection we have seen that women's positioning as mothers, with the children and family as core values, is central in relation to their work pattern and employment choices. An important feature of these women's lives is their sense of responsibility of running daily life and essentially being in charge of everyday family affairs. One-third of the women in our sample have partners who are long-distance workers, which affects them in various ways. Some expressed life as being highly stressful during periods when they were on their own. Furthermore, we have seen how this, in many respects, requires skills to manage and adapt to changing circumstances. Yet, few of the women questioned the structures that serve to create a division of labour in the labour market and in the household. In coping with everyday demands, the flexibility that working part-time can provide is of significant concern to these women, which we shall turn to next.

\subsubsection{Flexible labour market participation}

For the women in our sample, flexibility is a significant factor enabling labour market participation, not least for those with partners/husbands who are long distance-workers. Flexibility had different meanings to these women and involved being flexible and having flexibility with respect to the labour market. Overall there are three areas in which the women experienced flexibility: 1) having flexibility at the workplace, 2) being in a position of flexibility due to working times 3 ) having flexibility to work because of close support networks. We shall explore these in turn.

Many of the women in our sample indicated that they have flexible employers where supervisors and managers try to accommodate and work around their family commitments. Some also indicated that their husband's employer is flexible and understanding about e.g. sick children. Two women with long commutes to work reported that their superiors are flexible in structuring their working rota to suit their travel times. Several others reported work rotas being organised to fit their long-distance working husband's work schedule. One woman, married to a long-distance worker, reported having to seek new employment a few years ago due to a lack of flexibility: 
Johanna: My job, yes, I started at the old people's home, but it did not work out so well. When you have a seaman [long-distance worker] ... and you have a lot of shift work, then I couldn't leave during work the way I can now. They were looking for people at the in-home care service, so I applied for that. Because then one can just, if the children are in school and have forgot their swimming gear or their packed lunch, then you can go and pick it up. You can't do that when you work at the old people's home.

45-55 years, mid-sized town

In this case, for Johanna, being able to assist at home is an important aspect of her labour market participation, which led her to change employment. Furthermore, it is evident from the extract, and from the discernible pattern in our data, that women frequently adapt their employment and working hours to fit in with the needs of the family and the partner's/husband's employment.

Some women in our study have jobs with less flexibility, where their presence is required at all times, e.g. nursing and retail jobs. Being a parttime employee led to some actually experiencing less flexibility as all health-related personal appointments are expected to be arranged for days off, e.g. going to the doctor or dentist. Therefore, the few days they have off are often full of appointments, a requirement some women felt was not expected of full-time workers. Consequently, part-time work can mean experiencing more flexibility and less flexibility at the same time.

For several women, part-time employment leads to a greater sense of flexibility. For these women, working reduced hours means being able to work more, yet at their own discretion. It means not having to work fulltime, but being able to work more when it suits them, as we can see in the following quote:

Inga: Because I work less [than full-time], when it suits me to take an extra shift, then I will do it. Rather than when you go to full-time, then I would not have the space [time] to take more [shifts]. It was my choice [part-time]. But if I had been required to go up [to full-time], then I would feel it a bit, yes...somehow felt that one was disempowered? Because it is quite nice to be able to have some say over your own working time too.

35-44 years, large town

As in the example above, many women in our study work more than their number of contracted weekly hours. For them, having the flexibility to make that choice is important. Some receive pay for extra hours worked and others take time in lieu, both of which are considered valuable aspects of flexibility. 
One feature that stood out in our study is the consensus that close support networks are central to Faroese culture. Public childcare institutions are widely available in the Faroe Islands, yet throughout the interviews the women spoke of parents, in-laws, siblings and other family members as significant providers of childcare (e.g. picking children up from day care or caring for sick children). This is an enabling factor in women's labour market participation, especially for those with working partners/husbands with a long-distance job.

The women who do not enjoy a large network of support were inclined to explain themselves as to why this is the case. In this sense, they were acknowledging how their circumstances might be different to the norm in a culture where family support is considered to be an integral thread in the fabric of family life. One woman for instance stated that her husband being foreign means that their network is confined to one side of the family, thus restricting their support network. In a slightly different sense, some pointed out that they are hesitant about asking for help too much, being worried about burdening people who already are busy. This means essentially positioning themselves as different from the perceived cultural norm in the Faroe Islands of having large readily available support networks.

Others suggested that norms are changing, pointing out that many grandparents are active participants in the labour market and therefore not as readily available as in the past. This is a reality for several women and means that for some, the reliance on extended family in the care of children is a feature of Faroese society that is changing. One woman said: "...in the past, the grannies used to help, but grannies of today work" (2534 years, mid-sized town 2). Nevertheless, the importance of relying on family and other networks is a significant feature in enabling working life for many of our participants. In the extract below, two women whose husbands are long-distance-workers indicate how family and social networks have been integral to their labour market participation:

Christina: ... when I started, I was off Wednesdays and worked every other Friday morning so...there were at least two days every other week when I could pick [the kids] up myself. But sisters, grannies well aunts, grannies, aunts (laughs) everyone who could be useful...That is the thing with shops [retail work]; it can't quite be done, so I had to have help.

35-44 years, mid-sized town 1 
Alma: He has always been a seaman...you learn to plan according to that. I have a fantastic mother who...if it weren't for her, then I could never...nothing would work, then everything would capsize.

25-34 years, mid-sized town 2

These women are acutely aware of the support networks that the Faroe Islands is renowned for. In their discussions of the need for help when their children are sick and of daycare institutional opening hours, several women compared the Faroese situation with that of Denmark. Several references were made to better opportunities for support in the Faroe Islands. This is partly attributed to the geographical distance to close family and relatives elsewhere, leading to a reduction in work flexibility as a woman explains in the quote below:

Katrin: I have also tried to live down there [a term the Faroese use to refer to Denmark]. And I have also worked down there. And there's a big difference between how, how much more help you have here. ...Well I would say that the network is really important...

Interviewer: Yes. But what did you do when you were in Denmark and if your children...if one of your children was ill?

Katrin: (sighs) Yes, well down there, as a teacher we had the "child's first sick day" [pay entitlement in Denmark]. And my partner also had the "child's first sick day" in his contract...then you had to like, then one of us would call and say that he [our son] was sick and the other could not say anything about it at their work. And then the other would call the next day and say "my child is ill today", because we did not have anyone else. If there were several [days] then...I have sometimes used holidays or days off ehm...yes.

35-44 years, mid-sized town 2

As Katrin explains in the extract above, she and her partner found it challenging to work around children being sick as they risked their pay being reduced. Therefore, while living in Denmark, in their more confined network of support, this couple found themselves manoeuvring the system of children's first sick day.

In conclusion, it is clear from the data that flexibility is an important aspect of women's relationship with the labour market, and the flexibility comes in different forms. We have seen that several women indicated that they feel their employers are understanding and try to accommodate them, being flexible with organising the rota, for instance. Furthermore, the mere fact that these women have chosen part-time work provides some flexibility to work extra shifts or have time for activities outside 
work. Lastly, the women in our study experience flexibility by having support networks in the form of family and relatives who are available to assist with childcare. This characteristic of Faroese society was articulated by several women in our study as a valued feature of Faroese society. Yet in a society where the labour market participation rate is high, the women acknowledged that those who once made up the support network (typically grandmothers) are now themselves part of the labour force.

\subsubsection{Occupational demands and labour market constraints}

So far we have explored the impact of women's roles as mothers and their family commitments as well as the importance of having some forms of flexibilities built into their labour market participation. However, the women also spoke of the demands of the occupations in themselves as a factor impacting their choices to work part-time. One of the reasons for working part-time for the women in our study is the demanding nature of their occupations. Those working in e.g. health care, childcare, with medical responsibility and elderly care reported seeing their jobs as highly demanding. These demands are especially manifested in: 1) the demanding nature of shift work and 2) the demands of working in health and caring professions. Put together, these perspectives on occupational demands help shed light on the challenges that women experience in reconciling work and family life.

In our study women working shifts, e.g. nurses, spoke of the "burden of shift work", which they find to be challenging in several respects. From a practical perspective, the timing of work is difficult for family life and in particular single women and women with partners/husbands with longdistance jobs pointed to the challenge of having young children and showing up for work at $7 \mathrm{am}$. Furthermore, one woman mentioned how she feels that her many years of shift work have to some extent taken its toll on the children.

A structural feature of the Faroese labour market that some of the women gave a lot of attention to is the number of hours in a normal fulltime work week, which is 40 hours in the Faroe Islands and 37 in Denmark. Several women pointed out that they have experienced the Danish system and felt a difference when moving to the Faroe Islands. To them, this is one aspect of deciding to work part-time. Some women in our study work in retail, a sector in which full-time employment sometimes involves working 6 days a week and until closing time. For women in this 
sector who have partners/husbands with long-distance jobs, the late finish proves to be difficult for childcare arrangements.

Notwithstanding the challenges of managing shifts and work times, one significant factor with implications for the decision to work part-time is the demanding nature of these professions. Most are employed in female-dominated professions such as teaching, nursing, health care, social work and administrative occupations. The women spoke of the immense emotional investment and responsibility they experience.:

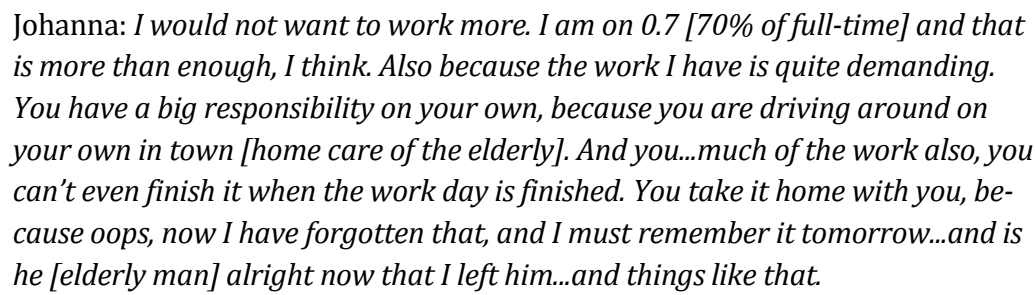

45-54 years, mid-sized town 2

Jóna: ...it is very strenuous for your head [working with medication] the whole day Yes, well also at worst, you are stressed and your head is somewhere else, and you kill someone.

35-44 years, large town

Durita: ...generally working in childcare institutions is...very hard. There is so much noise the whole time and then I would rather have some energy for my own children when I get home. And that is also one of the reasons why I work part-time... You have to be on the whole time, you need to use yourself the whole time. And sometimes I think it's not the children that are the most difficult, but the parents with all their demands.

25-34 years, large town

It is clear from the above quotes that women experience their jobs as demanding. They feel a great sense of responsibility and the very nature of care work entails emotional commitment, so much that they find it exhausting and difficult to leave behind when they go home. These women indicate that the demands of challenging jobs and being attentive mothers are difficult to reconcile. Furthermore, bearing in mind that women pointed out earlier that they feel they maintain the structure of everyday life, which requires them to have some energy left for family and household responsibilities. 
Notwithstanding the demands of their jobs, some of the women in our study were also inclined to construct their occupations as highly incompatible with full-time work. This is also evident in the structural barriers to full-time work in the labour market. In this sense, several of the women are in occupations where it is either difficult or not possible at all to obtain full-time jobs. One woman who works in a large institution pointed out that the budget for each department in her institution is divided into job fractions, mostly 0.8 and 0.9 of full-time. This enables the appointment of more staff to cover extra shifts and sickness. The women also participated in the discourse of certain occupations being too demanding for full-time, as we can see from the quote below:

Guðrun: If I am to work in the area of childcare, then I don't get 40 hours.

Interviewer: Why not?

Guðrun: Where I work, I will not get 40 hours [even if I ask], I get 30 hours, I don't get more than that. There is one who works 37 hours, the others work 30.

Interviewer: I see.

Guðrun: So it is...it is just established like that...

Interviewer: Why is that?

Guðrun: I guess it is just normally like that. I don't think that anybody in my town [in the other childcare institutions] works 40 hours, except the manager. Some work 34-36, but nobody works 40. I don't think one would be able to either. If one really had to [work full-time], well needed the money, then they would have to work somewhere else.

Interviewer: But the one who works 37 hours, how come she is allowed to do that?

Guðrun: She wanted more hours, but she can't handle it after all.

Interviewer: I see, and why is it that she cannot handle it?

Guðrun: Because it is too hard.

25-34 years, mid-sized town 2

In constructing their professions as challenging, the women appeared to be less inclined to question the structures in which the dominant mode of labour market participation is part-time work. Some of the women in our study were positive to the idea of working longer hours, especially the three women with grown children. One of the women in our study explained how she in her previous employment sometimes requested more hours. However, because she had a higher hourly wage than her co-workers, young school workers were given priority. Yet another example concerned a woman who recognised the incompatibility of her employment with part-time work. Following a period of accumulating several hundred 
hours of overtime, she convinced her employer to give her a full-time contract to enable her to have sufficient time to manage the demands and responsibilities of the job. This harks back to our earlier findings concerning how part-time work can sometimes leave women with less flexibility.

Our findings highlight how women in health and caring professions find their jobs to be emotionally demanding. In addition, the strenuous nature of shift work entails that work in health and caring professions are physically and logistically demanding. Employers in this sector often only offer part-time positions, which again reveals structural barriers to fulltime work in the labour market. Such structural barriers are inevitably located in gendered ideas of women's commitment to the labour market and the family, which we will turn to now.

\subsubsection{Women, gender culture and careers}

As explored above, most of the women in our study take primary responsibility in the daily running of the household. Some have partners/husbands who are highly active in carrying out many household tasks, especially during home periods for long-distance-workers. Nevertheless, the vast majority of our participants had a strong sense of being the organisers of daily life. This is in part indicative of a gender culture with a relatively clear gender division of responsibilities. In this section we shall further explore gender culture, women's understandings of being a woman and a mother and the implications of gender norms for perceived labour market opportunities.

From the perspective of many of these women, mothers are special providers of care and their importance in breast feeding leads to a more intense relationship, in which fathers become positioned slightly in the periphery. Throughout the interviews it was evident that the women feel that men as fathers have another way of seeing and therefore another way of being. This was also evident in the construction of maternity compared with a paternal approach to parenthood, as we can see in first of the two extracts next page:

Una: It is when they become bigger that he really becomes part of it. Because then it becomes more fun and he really becomes active. But the little children, whereas I think that it's fantastic with these tiny tiny little ones, who can't say anything

35-44 years, large town 


\begin{abstract}
Anna: The baby also lies at night and gets milk [breastfed] so it's 24 hours, well...(laughs) the man is kind of, at least the first six months, is pushed a bit a side.

Durita: And I don't think one does it consciously, women that is, I don't think so.

Several agree: No...yes unconsciously.

Inga: I think, that unconsciously, one does not even know it, but all of a sudden the role has just become that.
\end{abstract}

25-34 years and 35-44 years, large town

For these women, the intensity of the mother and baby relationship and the father's lesser role during the first period after birth lead to mothers and fathers gradually constructing different parental roles. The natural construction of motherhood, therefore, may be one of the key reasons for the domestic division of labour where women take responsibility for everyday life. In turn this domestic division of labour subsequently has a key impact on the division of labour in the labour market, e.g. women working part-time and men full-time. However, it is worth pointing out that not all the women responded to this conversation. Therefore, the possibility that a "truth" was constructed in the context of the group interviews must be considered, a truth not all our participants necessarily agree with or feel part of.

The cultural values associated with gender differences in parenthood were evident throughout all interviews. Generally, there was a consensus that men are less inclined to have feelings of guilt due to being away from the children. However, as we will point out later, there were moments when there was not total agreement on this issue. Furthermore, the women spoke of fathers as feeling a sense of relief in being able to go to work or be away during periods of long-distance work. There was a perception that men experience domestic life as chaotic and for fathers being away means, to some extent, escaping the challenges of everyday life. One woman spoke of men's focus being out of the domestic sphere (towards the labour market) while women are drawn inward (to the family).

While the women in our study feel a strong sense of focus on the family, work is also important to them. Some were committed to their careers but recognised that it is challenging to reconcile the two domains, not least due to wanting to be a mother, as the woman in the quote below explains:

Una: I think, work-wise, I think that it is really great to be able to have a career. It is kind of like, permitted, and you do it and you can. And if it runs smoothly it is really great fun and exciting. Then you have children and ...ohh I also want to be a mother, that is kind of like the most important thing, then kind of like work...you are in a bit of a dilemma. If only I could be a man and have a wife at home who took care of the children and did that, but I am not. I am a mother 
and I want to be a mother, but I also want to work. I think that when you have children, then you find yourself in a dilemma.

35-44 years, large town

In this extract Una, who is perusing her career and juggling motherhood at the same time (with a husband who is a long-distance worker), experiences the conflicting demands of working and being a mother. She entertains the thought of being a man and having a wife at home taking care of the children, but reverts back to her mothering discourse. Yet Una is clear on that she wants to be a mother and for her that means combining work and family life through part-time work.

The gendered structure of the Faroese labour market, with many male long-distance workers, entails that fathers are away from families for long periods of time. Consequently, in the Faroese culture, it is an accepted feature of fatherhood. Therefore, the women in our study did not question whether men should adjust their working patterns to suit the family. In contrast, the women were questioned by their communities if they were too much away. Indeed, one participant, whose husband works long distance, explained that she works many shifts when her husband is at home and none while he is away, due to childcare commitments. This prompted a response from people in her community. In her own words (laughs): "A lot of people have asked me if my husband puts up with it [working many shifts when husband is at home] (Sanna, 35-44 years, mid-sized town 1). Therefore, the cultural acceptance of the necessity of men's long-distance work is quite unlike the tolerance of women having periods of time with a heavy workload - most especially as the husband's absence may be perceived as a necessity. This frame of understanding seems to prevent the women in our sample from questioning the structure. Therefore, in participating in and reproducing such a reality, they find themselves adjusting and being accommodating to that reality.

The women in our study were nevertheless conscious of cultural norms and spoke of how social sanctions are imposed on behaviour perceived as non-maternal. They explained that society viewed women with long-distance employment almost as lesser mothers:

\footnotetext{
Sanna: We are socialised to...ehm think, well you know, it is the norms. That it is OK for a man to go away [work away from home, e.g. long-distance working], it is in a way, well it is not equally as OK that a woman goes...if Vanja [other participant] ... when her baby was 9 months old, started working at sea then someone would think...seriously, does she not love her children?
}

Alma: Now she has lost it (laughter). 
Katrin: ...I think there is that kind of attitude...that you can't be too far away. Really, it is OK that the fathers...

Group response: Yes

Katrin: ...are away somewhere, but if the mother goes somewhere, that you hear about it...because the mother is...

Beinta: [long-distance commuter] That I had decided, I was not going to listen to...I had got an education and I wanted to use it...A mother who commutes is not [considered] a good mother.

25-34 years and 55+ years, mid-sized town 2

In the above extracts, the women are highly aware of the way mothers who spend too much time working are perceived. The consequence is social sanctioning as such mothers are spoken of as not good mothers, even to the extent that the motherly devotion to her children is questioned. Such sanctioning sets relatively strict norms for motherly behaviour. These extracts also make visible cultural values in terms of gendered parenthoods, namely that mothers are the primary carers of children.

Despite a somewhat critical stance towards such norms, the women were still inclined to point out the gender differences in performing parenthood. And where men "failed" in their eyes, the women responded by adjusting their parental behaviour, e.g. by working less. The women spoke of men as not feeling the same degree of guilt towards children if they worked too much, and they feel that men think differently in terms of the family. For instance, their discourse was that men are able to cope with being away from their children, whereas they as mothers feel that they cannot cope with being absent (for instance for long-distance work). A few mothers, however, did not agree and stated that their partners/husbands did indeed feel guilty and would like to work less. These men, too, may be caught up in a rigid gender culture that makes it difficult for both men and women to break a traditional division of labour. There was a general feeling among the women that fathers have a clear conscience precisely because they know their partners/wives are around the children - and as such the women are a secure foundation for the family, enabling them as men to commit to work.

In discussing women's opportunities in the Faroese labour market, several women indicated that it is possible to have a career and work part-time. Indeed, some of the women in our sample are in management positions. They further agreed that if a woman really wants to dedicate herself to a career and progress into management, then it is possible. Yet 
many of the women have a somewhat ambiguous relationship with the term career, indicating that they associate it with a different set of values and structural conditions. As a concept, the term career is for these women, especially in the two mid-sized towns, associated with values in larger societies, e.g. in cities in Denmark:

Johanna: In Denmark, there, everything is just career.

Sanna: Yes, that is true, yes. And especially in the city.

Johanna: Yes, and they don't care as much about each other.

Guðrun: But here in the Faroe Islands I think people don't see each other much, well yes some families, but it has maybe also become more, you see each other at birthdays and things like that...

25-34 years, 35-44 years, 45-55 years, mid-sized town 1

Nina: I think that in...in Denmark or other countries, I think it has become more and more, but there it is so very evenly allocated with tasks [between men and women] ...both have a job, work out of the home, but then when they come home it is 50/50...in the homes, men wash and do dishes...everything.

Siri: I don't know if one can really compare with half of the men in the Faroes not being here, half of the time...

Beinta: What I think about [regarding the differences between the Faroe Islands and other countries] is how women present themselves...very big difference. They [the Danish women] have presentation after presentation, well they stand there and there are no obstacles to anything...they talk even if they don't know half of it...have an opinion about everything...

Katrin: They are just taught that way. And we are more like: Never mind.

Nina: They are also very...career...before they have children and a house and all that.

Katrin: Yes, we are not quite there yet.

Nina: No we are not there, we...children first.

Beinta: It has come here [career-mindedness].

Katrin: It is coming; it is coming more and more.

25-34 years, 35-44 years, 55+years, mid-sized town 2

In these two extracts, the women are essentially debating Faroese cultural values as opposed to other (Danish) values. The women see cultures elsewhere as being more individualised and more focused on careers. At the same time, they are clear that the increased focus on women and careers elsewhere has implications for the positions of women. In this sense they spoke of an equal division of labour at home, and of both men and women working on their careers. Beinta (in the latter extract above) also draws 
attention to the confidence of Danish women in the labour market, a very different perspective compared with her view of Faroese women.

In these extracts it is evident that women elsewhere (especially in Denmark) are perceived as more career oriented, which for the women in our study is symptomatic of a different set of values. There is also a clear indication that the women see the Faroese culture as more caring and less individualistic. The women to some extent distance themselves from the individualistic cultures they are describing by pointing out negative characteristics (not caring about each other). In this sense, their creation of a distance is a powered positioning in contrast to the other (in this case gendered values of other cultures). Yet, as in previous quotes, the women identify changes in Faroese society and sense that Faroese (family) values might be changing from the traditional to the individualistic and late modern.

Notwithstanding the perspective of female career orientation in other countries, it is clear that the women of mid-sized town 2 experience geographical career barriers. They spoke of few job opportunities in the area and some even went as far as to say that for those who want to live in the area, it is necessary to take whatever jobs there are. They spoke of both career-oriented women abroad and greater career opportunities for women in the capital of the Faroe Islands. This means for them that career-oriented Faroese women who have studied abroad simply do not return to the area. Therefore, for the women of mid-sized town 2, geography is a very real obstacle.

One of the groups we interviewed, from the large town, focused on the societal perception of part-time work. There was a feeling among some of the women that they had experienced a negative attitude to women who work part-time, as we can see in the extract below:

Karin: One thing that I was going to ask you about: If someone asks you where you work, who you don't know that well. Then you say at such and such. Then they ask: Do you work full-time? Does anyone ask you that? Do you work fulltime? Then I say, no I work part-time. A lot of people ask that. Interviewer: Do they?

Durita: Very frequently.

Karin: Yes, but why is that? What is...why do they have to ask that?

Interviewer: Why do people ask about that?

Karin: I don't know, I think it is really strange...

Durita: And also very contemptuous, kind of like...yes, "why do you work so little? Do you realise how low your pension will be" and "Are you just going to live off of your husband" and, like, condescending questions.

Karin: (laughs) There is a lot of that, I think.

Interviewer: What kind of people ask? 
Durita: Often those who are probably quite well educated I think...

Inga: When I reduced my hours, well down to 0.9, then people wondered... "What! Why have you reduced your hours?" ... well I say, actually it was too demanding to work full-time, I did not have the energy, kind of. But....defend yourself, defend yourself...then I even went down to 0.8 because I had another child and it suited me better. And then again... then I hurried to say that it is actually because.... I was like justifying to myself and others why I was working as I did...It's like you are defined based on how many hours you work.

25-34 years, 35-44 years, 45-54 years, large town

In this conversation the women are discussing the reaction of others when they say they work part-time. The women confirm that they often get asked about their hours worked and some question the necessity of such enquiries. However, the extract reveals multiple and conflicting discourses. In the first instance, the women indicate a sense of being criticised and being less committed to the labour market. Furthermore, and as our other data confirms, this is also based on the cultural values of paid work and unpaid (house/caring) work. Some feel less respected for their choice and like they are spoken to in a condescending manner.

At the same time, Inga finds herself not only defending her decision, justifying her choice to work part-time to others, but also to herself. This may be evidence of the dilemma that women can find themselves in when they have children; wanting to work and wanting to be mothers. Furthermore, it may be evidence of the dilemma of experiencing the dichotomy of the private/public sphere, which might become much more prominent after starting a family. However, Inga's justification may also be related to the perceived (lesser) value of caring work as she finds herself trying to argue for the worth of her decision.

Another discourse that is evident from the extract above is the gendered discourse of being independent. In other words, as modern women, Faroese women have the opportunity to be financially independent. Yet Durita finds herself being criticised for being too dependent on her husband and for putting her future pension at risk. She further comments that it is primarily the well-educated who enquire about working hours. Thus, we observe a gendered power discourse. In this sense, the women who are posing the question and criticising these women's choice are constructing a powered position, a hegemonic discourse, vis-a-vis those working part-time.

In the final sentence, Inga states that she actually feels defined based on her hours worked. This statement reveals the perception that some 
people value paid work higher than unpaid work, which from a gender perspective reflects the notion of typically masculine domains such as income being more valuable than typically feminine domains such as caring or domestic work. Yet, despite feeling criticised for their labour market participation, they too participate in the reproduction of the discourse by questioning themselves and their position and choice. Thus, we are once again presented with women's dilemma of mothering in combination with changing cultural values of the Faroe Islands, traditional family values, women's gender roles and career-orientation in late modernity.

In this subsection we have explored the experiences of women in the context of gender culture and careers. The women construct their motherly role as a strong connection that happens during the first crucial period of breastfeeding, during which men somehow become more peripheral. Thus, the gender division of parenthood and domesticity emerges as a gradual process that takes place over time. Yet we are also presented with women's agency in their expression of a desire to work and be mothers and in their choice to be mothers. While the women in this study are conscious of the impact of socialisation and upbringing on gender identity, they are also content in maintaining, and in some respects claiming, their identities as primary carers.

One of the important findings in this subsection is the women's discussions about traditional (gendered) family values being challenged by late modernity with its more individualistic orientation. For women and work, this entails a societal questioning of paid and unpaid work and thus part-time work and caring/domestic work. Thus, the women in our study, regardless of geographical area, to some extent find themselves addressing the issue of changing values and whether it is detrimental to traditional family values.

\subsection{Discussion}

The explanations for women's part-time work, and the meanings that women attribute to their work, the family and what it means to be a mother, are layered and complex. The Faroe Islands has a high female labour market participation rate, one of the highest in the world. Yet we see that the experiences of women within the labour market system are different and that their reasons for working part-time vary. Throughout the data, we are presented with underlying cultural values of the Faroe Islands with respect to gender, paid work and the family. Such values are manifested in labour market structures and define what choices are there 
to be made. We shall address these below by framing our discussion of part-time work into three main areas: 1) gender culture and part-time work, 2) labour market structures and part-time work and 3) the changing of the traditional family and part-time work.

\subsubsection{Gender culture and part-time work}

Overall, the women in our study are satisfied with their work situation, their choices being based mainly on family-orientated reasons, their work demands and the partner's/husband's labour market participation. According to Beck (1997), individualism in second modernity means that people are freed from traditional roles. With that freedom comes the responsibility to make a vast array of life choices, including labour market choices. This includes as in our case working hours, career decisions and the division of domestic labour (Närvi, 2012). From a different perspective, Hakim's (2006) preference theory would have it that women's and men's labour market choices are based on genuine orientations towards work and family. Thus, women's labour market participation and decisions to work part-time are, according to Hakim, grounded in a relatively stable family preference, which is a result of socialisation (Abrahamsen, 2009).

Therefore, from Hakim's perspective, very few women are seriously committed to the labour market. However, preferences do not emerge passively through socialisation. While individual preferences should not be neglected, this approach ignores the structural constraints within which women and men interact. Furthermore, it cannot explain the national variations in women's labour market participation (Fagen \& O'Reilly, 1998). Rather, we find it necessary to explore the interaction of culture, structure and agency to understand the working patterns of the women in our study.

The women in our study have chosen to prioritise their families and therefore work less. Yet this must be seen as occurring through a process of negotiation with their partner/husband in the division of labour at home and consequently in the labour market. We found that women are highly aware of the cultural expectations of females and males in relation to the family. At the same time, the mothers want to practise mothering and in their discourse rendered themselves the more natural carers. Within the cultural context men are also positioned within discourses of expectations in relation to fatherhood. We indeed saw examples of men who would like to work less and be more involved in fatherhood. Yet, the 
culturally accepted caring ideals of motherhood not only create expectations for how women are good mothers, they also render men in some respects less powerful in accessing the role as equal (primary) carers.

Our study further revealed that women who work part-time feel a great sense of responsibility for the organisation of everyday life and for the whole family. It was evident that many of the women feel that the running of daily life with children is hectic. This finding is similar to that of Deding and Lausten (2008), who found that women, despite working part-time, are more likely than men to be stressed in everyday life. In some cases in our study, it was evident that men's greater labour market focus leads them to be unaware of the sheer workload of the running of everyday life. This highlights the undervalued nature of domestic work. Thus, working part-time does not necessarily result in lesser work, but more likely in a shift from paid work to unpaid work, something that other studies also have found (Webber \& Williams, 2008).

The study revealed that the gender culture of the Faroe Islands and the ideals in relation to gender division of labour are still relatively traditional and the cultural acceptance of career-orientated women may be behind that in some other Nordic countries. The women in our study are acutely aware of societal expectations of what it means to be a mother. At the same time, they acknowledge the social sanctioning of mothers who step outside the realm of accepted labour market orientation for women (e.g. long-distance work). Therefore, they act within these values and participate in the discourse, yet they do not passively accept cultural ideals. The women in our study are also agents making their own choices and are clear that they want to mother children and acclaim the values of caring and family.

\subsubsection{Labour market structures and part-time work}

Notwithstanding their free choices, women with children may find themselves in a moral dilemma, torn between work and care interests (Pfaueffinger, 1998). Yet, the realities in which these choices are made cannot be ignored. There are two overriding labour market structures shaping the opportunity spectrum for women in the Faroese labour market: 1) the nature of men's work and 2) the part-time culture of some female-dominated professions in the Faroe Islands.

Before delving into the current structural labour market conditions concerning men's work it is necessary to point to the historical nature of men's long-distance work. For over a century the Faroese labour market has been characterized by men working away from home, at sea. These 
work patterns have had a lasting impact on the Faroese labour market. Granted, not all men are long-distance workers today and only around one-third of the women in our study had partners/husbands who work away from home. However, historically in Faroese society, men have been constructed as providers for the household which has entailed working in the fishing industry or finding work abroad (Jákupsstovu, 2007). Either way, women were left with the primary caring responsibilities for long periods of time. The traditional cultural values and perceived necessity associated with men's long-distance work have no doubt impacted the labour market opportunities of Faroese women today. This no doubt reinforces the ideal of men as main breadwinners and providers - even for those who do not work away from home. Consequently, a long-standing gender arrangement is not easily changed and serves as an underlying feature of the entire labour market.

Such structures are of significance in framing women's choices to work part-time or full-time. At the same time, our study shows that the labour market in itself provides flexibility for women to participate, despite the challenges of juggling employment and a family while the partner/husband is away. Therefore, the sheer amount of men working away from the islands gives women some leeway in the labour market. Furthermore, it is highly conceivable that the close-knit Faroese society with multiplex relations may impact employer flexibility towards staff.

Our second point with respect to labour market structures is related to the nature of employment in welfare services, in particular in the health and caring occupations. The women in our study indicated how these jobs are highly demanding due to the nature of shift work and/or the emotional labour involved. Even more importantly, a great deal of the job vacancies in such occupations are advertised as part-time positions and thus full-time work is not an option for some.

Some studies have pointed out that such employment practices and family-friendly policies assume female primacy in family responsibilities (Mandel \& Semyonov, 2006). Thus the underlying assumption is that women will reduce their working hours to fit their family commitments (Drange \& Egeland, 2014), which arguably can create a part-time culture in certain professions. As our findings do not represent entire professions, we are cautious with such conclusions.

Nevertheless, there are indications that in some of the professions represented in our study, there did indeed appear to be a part-time work culture, i.e. a culture in professions where the norm becomes part-time and where there is an understanding among staff that the challenges of 
the job and family commitments necessitate part-time work. This, Abrahamsen (2009) has argued, can be termed an adaptive preference. By this she means that workers are aware of structural constraints at the level of employment and adapt their preferences to what is possible rather than to what is not possible - in this context, full-time work.

\subsubsection{The changing of the traditional family and part-time work}

The Faroe Islands is in many respects a highly modern society with a welfare system and family policies that can be likened to those of the other Nordic countries. Yet the islands have been described as being a late modern society with traditional family values (Gaini, 2010). In this respect, as Gaini further notes, the values of the traditional family are conveyed as natural rather than as a culturally constructed and contested institution. This leaves little room to critically question the institution or arrangements (especially gender arrangements) surrounding and supporting the established structure.

Throughout our study we found that traditional family values function both as an enabler and a constraint to women's labour market participation. Firstly, women's high level of labour market participation in the Faroe Islands is in part due to the extended family serving as carers. Thus, we are presented with some degree of familialism in the Faroe Islands, a feature of the welfare model also identified by other authors (Sundström, 2006). Furthermore, family and kin are frequently geographically nearby each other. In other words, the close-knit family as a safety network is available to help with childcare. Thus, the traditional, (partly) extended family is an important support mechanism for families with young children and in particular for women who bear the primary care responsibility.

The impact of family values cannot be explored outside the gender context, considering that one of the most significant discourses surrounding the family is the division of labour. In her analysis of three different labour markets, Pfau-Effinger (1998) pointed out that mothers in Finland do not face the same conflict between self-interests and care-interests as those in Germany and the Netherlands, i.e. a sense of wanting to be two places at the same time. This, she concludes, is largely because childhood in Finland is constructed as a public matter rather than as belonging in the home, in the private sphere. 
Faroese family values place childcare very much within the family context. Despite widely available and much used public childcare provision, we saw in our study that parents do not wish their children to spend too much time in public childcare - one of the key reasons why the women in our study work part-time. Thus, the Faroe Islands with its traditional family values and as a child-centred society (Gaini, 2012) significantly frames women's labour market choices. This is especially evident in light of public childcare not being constructed to fit the reality of many women, e.g. being on their own with children half of the year while working shifts.

Our findings further indicate that cultural values in the Faroe Islands are in a process of change. The women in our study pointed to traditional values gradually being replaced with individualistic and career-oriented values. For the participants in our study, this entailed a greater labour market focus among women at the detriment of core values of social relations, family and community. Therefore, there was a perception of a society in change, and by implication a labour market in change. This was not least evident in the discussion among the women from the large town, who debated societal perceptions of part-time work. Some had encountered criticism for their part-time work, the critique being grounded in discourses of gender equality and financial dependency. It was evident that the women constructed gender equality issues and the gender division of domestic labour elsewhere (in Denmark) to be more individualistic and late modern. Thus, the women find themselves at the crossroads of changing values and discourses of independence.

\subsection{Conclusion}

The overall aim of our study was to investigate why women in the Faroe Islands work part-time. In doing so, our objective was to explore the employment and family experiences and practices of women who work part-time.

The women in our study work part-time mainly due to family priorities, i.e. ensuring that everyday life is not too stressful for the family, and the children in particular, is one key reason for working part-time. The women lead busy lives and the vast majority of them carry the overall responsibility for ensuring smooth running of the household and family life. In doing so, they position themselves powerfully within the domestic sphere and actively reconstructed gendered discourses, essentially maintaining a powered position. This does not mean that men do not contribute and participate in domestic work and the provision of care. Rather, it 
means that women organise and manage everyday life for the entire family. Yet women with partners/husbands who are long-distance workers have somewhat different experiences. For many women, everyday life is transformed when partners/husbands are home and take on a sizable share of domestic responsibilities.

Flexibility is an important reason for working part-time. Being able to work less gives women flexibility and freedom to decide for themselves, should they wish to work more. However, flexibility is also a common feature of the Faroese labour market in general, with employers and managers creating the space for women to participate. Labour market participation is further supported by the flexibility that the women in our study experience through the family as a support network, functioning as a significant enabler for them.

The women in our study value their work and are relatively well educated yet find the importance of a healthy work/life balance to be the key to their labour market decisions. This is manifested in Faroese family and career values, which the women see as being different compared with those observed elsewhere. The women are aware of increasing individualisation and career orientation elsewhere and recognise that Faroese society too is becoming more individualised and career orientated.

The Faroese labour market exhibits a relatively traditional division of labour, and the nature of men's work is culturally prioritised. Prioritising men's work and role as breadwinners is inextricably linked to the division of labour at home. This in turn is constraining for both men and women in their sharing responsibilities on the labour market and at home. Consequently, women are embedded in a labour market structure where the traditional view of the importance of men's work frames their adaptive labour market preferences.

Overall we can conclude that for the women in our study, the choice to work part-time is a complex decision involving cultural values, structural constraints, as well as personal circumstances and preferences. This conclusion is similar to findings regarding part-time work in the Nordic countries (Drange \& Egeland, 2014), yet possibly more pronounced. However, we find that the Faroese labour market appears to present women with certain constraints that may not be as evident elsewhere. These constraints are in particular the values of family and gender culture on the one hand and the working patterns of men, including long-distance work, on the other.

Our study provides some insight into the underpinnings of women's choices to work part-time, and their experiences of being mothers, in families and the Faroese labour market. However, more research needs to be 
conducted on the important issue of women's experiences in small peripheral labour markets. Studies applying an intersectional perspective on issues such as independence and interdependence are needed. Such studies would allow for underlying discursive mechanisms can be exposed, questioned and challenged. This would enable new patterns of conceptualising or addressing structural barriers affecting women and men's work/life balance.

We also call for more research on the supply side, i.e. the employer's perspective. Furthermore, we welcome research exploring on a larger scale working patterns on the labour market, both part-time and full-time, from a quantitative and qualitative perspective. Quantitative data would also be helpful to extend our understanding beyond mere contracted working hours. Rather, we consider it necessary to register real working hours, i.e. contracted hours plus extra hours worked - including unpaid hours. Last but not least, it is important to hear men's voices and their experiences of the Faroese labour market and of being a father, and where applicable their experiences of long-distance employment. 



\section{Conclusion and recommendations}

This report gives an overview of part-time work in the Faroe Islands, Greenland and the Åland Islands. We have described and where possible explained the role of part-time work in the context of gender. On several occasions we have pointed out that part-time work is a complex issue, as the previous report on part-time work in the Nordic countries also concluded (Drange \& Egeland, 2014). Firstly, the reasons for and experiences of part-time work are multilayered. They may be structural, cultural, or pertain to personal preferences or individual unique circumstances. Secondly, the definition of part-time work is not standardised across the Nordic region, which necessitates the use of datasets in which the notion of part-time work can have several different meanings.

Thirdly, and perhaps most importantly, the concept of part-time work is problematic in the first place, since the existence of part-time work is contingent upon a full-time norm, which does not have a universal definition either. The full-time norm and statistics based on that norm generally omit the working patterns of those who work in excess of the full-time norm. In other words, someone who works 40 hours per week may be classified as full-time as will the person who works 60 hours per week. The full-time/part-time dichotomy may, therefore, conceal important labour market characteristics and here gives the false impression that there are two main categories of workers in the labour market.

With these caveats in mind, a focus on part-time work is still useful, as it may tell us something about working patterns in the labour market. In the context of gender, it goes beyond questions of whether men and women work or not. Rather, we catch sight of one aspect of labour market behaviour, i.e. how much people work (at least on paper). However, there are inevitable gender issues that must be explored in the context of labour market participation, namely that full-time work is likely to be accompanied by higher income and, by implication, higher pensions as well as better access to more influential positions in the labour market.

In our mapping of part-time work in the three self-governing areas, we have demonstrated that part-time work is a much more common 
among women than men in the Faroe Islands and the Åland Islands. Indeed, the level of part-time work among women in these two areas is among the highest in Europe. We therefore conclude that the cultural mandate surrounding women's part-time work, as Drange \& Egeland (2014) found in several Nordic countries, appears to be evident in these two areas. In the case of Greenland, we found no difference in the extent of part-time work between women and men, although, women earn significantly less than men on average. A difference we find in Greenland, however, is that people living in rural areas are more likely to work parttime (or be underemployed as it is termed in Greenland) than those living in urban areas. Thus, structural features associated with labour market opportunities in rural and urban Greenland are of greater significance than gender in determining working hours.

Part-time work, then, as we see it, is not a problem in itself, but rather is symptomatic of modern families striving to balance work and family life. This is at least the case for so-called voluntary part-time work. However, we find that the sheer amount of women working part-time in the Faroe Islands and the Åland Islands is indicative of the gendered nature of work, in both the public (labour market) and the private (home) sphere. The fact that the self-governing areas have highly gender-segregated labour markets is a further reflection of the resilience of gender roles in the labour market, as many occupations still have overwhelming majorities of either men or women. This may especially be the case since traditional male industries dominate the labour markets in the Faroe Islands, Greenland and the Åland Islands. Given this occupational gender segregation, we also observe, not surprisingly, that women are overrepresented in the public sector, especially in health and caring professions.

Educational choices are to a large extent still gender segregated, which inevitably has some bearing on the subsequent occupational segregation in the labour market. More importantly, though, educational level appears to have an impact on men's part-time work. This is a feature of the Faroe Islands in particular, and to some extent of the Åland Islands. ${ }^{35}$ In other words, men with a lower level of education are more likely than men with a higher level of education to work part-time. As for women, a high proportion work part-time regardless of educational level.

In Greenland, women have now surpassed men in terms of level of education, but this is not yet reflected in the average female pay. In other words, women in Greenland still earn less, despite being better educated.

35 In Chapter 3 we saw that for Greenland, a lower educational level leads to a higher likelihood of working part-time. However, we do not have these figures grouped by gender. 
Although women are generally better represented among students in tertiary education in the self-governing areas and in the Nordic region as a whole, it remains to be seen whether educational level will prove to have an effect on female pay and/or full-time employment in the future.

Women in the self-governing areas still take by far the largest share of parental leave. This means that men are much less likely to take on primary caring responsibilities for children. In all probability, this has implications for women's labour market participation. Furthermore, men may be rendered less powerful in roles of caring and childrearing. Either way, the division of labour results in unequal opportunities for men and women to share responsibilities in the labour market and the domestic sphere. When we combine educational and labour market segregation with the fact that women carry more responsibility in the household, it is clear that working outside of the home for long hours or periods of time is still more acceptable for males. At the same time, spending more time caring for children and running everyday family life is still embedded in traditional feminine and masculine ideas of gender identities. This remains an area of research that needs to be further investigated in the Faroe Islands, Greenland and the Åland Islands.

Indeed, the above-mentioned division of domestic and care labour is substantiated by our exploratory study of female part-time workers in the Faroe Islands (Chapter 4). The study highlighted that despite most of the women having chosen to work part-time, the cultural expectations, structures, personal preferences and individual circumstances frame that choice. Motherhood is important to the women and labour market participation is framed around their responsibilities towards the family.

For women, wanting meaningful jobs while at the same time prioritising family often leads to a greater desire for flexibility in relation to their work, which may involve working part-time. One important feature of Faroese culture is the extended family as a support network, assisting with childcare in order for parents (and especially women as in our case) to work. Work flexibility is a way of adjusting to a labour market structure where the traditional view of the importance of male work is widely accepted. Notably, the greater domestic responsibility of women is not consciously maintained by either male or female actors, rather it is a result of structural and cultural reproduction. Indeed, men too juggle with and negotiate within the constraints of cultural expectations of them as men, in relation to the labour market and the family. However, the study further demonstrates that traditional understandings of work and family are being challenged and renegotiated, and that it is becoming increasingly accepted for women to be individualistic and career oriented. 
Whether the characteristics of Faroese gender culture, as presented in our exploratory study, also apply to the Åland Islands and Greenland is yet unclear. However, in view of certain educational and work pattern tendencies in the two areas, future studies may find some parallels. Further investigating this topic may contribute to knowledge on how working patterns are continually shaped by gendered expectations, and in turn shape gender culture. This is not least important in view of (young) female out-migration in all three areas, albeit more so the Faroe Islands and Greenland. From a policy perspective, it is essential that the particular labour market challenges facing the Faroe Islands, Greenland and the Åland Islands are available to policy makers. As small societies, which look to the larger Nordic countries, it is paramount that the Faroe Islands, Greenland and the Åland Islands have knowledge of their own unique labour market circumstances in the context of gender.

Throughout our study, we have found ourselves comparing data compiled at different times, using different methods and measures and based on different criteria for how part-time work should be defined. Therefore, we call for more research that can provide a more accurate, comparable and detailed picture of working patterns in the self-governing areas. This involves more consistent and more extensive registration of working patterns over time. Furthermore, when working with such small samples, as is the case for the Faroe Islands, Greenland and the Åland Islands, due consideration must be taken of how and what type of data should be gathered. This is of significance owing to the greater uncertainty of measures in small populations.

As part of a wider understanding of gender and working patterns in the labour market, research should look beyond the part-time/full-time dichotomy. Rather, we call for a broader approach for the self-governing areas that can provide insight into how many hours men and women work per week, different working patterns e.g. shift work and long-distance work, and how contextual factors, e.g. having one, two, three or more children and children's ages, can impact working patterns, to name but a few relevant factors.

There is, furthermore, a need to address and better understand the distinctive nature of these three labour markets, not least the Greenlandic case with high levels of seasonal work. The universal definition of part-time work may entail imposing a framework on the Greenlandic labour market that in some respects is unsuitable for understanding the nature of work and gender in Greenland. Rather, we call for diverse methods of research to fully grasp the complex nature of the Greenlandic labour market. 
Generally, there is hardly any research on people's experiences of working hours and labour market commitment in the Faroe Islands, Greenland and Åland Islands. We therefore call for studies that can shed light on how men and women experience working life in these areas. However, we also call for studies exploring the employer perspective, i.e. the supply side of the labour market. This is essential in order to understand the employment practices, expectations and context in which women and men in the peripheral Nordic areas work.

Our exploratory study has shed light on some important issues with respect to women's experiences within small labour markets characterised by primary resource industries. However, there is a need to conduct more research on the meanings that men and women attribute to work in peripheral Nordic labour markets. This is not least the case, when bearing in mind that many women in these areas have partners/husbands who are away from home for periods of time. It is important to understand how such cultures frame the spectrum of realistic opportunities, for women and men alike. There is furthermore a timely need for more research on gender and expectations of men and women as workers and parents, since gender, the labour market and the family are intertwined factors that cannot be separated. 



\section{Literature}

Abrahamsen, B. (2009). Forskjeller i kvinners arbeidstid - et spørgsmål om preferanser? Sociologisk Tidsskrift, 17(4), 311-332.

Absalonsen, R. (2009). Førleiki í Útlegd: Hugburðar, samleikar og framtíðarætlanir hjá føroyskum útisetum í Bretlandi. Tórshavn: Føroya Landsstýri.

Ackrén, M. \& Lindstöm, B. (2012). Autonomy development, irredentism and secessionism in a Nordic context. Commonwealth and Comparative Politics, 50(4), 494-511. http://dx.doi.org/10.1080/14662043.2012.729732

Ålands Landsskapsregering. (2016). Personal correspondence (Vivan Nikula). Mariehamn.

Beck, U. (1997). Risikosamfundet: På vej mod en ny modernitet. Copenhagen: Hans Reitzels Forlag.

Boolsen, M. W. (2010). Uddannelsesplanen: Rapport 3. Nuuk: Det Grønlandske Selvstyre - Uddannelsesdepartementet.

Christensen, E. (2013). Ung i det Grønlandske samfund. Copenhagen: SFI - Det Nationale Forskningscenter for Velfærd.

Dahlström, M., Aldea-Partanen, A., Fellman, K., Hedin, S., Larsen, N. J., Jóhannesson, H., Petersen, T., et al. (2006). Challenges to Income Systems in Åland. In: How to Make a Living in Insular Areas - Six Nordic Cases (pp. 89-98). Stockholm: Nordregio.

Deding, M. \& Lausten, M. (2008). Kønsarbejdsdeling i familien og på arbejdsmarkedet - en analyse blandt beskæftigede mødre og fædre. In: R. Emerek \& H. Holt (Eds.), Lige muligheder - frie valg? Om det kønsopdelte arbejdsmarked gennem et årti (pp. 293-315). Copenhagen: SFI - Det Nationale Forskningscenter for Velfærd.

Drange, I. \& Egeland, C. (2014). Part-Time Work in the Nordic Region II. Copenhagen: Nordic Council of Ministers. TemaNord 2014:560. http://dx.doi.org/10.6027/TN2014-560

Eistrup, J. \& Kahlig, W. (2005). Historiske forandringer på ligestillingsområdet $\mathrm{i}$ Grønland som faktor for velfærdsudvikling. In: A.-K. Berglund, S. Johansson, \& I. Molina (Eds.), Med periferien i sentrum: - en studie av lokal velferd, arbeidsmarked og kjønnsrelasjoner i den nordiske periferien (pp. 201-214). Alta: Norut NIBR Finnmark. Eurostat. (2015). EU labour force survey - methodology. Retrieved 16 December, 2015 from http://ec.europa.eu/eurostat/statistics-explained/index.php/EU_labour_force_survey_-_methodology

Faber, S. T., Nielsen, H. P., \& Bennike, K. B. (2015). Sted, (U)lighed og Køn. Copenhagen: Nordic Council of Ministers. TemaNord 2015:557. http://dx.doi.org/10.6027/TN2015-557

Fagen, C. \& O'Reilly, J. (1998). Conceptualizing part-time work: The value of an integrated comparative perspective. In: C. Fagen \& J. O’Reilly (Eds.), Part-time prospects (pp. 1-31). London: Routledge.

Faroe Islands Agency of Accounting \& Financial \& IT Administration. (2015). Statistics supplied 25/10/15. Tórshavn: Føroya Gjaldstova.

Faroe Islands Unemployment Agency. (2014). Personal correspondence (Magni Olsen). Tórshavn. 
Fiskimannafelagið. (2014). Personal correspondence (Hans Jacob Joensen). Tórshavn.

Føroya Landsstýri. (2013). Heildarætlan: Fólkaflyting og fólkavøkstur. Tórshavn: Føroya Landsstýri.

Gaini, F. (2010). Fortíðarinnar hetjur í andróðri. Retrieved 4 February 2016, from http://www.javnstoda.fo/documents/7FAAD5A3-ABC6-4320-A89C9E3A5EB70138.pdf

Gaini, F. (2012). Child Centric Families and the Vulnerability of Small Scale Island Communities. Anthropology News, (April Edition Online).

Gíslason, I. V. (2011). Introduction. In: I. V. Gíslason \& G. B. Eydal (Eds.), Parental leave, childcare and gender equality in the Nordic countries (pp. 13-30). Copenhagen: Nordic Council of Ministers. TemaNord 2011:562. http://dx.doi.org/10.6027/TN2011-562

Government of Åland. (2012). Government of Åland framework programme for gender equality 2012-2015. Mariehamn: Government of Åland.

Government of Greenland. (2015). Den nødvendige koordinering - Landsplanredegørelse. Nuuk: Government of Greenland.

Government of Greenland. (2016). Personal correspondence (Niels Thomas Andersen). Nuuk.

Haagensen, K. M. (2014). Nordic Statistical Yearbook 2014. Copenhagen: Nordic Council of Ministers. Nord 2014:001. http://dx.doi.org/10.6027/Nord2014-001

Hakim, C. (2006). Women, careers, and work-life preferences. British Journal of Guidance \& Councelling, 34(3), 279-194. http://dx.doi.org/10.1080/ 03069880600769118

Hamilton, L. C. \& Otterstad, O. (1998). Sex ratio and community size: Notes from the Northern Atlantic. Population and Environment: A Journal of Interdisciplinary Studies, 20(1), 11-22. http://dx.doi.org/10.1023/A:1023347817418

Hamilton, L. C. \& Rasmussen, R. O. (2010). Population, sex ratios and development in Greenland. Arctic, 63(1), 43-52. http://dx.doi.org/10.14430/arctic645

Hayfield, E. A. (under invited revision). Exploring transnational realities in the lives of Faroese youngsters. Nordic journal of migration research.

Hayfield, E. A. (2016). Gender segregation in the periphery - The Faroe Islands as a case in point. In: L. Lyck (Ed.), Hvordan sikres bæredygtige arbejdsmarkeder i Nordens yderområderarbejdsmarkeder i Nordens yderområder (pp. 1-6). Report from conference in Tórshavn, Faroe Islands. 26 August 2015.

Hovgaard, G. (2015). Being away; being at home; being both - The case of Faroese maritime workers. In: S. T. Faber \& H. P. Nielsen (Eds.), Remapping gender, place and mobility (pp. 175-189). Surrey: Ashgate Publishing Limited.

Hovgaard, G., Eythórsson, G. T., \& Fellman, K. (2004). Future challenges to small municipalities: The Cases of Iceland, Faroe Islands and Åland Islands. Stockholm: Nordregio.

Jákupsstovu, B. í. (2007). Velferd på Færøyerne - ny velferdsmodell i støpeskjeen. In: G. L. Rafnsdóttir (Ed.), Arbejde helse og velfærd i vestnorden (pp. 27-40). Reykjavík: Háskólaútgáfan, Rannsóknastofa í Vinnuvernd.

Joensen, H. D. (2014). Heilsulýsing Landslæknans 2013-2014. Retrieved 29 January 2016, from http://landslaeknin.fo/upload/heilsul\%C3\%BDsing_2013_-

_2014_fo.pdf

Joensen, J. (2009). Fáa kvinnur og menn somu løn frá tí almenna? Og hava børn nakra ávirkan á lønina hjá kvinnum á almenna arbeiðsmarknaðinum? Retrieved 1 July 
2015, from http://www.hagstova.fo/sites/default/files/

8-analysa_javnsstodunevndin.pdf

Kautto, M., Heikkillä, M., Hvinden, B., Marklund, S., \& Plough, N. (1999). Nordic social policy. changing welfare states. London: Routledge.

Knudsen, K. J. L. (2009). Køn og magt i politik og erhvervsliv på Færøerne. In: K. Niskanen \& A. Nyberg (Eds.), Kön och makt i norden: Del I Landsrapporter (pp. 321340). Copenhagen: Nordic Council of Ministers. TemaNord 2009:569. http://dx.doi.org/10.6027/TN2009-569

Kvale, S. (2007). Doing interviews. London: Sage.

Lanninger, A. W. \& Sundström, M. (2014). Part-Time Work in the Nordic Region Part-time work, gender and economic distribution in the Nordic countries. TemaNord 2014:560. Retrieved 1 Febuary 2015, from http://dx.doi.org/10.6027/ TN2014-560

Mandel, H. \& Semyonov, M. (2006). A welfare state paradox: State interventions and women's employment opportunities in 22 countries. American journal of sociology, 111(6), 1910-1949. http://dx.doi.org/10.1086/499912

Maykut, P. \& Morehouse, R. (1994). Beginning qualitative research: A philosophic and practical guide. London: Falmer Press.

Miiros, E. (2008). Kvinnors företagande på Åland i spänningsfältet mellan tradition och frihet. Åland: Åland Polytechnic.

Ministry of Trade \& Industry. (2014). Løgtingsmál nr. 126/2013: Uppskot til løgtingslóg um broyting í løgtinglóg um barsilsskipan. Retrieved 18 December 2015, from http://www.logting.fo/files/casestate/14353/126.13 U.t.ll. um br. i ll. um barsilsskipan.pdf

Närvi, J. (2012). Negotiating care and career within institutional constraints - work insecurity and gendered ideals of parenthood in Finland. Community, work \& family, 15(4), 451-470. http://dx.doi.org/10.1080/13668803.2012.724827

Nordregio. (2010). Mobilitet I Grønland: Sammenfattende analyse. Stockholm: Nordregio.

Nordregio. (2016a). Personal correspondence (Linus Rispling). Stockholm.

Nordregio. (2016b). Personal corrspondence (Rasmus Ole Rasmussen). Stockholm.

OECD. (2007). Babies and bosses: Reconciling work and family life. Retrieved 10 December 2015, from http://www.cepal.org/mujer/noticias/noticias/3/ 40283/babies_and_bosses_ocde_huerta.pdf

Patursson, E. (1942). Fólkaflytingin úr Føroyum. Copenhagen: Blaðfelagið.

Pfau-effinger, B. (1998). Culture or structure as explanations for differences in parttime work in Germany, Finland and the Netherlands? In: J. O’Reilly \& C. Fagen (Eds.), Part-time prospects - An international comparison of part-time work in Europe, North America and the Pacific Rim (pp. 177-198). London: Routledge.

Pfau-Effinger, B. (1998). Gender cultures and gender arrangement - A theoretical framework for cross-national gender research. Innovation, 11(2), 147-166. http://dx.doi.org/10.1080/13511610.1998.9968559

Pfau-Effinger, B. (2004). Development of culture, welfare states and women's employment in Europe. Surrey: Ashgate Publishing Limited.

Poppel, M. (2010). Kvinder og Velfærd i Grønland. In: G. L. Rafnsdóttir (Ed.), Kvinder og velfærd $i$ Vestnorden (pp. 39-68). Copenhagen: Nordic Council of Ministers. TemaNord 2010:578. http://dx.doi.org/10.6027/TN2010-578 
Poppel, M. (2015). Changes in gender roles in Greenland and perceived contributions to the household. In: B. Poppel (Ed.), SLiCA: Arctic living conditions - Living conditions and quality of life among Inuit, Saami and indigenous peoples of Chukotka and the Kola Peninsula. (pp. 297-318) Copenhagen: Nordic Council of Ministers. TemaNord 2015:501. http://dx.doi.org/10.6027/TN2015-501

Poppel, M. \& Kleist, J. C. (2009). Køn og magt i politik og erhvervsliv i Grønland. In: K. Niskanen \& A. Nyberg (Eds.), Kön och makt i Norden. Del 1: Landsrapporter. (pp. 341-358). Copenhagen: Nordisk Ministerråd. TemaNord 2009:569. http://dx.doi.org/10.6027/TN2009-569

Practical Nurse Association. (2014). Personal communication (Majbritt Mohr). Tórshavn.

Rasmussen, R. O. (2009). Gender and generation: Perspectives on ongoing social and environmental changes in the Arctic. Signs, 34(3), 524-32. http://dx.doi.org/ $10.1086 / 593342$

Smith, M., Fagan, C., \& Rubery, J. (1998). Where and why is part-time work going in Europe? In: J. O’Reilly \& C. Fagan (Eds.), Part-time Prospects - An international comparison of part-time work in Europe, North America and the Pacific Rim (pp. 35-56). London: Routledge.

Statistics and Research Åland. (2008). Kvinnors företagande på Åland - En samhällsekonomisk resurs med tillväxtpotential. Mariehamn: Ålands Statistik och Utredningsbyrå.

Statistics and Research Åland. (2012a). På tal om jämställdhet. Mariehamn: Statistics and Research Åland.

Statistics and Research Åland. (2012b). Skillnader i kvinnors och mäns ekonomiska situation. Mariehamn: Ålands Statistik och Utredningsbyrå.

Statistics and Research Åland. (2013). Kvinnor och mäns val och villkor i samhälle och arbetsliv. Mariehamn: Ålands Statistik och Utredningsbyrå.

Statistics and Research Åland. (2014). Kvinnor och mäns livsvillkor och hälsa. Mariehamn: Ålands Statistik och Utredningsbyrå. Retrieved 1 October 2015, from http://www.asub.ax/twocol.con?iPage $=72 \& \mathrm{~m}=150 \&$ sub $=120$

Statistics and Research Åland. (2015a). Antalet företag på Åland fortsätter att växa. Retrieved 12 January 2016, from http://www.asub.ax/ archive.con?iPage=12\&art_id=1638

Statistics and Research Åland. (2015b). Antalet sysselsatta minskade med tre personer år 2013. Retrieved 14 January 2016, from http://www.asub.ax/ archive.con?iPage=12\&art_id $=1683$

Statistics and Research Åland. (2015c). Bruttonationalprodukten per person i löpande priser. Mariehamn: Ålands Statistik och Utredningsbyrå.

Statistics and Research Åland. (2015d). Kvinnor och män i livets olika skeden. Mariehamn: Ålands Statistik och Utredningsbyrå.

Statistics and Research Åland. (2015e). Personal correspondence (Jonas Karlsson). Mariehamn.

Statistics and Research Åland. (2015f). Statistics database (own calculations).

Statistics and Research Åland. (2015g). Statistisk årsbok för Åland 2015. Mariehamn: Ålands Statistik och Utredningsbyrå.

Statistics Faroe Islands. (2014a). Um 40\% av fólkinum hava búð uttanlands og eru flutt higar síðani 1980. Retrieved 1 June 2015, from http://www.hagstova.fo/fo/ folkateljing/folkid-111111/um-40-av-folkinum-hava-bud-uttanlands-og-eru-flutthigar-sidani-1980 
Statistics Faroe Islands. (2014b). Vanligari hjá kvinnum at arbeiða partstíð. Retrieved 20 August 2015, from http://www.hagstova.fo/fo/folkateljing/arbeidi/ partidararbeidi-hja-kynunum-samanborin-vid-onnur-lond-fyribils-yvirskrift

Statistics Faroe Islands. (2015a). Flest arbeiðsvirkin í Føroyum í mun til fólkatalið. Retrieved 20 August 2015, from http://www.hagstova.fo/fo/talt-og-hagreitt/arbeidi/flest-arbeidsvirkin-i-foroyum-i-mun-til-folkatalid

Statistics Faroe Islands. (2015b). Statistics database (own calculations). Tórshavn: Statistics Faroe Islands.

Statistics Greenland. (2015a). Statistics database (own calculations). Nuuk: Statistics Greenland.

Statistics Greenland. (2015b). Statistisk Årbog. Nuuk: Statistics Greenland.

Statistics Greenland \& Nordregio. (2015). Supplied statistics. Unpublished data. Studni. (2015). Supplied statistics (own calculations). Tórshavn. Retrieved from www.studul.fo

Sundström, M. (2006). Välfärdspolitiska förhållanden i Västnorden. Copenhagen: Nordic Council of Ministers. TemaNord 2006:520. http://dx.doi.org/10.6027/ TN2006-520

The North Atlantic Group in the Danish Parliament. (2008). Hagtøl um føroyskar útisetar. Copenhagen: Norðuratlantsbólkurin á Fólkatingi.

The Social Insurance Institution of Finland. (2015). Supplied statistics (own calculations). Statistical Information Service. Retrieved 12 December 2015, from http://www.kela.fi/web/en/statistics

The World Bank. (2015). Population density (people per sq. km of land area). Retrieved 10 December 2015, from http://data.worldbank.org/indicator/ EN.POP.DNST?or-

der=wbapi_data_value_2014+wbapi_data_value+wbapi_data_value-last\&sort=asc

Van Voorst, R. (2009). I work all the time - He just waits for the animals to come back: Social impacts of climate changes: A Greenlandic case study. Jàmbá: Journal of Disaster Risk Studies, 2(3), 235-252. http://dx.doi.org/10.4102/jamba.v2i3.29

Webber, G. \& Williams, C. (2008). Part-time work and the gender division of labor. Qualitative Sociology, 31, 15-36. http://dx.doi.org/10.1007/s11133-007-9088-3

Weyhe, T. (2011). Finanskrisen og arbejdsmarkedet i Grønland. In: S. B. Nielsen (Ed.), Nordiske mænd til omsorgsarbejde! - en forskningsbaseret erfaringssamling på initiativer til at rekruttere, uddanne og fastholde mænd efter finanskrisen (pp. 248259). Roskilde: Roskilde Universitet - VELPRO - Center for Velfærd, Profession og Hverdagsliv. 



\section{Sammanfattning}

Kvinnor på Färöarna och Åland arbetar mest deltid i Norden. Det är en hög andel deltidsarbetande kvinnor även sätt till andra länder i Europa. På Grönland finns det ingen påvisbar skillnad i deltidsarbete mellan kvinnor och män. De olika förutsättningarna på landsbygden och i städerna på Grönland är viktigare än kön för att bestämma arbetstiden, då de som bor på landsbygden är mer benägna att arbeta deltid än de som bor i städer.

Det är några resultat i denna kartläggning av deltidsarbete och kön på Färöarna, Grönland och Åland. Rapporten har tagits fram av Nordisk information för kunskap om kön, NIKK, på uppdrag av Nordiska ministerrådet. Den är skriven av Erika Anne Hayfield, docent i sociologi vid Färöarnas universitet, Rógvi Olavson, med en masterexamen i sociologi, och Lív Patursson, forskningsassistent vid Färöarnas universitet. NIKK har sedan tidigare publicerat två rapporter om deltidsarbete och kön i Norden och denna rapport ger en kompletterande bild med särskilt fokus på Färöarna, Grönland och Åland.

Rapporten ger en allmän översikt av arbetsmarknaderna, utbildningsnivån och demografin för de tre områdena, utifrån vad som är relevant för deltidsarbete. Forskarna beskriver vad som är känt om deltidsarbete på Färöarna, Grönland och Åland, med särskilt fokus på förhållandet mellan deltidsarbete å ena sidan och sysselsättning, löner, utbildning och familjepolitik å andra sidan.

I rapporten ingår också en mindre studie av kvinnor på Färöarna som har intervjuats om varför de arbetar deltid. Studien visar att trots att de flesta av kvinnorna har valt att arbeta deltid, så sker beslutet inom ramen för sociala strukturer och kulturella förväntningar, samt individuella omständigheter. Till exempel är moderskapet, och förväntningar som följer med det, viktigt för de intervjuade kvinnorna och deltagandet på arbetsmarknaden begränsas av ansvaret gentemot familjen. 
Forskarna synliggör i rapporten framtida forskningsbehov på Färöarna, Grönland och Åland. Det finns behov av mer statistik och forskning om hur deltids- och heltidsarbete fördelas beroende av kön. Det är av yttersta vikt att Färöarna, Grönland och Åland har kunskap om sina egna unika omständigheter på arbetsmarknaden kopplat till kön och jämställdhet, menar forskarna i rapporten. Detta är inte minst viktigt med tanke på att många unga kvinnor flyttar från dessa tre områden, särskilt Färöarna och Grönland. Ur ett politiskt perspektiv är det betydelsefullt att de särskilda utmaningarna på arbetsmarknaden i Färöarna, Grönland och Åland är tillgängliga för beslutsfattare. 
Nordic Council of Ministers

Ved Stranden 18

DK-1061 Copenhagen K

www.norden.org

\section{Part-Time Work in the Nordic Region III}

Gender equality in the labour market is a key topic in the Nordic cooperation on gender equality. As a follow up to two earlier reports on part-time work this third report is an introductory study to part-time work and gender in the Faroe Islands, Greenland and Åland Islands. The aim is to map what is known about part-time work, and where possible, explain working patterns in these areas. The report gives an overview of the labour markets of the three areas and introduces part-time work based on existing data. The report also present findings from an exploratory study with women who work part-time in the Faroe Islands. Erika Anne Hayfield, PhD, Assistant Professor of Social Sciences at the University of the Faroe Islands, Rógvi Olavson, MSc Sociology and Lív Patursson, MSc Gender Studies wrote the report on request by NIKK, for the Nordic Council of Ministers.

TemaNord 2016:518

ISBN 978-92-893-4531-6 (PRINT)

ISBN 978-92-893-4529-3 (PDF)

ISBN 978-92-893-4528-6 (EPUB)

ISSN 0908-6692

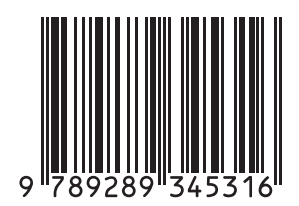

